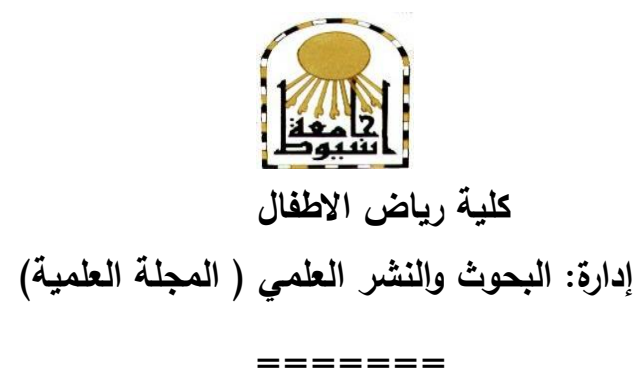

\title{
أثر المساندة الاجتماعية علي المرونة النفسية لدي أولياء أهور الأطفال ذوي الامتياجات الخاصة
}

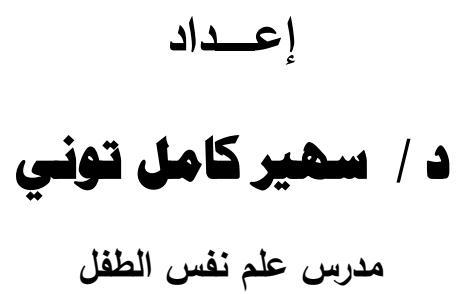

كلية التربية للطفولة المبكرة - جامعة المنيا

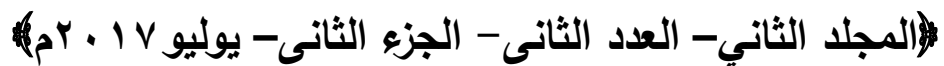




\section{الملخص باللغة العربية :}

تهدف الدراسة الحالية إلى التعرف على طبيعة العلاقة بين المساندة الاجتماعية من قبل

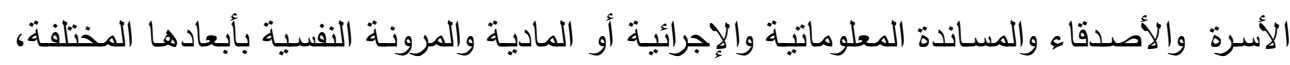
كما تهدف إلي التعرف علي الفروق في مستوبي كل من المساندة الاجتماعية والمرونة النفسية لدي أولياء أمور الأطفال ذوي الاحتياجات الخاصة تبعا لنوع الإعاقة، ثم التعرف علي مدي إسهام أبعاد

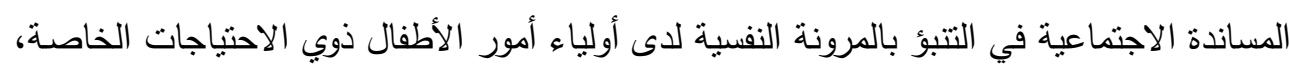
و التاثيرات المباشرة وغير المباشرة لأبعاد المساندة الاجتماعية التي تؤئز علي المرونة النفسية لدي

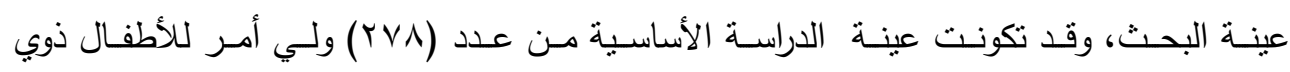

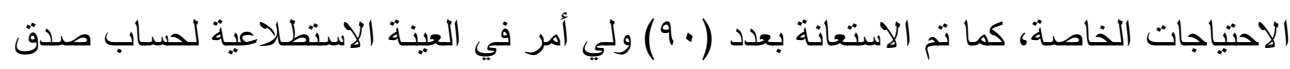
وثبات الأدوات من غير العينـة الأساسية، وقد تم استخدام مقياس المساندة الاجتماعية لدي أولياء أمور الأطفال ذوي الاحتياجات الخاصة (إعداد الباحثة) ، مقياس المرونـة النفسية لدي أولياء أمور الأطفال ذوي الاحتياجات الخاصة.(إعداد الباحثة)، وأسفرت النتائج عن عدم وجود فروق ذات دلالة احصائية في المرونـة النفسية لدي أولياء أمور الأطفال ذوي الاحتياجات الخاصـة تبعا لمتغير نوع الإعاقة، عدم وجود فروق ذات دلالة احصائية في المساندة الاجتماعية لدي أولياء أمور الأطفال ذوي الاحتياجات الخاصة تبعا لمتغير نوع الإعاقة ما عدا بعد المساندة المادية أو الإجرائية، توجد علاقة ارتباطيـة طرديـة دالة إحصائية بين المساندة الاجتماعيـة والمرونـة النفسية لدي أولياء أمور الأطفـال ذوي الاحتياجـات الخاصـة، وأن المسـاندة الأسـرية تعـد أكثر أبعـاد المســاندة الاجتماعيـة إسهاما في المرونة النفسية، يليها المساندة المعلوماتية، ثم مساندة الأصدقاء وأخير المساندة المادية.

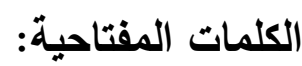

- المساندة الاجتماعبة - المرونـة النفسبة - أولياء أمور الأطفال ذوي الاحتياجات

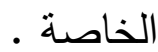




\section{Abstract}

The present study aimed at identifying the nature of the relationship between social support by family, friends, informatics, procedural or physical and psychological resilience in different dimensions. It also aimed at identifying the differences in the level of social support and psychological resilience among parents of children with special needs according to the type of disability. In addition, it aimed at identifying the contribution of social support dimensions in predicting the psychological resilience of parents of children with special needs, and the direct and indirect effects of the social support dimensions on the sample psychological resilience. The main sample of the study consisted of 278 parents of children with special needs. In addition, 90 parents were used in the pilot study to calculate the validity and reliability of the non-basic instruments. The study utilized the social support scale of the parents of children with special needs and psychological resilience scale of the parents of children with special needs (by the researcher). Results showed that there were no statistically significant differences in the psychological resilience of parents of children with special needs according to the type of disability. Also, there were no statistically significant differences in Social support of parents of children with special needs according to the type of disability, except the variable of physical or procedural support. In addition, there was a significant positive correlation between social support and psychological resilience among parents of children with special needs, and family support is the most important aspect of social support in psychological resilience, followed by information support, friends' support, then physical support.

Key words: Social support - Psychological resilience - Parents of children with special needs. 
عندما يولد الطفل تعم الفرحة أسرته، سواء أكان ذكراً أم أنثى، ولكن عندما تكتشف الأسرة

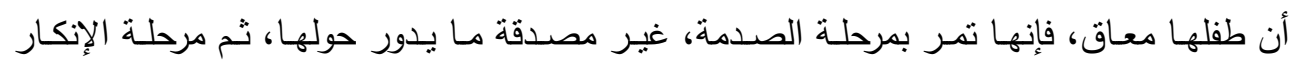

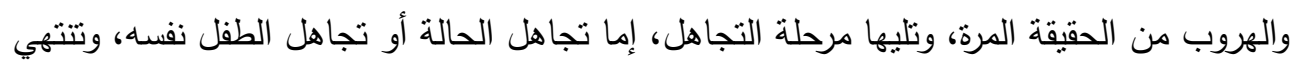

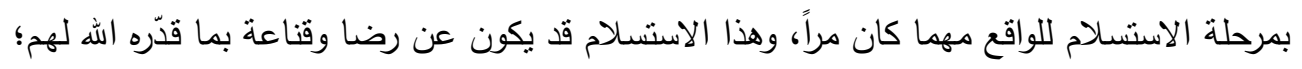

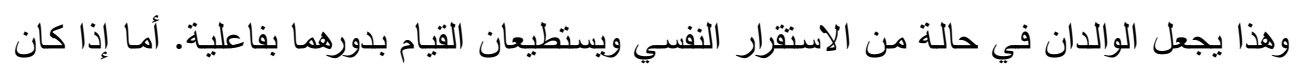

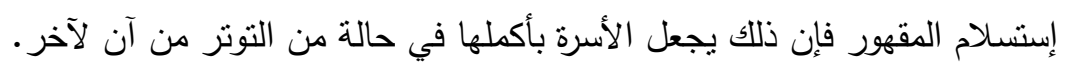

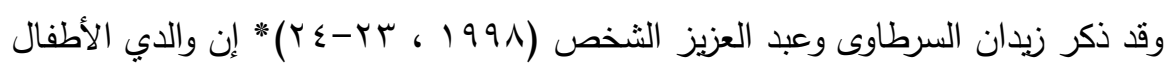

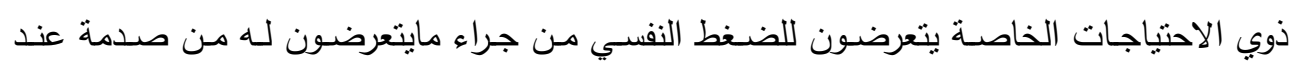

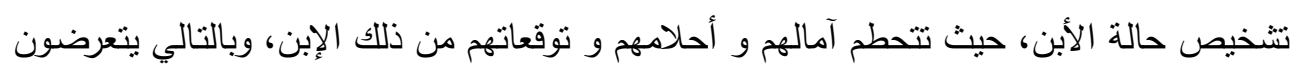

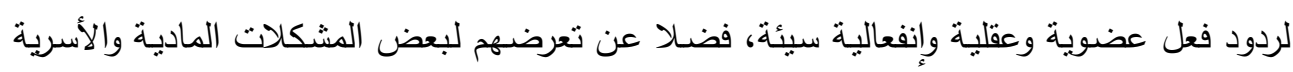

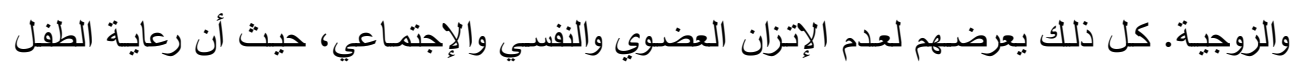
المعاق تتطلب جهذًا قد ينوء بكاهل الوالدين فضلا عن إستمرارية ذلك.

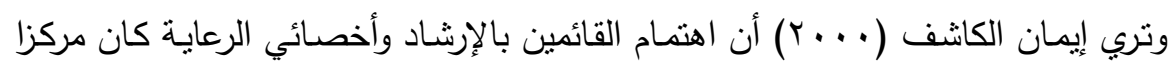

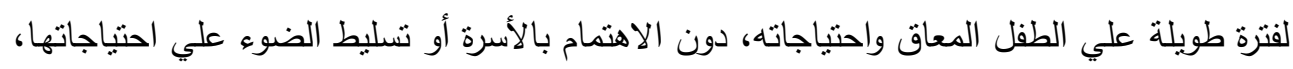

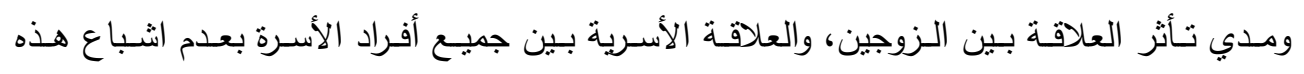

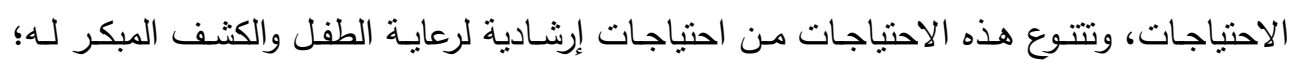

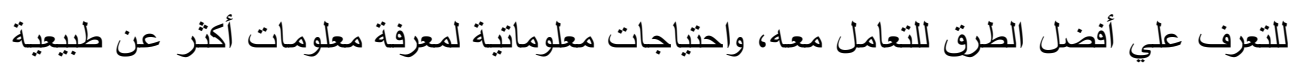

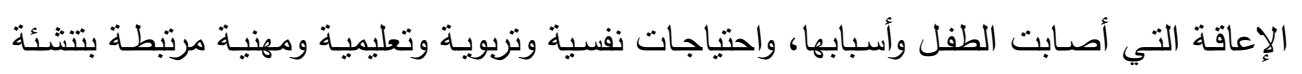
الطفل ومستقبله.

وقد أثنار كل من Soponaru,C. \& Iorga, M. (2015) إلي أن وجود طفل معاق

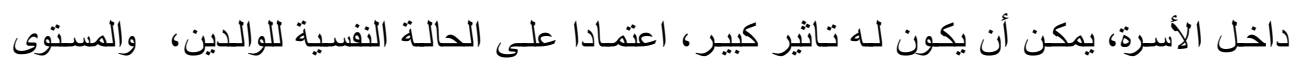

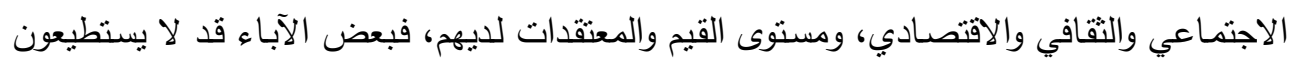

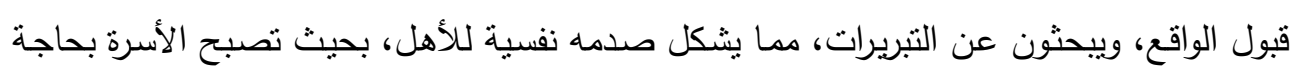
إلى رعاية ومسانده اجتماعية. * تتبع الدراسة الحالية في التوثيق الأسم الأول والأخير للمؤلف أو الباحث. 


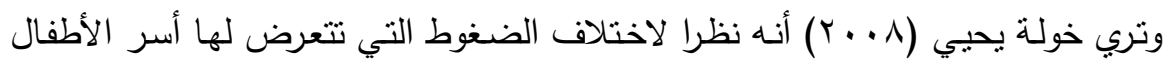
المعاقين، فإن الجهود المبذولة لمساعدة الوالدين ودعمهما، منتوعة ومختلفة، وتشمل تقديم مجموعة من الخدمات التي تتراوح بين إرشاد الأسر ، وإقامة شبكات دعم اجتماعية ومهنية متخصصة. ولذا فإنها تحتاج إلى مـا يقدم لها بـ العون والدعم والمسـاندة الاجتماعيـة؛ لكي تتحلي بالمرونة النفسية والقدرة علي التكيف الناجح ومواجهة الضغوط والتأقلم معها. ويعرفها كل من علا الحويان، نسيمة داود (10 • Y، V. \& ) المرونة النفسية بأنها عملية دينامية يظهِر الفرد من خلالها السلوك الإيجابي التكيّفي في الوقت الذي يُجابه فيه مصساعب جمـة أو صدمات أو مآسٍ.

وتذكر (Masten, A., 2001, 228) أن المرونـة النفسية ظاهرة نفسية تعود على الفرد بنتائج جيدة وايجابيـة، رغم مختلف عوامل التهديد للتكيّف أو النمو التي يمكن أن يمر بها الفرد خلال حياته. وهي تعكس الفروق الفردية بين الأفراد في الاستجابة لعوامل التهديد والتوتر، فهناك من يستجيب بطريقة ايجابية لظروفه القاسية، وهناك من تؤثز عليه هذه الظروف، وتنعكس بشكل سلبي على حياته. وهذا مايفسر وجود أفراد يتمتعون بصحة نفسية جيدة رغم أنهم يعيشـون في ظروف صعبة.

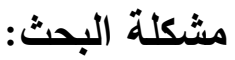

ذكرت فاطمة عبد ربه (Y Y r Y) أن قدوم طفل معاق للأسرة قد يسبب العديد من الضغوط

النفسية والاقتصادية والاجتماعية لأسرته، وقد تختلف مواجهة الأسرة لهذه الضغوط بحسب العلاقات السائدة فيها، فإن كانت الأسرة غير مستقرة فقد يحدث قدوم هذا الطفل زيادة في التفكك الأسرى، والضغوط التي تواجه الوالدين، أما إذا كانت العلاقات الأسرية قوبة قبل مجيء هذا الابن المصاب بالإعاقة، فربما نزداد الروابط بين أفراد الأسرة، لمواجهة تللك الضغوط التي تؤثز على جميع أفرادها. ويري علي حنفي (V . . . أن شعور أسر الأطفال ذوي الاحتياجات الخاصـة بالضغوط

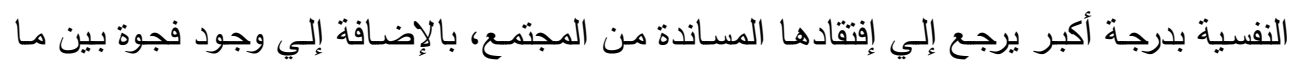
يتوقعه الوالدان من المتخصصين، وما يقدم لهما بالفعل من معلومات وخدمات لطفلهما. وتوضح أميرة بخش (r . . r) أن الضغوط الأسرية هي عبارة عن مجموعة من الخبرات المتراكمة الناتجة عن حدث معين يصيب أحد أفراد الأسرة ويؤثز في جميع أفرادها بدرجات متفاوتة، 
وينتج عن هذا الحدث مجموعة من الحاجات النفسية والمادية والإجتماعية غير المشبعة مثل عدم دراية الأسرة بكيفية مواجهة هذا الحدث ، ونقص الموارد والخدمات المناحة، ويؤدي هذا إلى زيادة

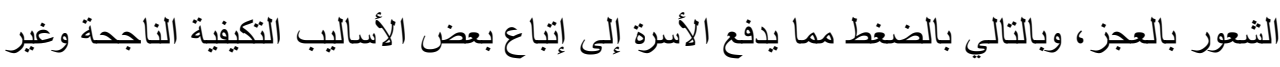

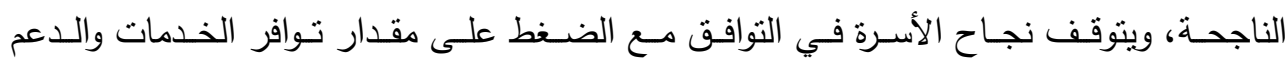
الإجتماعي التي تحصل عليه من البيئة المحيطة.

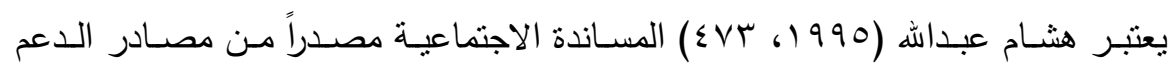
الاجتماعى الفعال الذي يحتاجها الفرد حيث يؤثر حجمها، ومستوى الرضا عنها فى كيفية إدراك

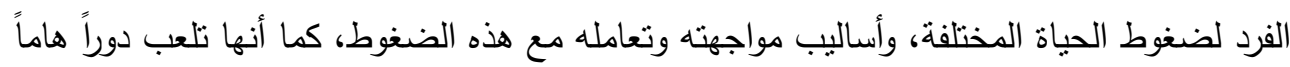

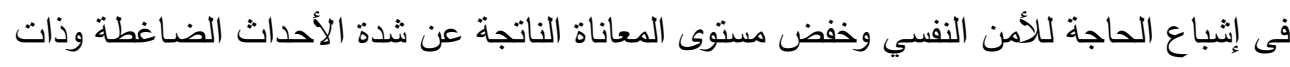
أثر فى تخفيف حدة الأعراض المرضية.

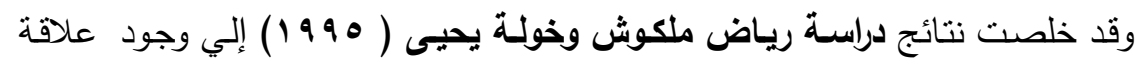

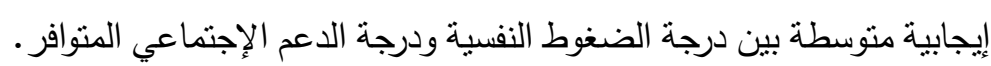

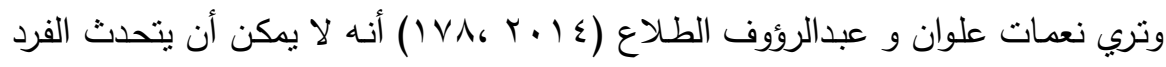

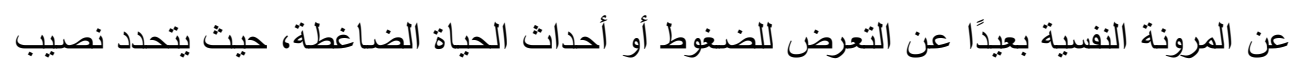
الفرد من المرونة النفسية بقدر ما بستطيع أن يتغلب أو يواجه تلك الأحداث الضاغطة ويتأثر بها،

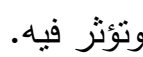

وكثفت دراسـة Heiman, T. Tن مدي تمتع أسر الأطفال المعاقين بالقدرة

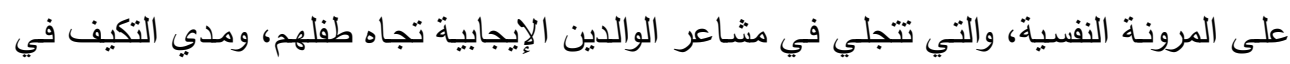

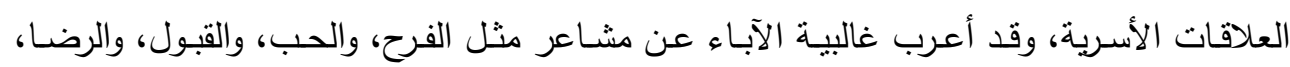

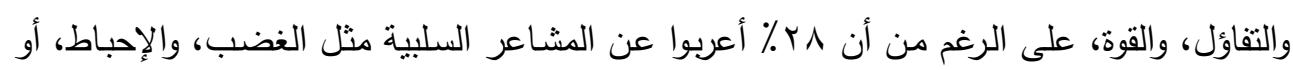
الذنب حول تربية الطفل ذو الإعاقة.

كما أظهرت دراسة Gerstein, E, et al (2009) أنه بالرغم من إزدياد الإجهاد اليومي

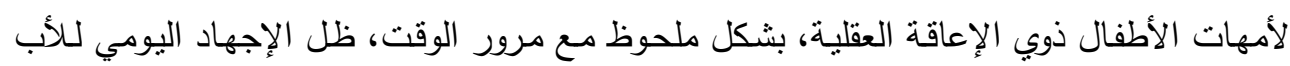

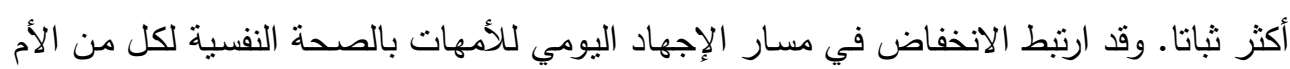

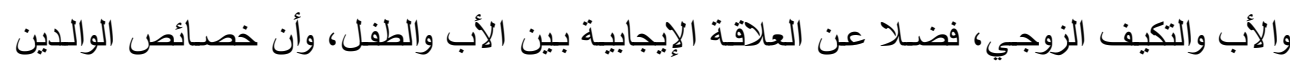

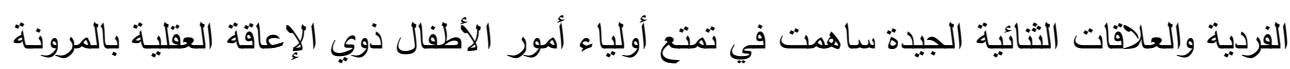


ولقد ألقت نتائج دراسـة (Plumb, J., 2011) الضوء على دور المساندة الاجتماعية

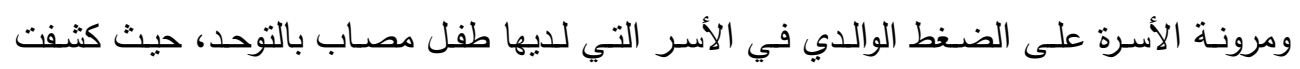

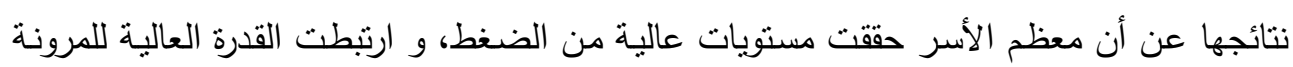

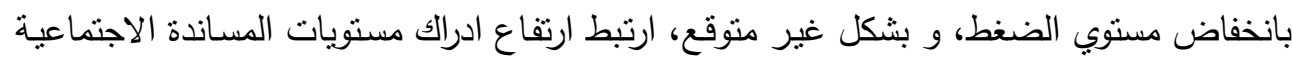

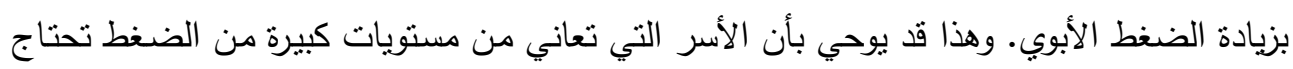

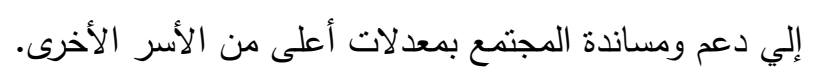

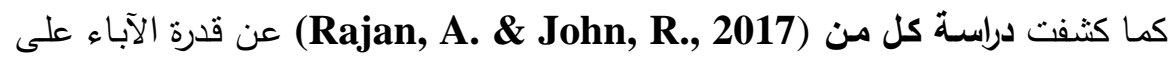
التحلي بالمرونة النفسية في سياق تربية طفل يعاني من إعاقة ذهنية، وقد أظهرت أن تربية الأطفال

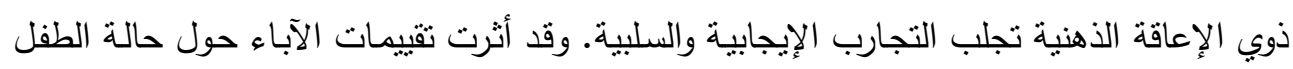

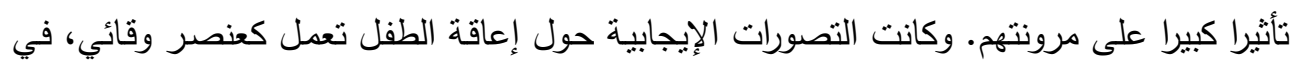

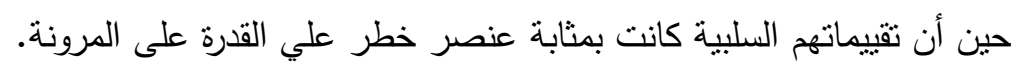

ويري (M. Bayat, 2007) أن مرونة الأسرة تعد من المجالات التي تزايد دراستها

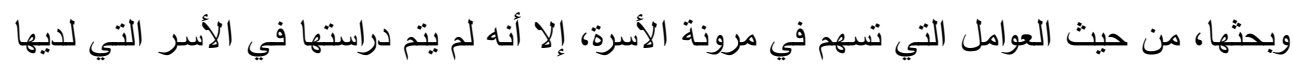

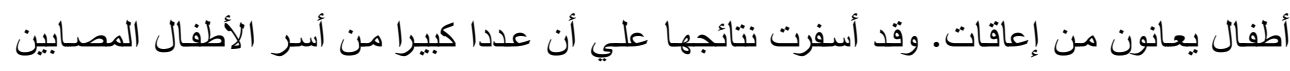

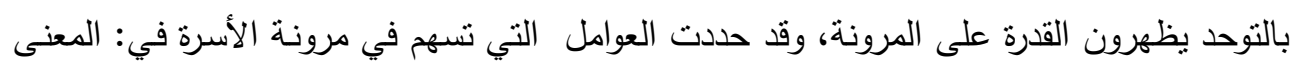

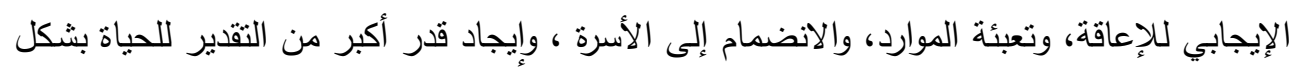
عام، و للأشخاص بشكل خاص؛ واكتساب القوة الروحية.

كما حدد كل من (Greeff, A. \& Walt, K., 2010) الخصائص التي تمتلكها الأسر والتي تمكنها من التكيف بنجاح، والتعامل بمرونة على الرغم من وجود طفل نوحدي في الأسرة

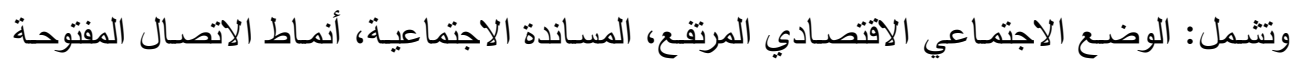

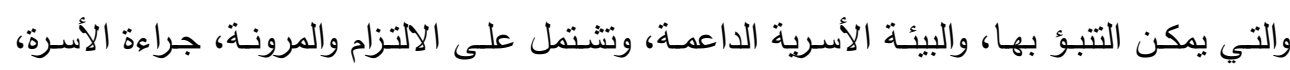

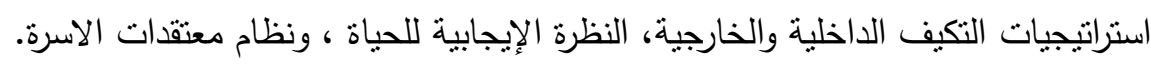

كما أكدت العديد من الدراسات ( Skinner et al. 1999; Scorgie \& Sobsey2000 (Taunt \& Hastings 2002; Hastings et al. 2005 بشكل إيجابي مع وجود طفل معاق. وكان لهؤلاء الآباء زواج ناجح وأطفال عاطفيون جيدون التكيف الأباء مع الأطفال المعاقين وغير المعاقين. 
في حين أظهرت دراسـة كل من Freedman \& Boyer (2000) أن بعض أسر

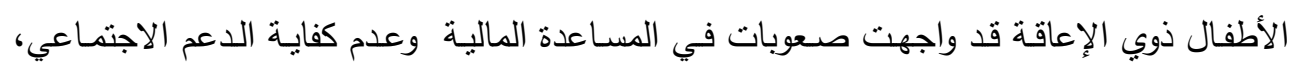

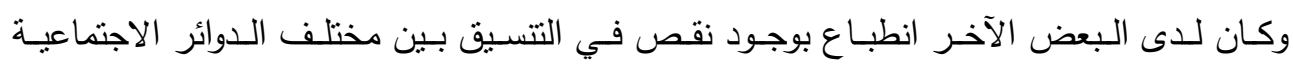
والوكالات والعاملين في مجال الإعاقة.

كما كثفت دراسـة كل من (Kerr, S. \& Mc Intosh, J., 2000) أن آباء الأطفال

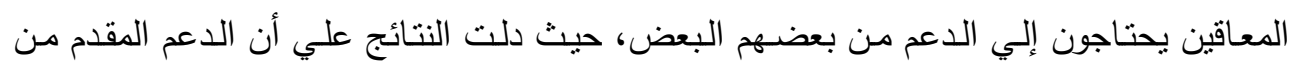

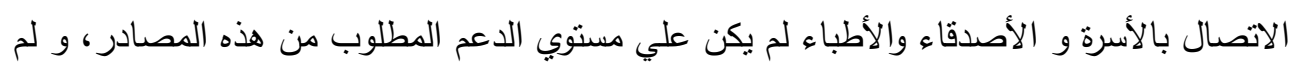

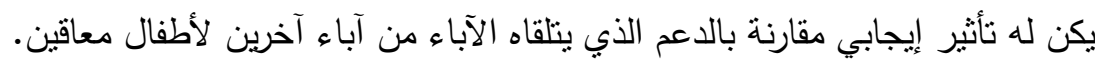

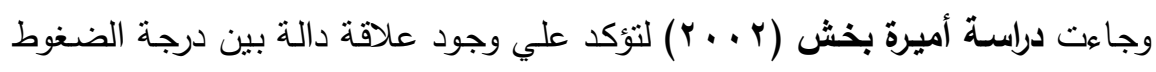

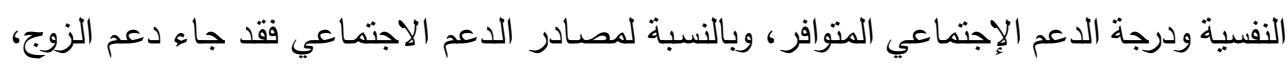

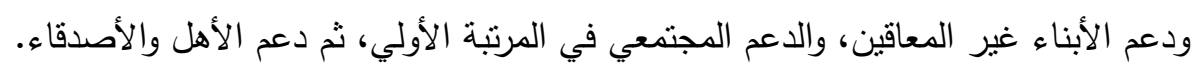

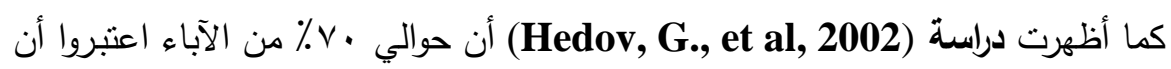
المعلومات عن الإعاقة غير كافية، و ـ ؟ ٪ شعروا بأنهم لم يكونوا مدعمين. وقد بينت دراسة (Hill, et al, 2003) احتباج أمهات الأطفال مدن لديهم إعاقة ذهنية إلي الدعم حتي يتمكنً من تقديم الدعم لابنائهن.

كما أثنارت دراسة كل من (Graungaard, A. \& Skov, L. , 2006) إلي انخفاض

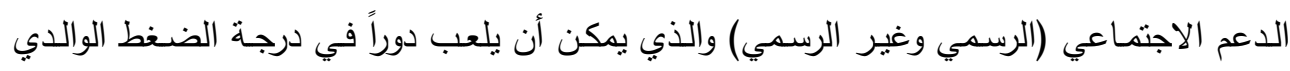

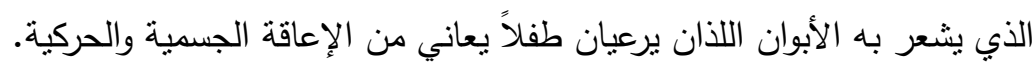
ويؤكد هارون الرشيدي (999 199 أن المساندة الاجتماعية سواء في العمل أو المنزل أو

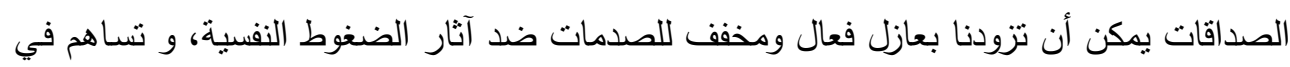
التوافق النفسي الاجتماعي الفعال في البيئة المحيطة بالفرد. تُوني كما أظهرت نتائج دراسة كل من (Sen, E. \& Yurtsever,S. , 2007) أن معظم الآباء (والادي الأطفال المعاقين عقليا في تركيا) يفتقدون إلي المعلومات الكافية عن طبيعة الحالة التي يعاني منها أبناءهم. 
كما بينت نتائج دراسـة يوسف (Yusoff,2012) أن المساندة الاجتماعبة (المساندة من الأصدقاء والآخرون) له علاقة جوهرية بالتوافق النفسي.

كما كثفت دراسـة كل من (Meral, .B. \& Cavkaytar, A., 2012) أن موارد المساندة الأكثر شيوعا للوالدين الذين لديهم أطفال توحديين هي الأسرة.

كما دعا (Cuzzocrea,F. , et al, 2015) إلي تعزيز استراتيجيات التكيف الوظيفي والمساندة الاجتماعية لأسر الأطفال المعاقين ،وخاصة للأطفال الذين يعانون من التوحد الوظيفي المنخفضن

كما هدفت دراسة Felizardoa, S. , et al (2016) معرفة الفروق في الضغط الأبوي والمساندة الاجتماعية بين مجموعات من الوالدين الذين لديهم إعاقات مختلفة في سياق التكيف

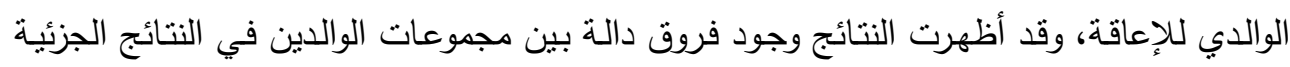

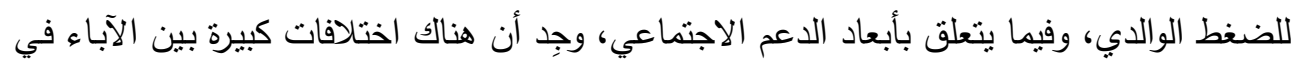
مدى وامكانية نوفر شبكة المساندة الاجنماعية لديهم.

كما أظهرت دراسة (Ha, J. et al , 2012) أن التاثيرات السلبية لإعاقة الطفل على الصحة النفسية للوالدين تتخفض عندما يحصل الوالدين على دعم إيجابي أكبر من الأسرة . مما سبق بتضح أن الأسرة التي لديها أطفال ذوو احتياجات خاصة نواجه مشكلات جمه،

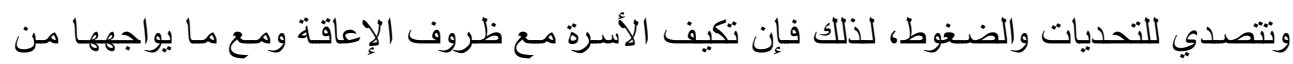
تحديات وصعوبات يختلف من أسرة لأخري، وحتي يستطيع أولياء أمور الأطفال ذوبي الاحتياجات

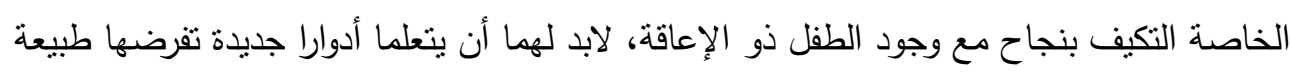

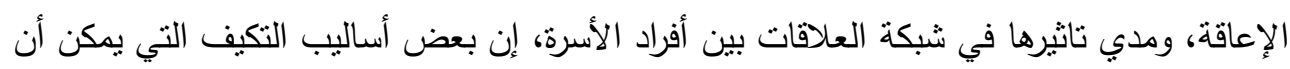

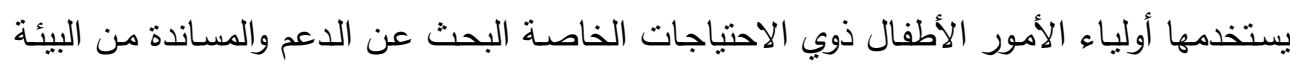
الاجتماعية.

وهذا ما تتتاوله مشكلة البحث الحالي لذا تسعي الاراسة للإجابة عن السؤال الرئيس التالي: هل تؤثثر المساندة الاجتماعية علي المرونـة النفسبة للدي أوليـاء أمسور الأطفال ذوي الاحتياجات الخاصة؟ 


\section{المجلة العلمية لكلية رياض الاطفال - جامعة اسيوط}

\section{ويتفرع من هذا السؤال الرئيس الأسئلة الفرعية التالية:}

1) هل تختلف المسـاندة الاجتماعيـة بين أوليـاء أمسور الأطفال ذوي الاحتباجـات الخاصـة

$$
\text { باختلاف نوع الإعاقة؟ }
$$

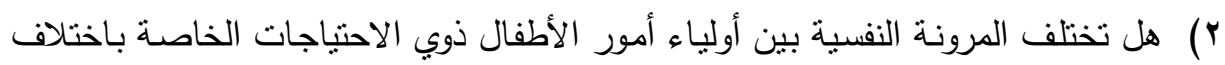

$$
\text { نوع الإعاقة؟ }
$$

r) هل توجد علاقة ارتباطية بين المساندة الاجتماعية و المرونـة النفسية لدي أولياء أمور

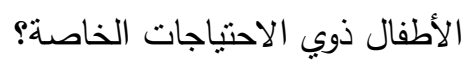

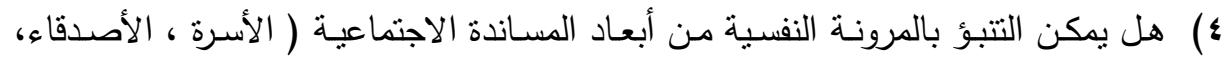

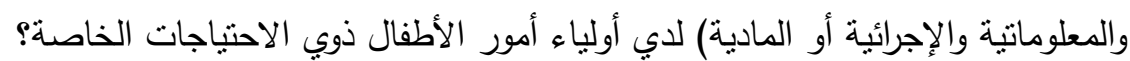

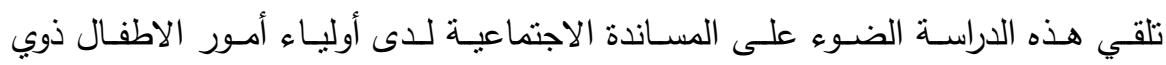

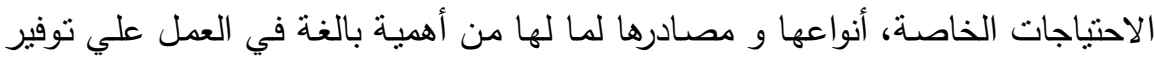
هذا الدعم والمساندة الاجتماعية لهم.

تتاول الدراسة الحالية لففوم المرونة النفسية، ذلك المفهوم الثري، والمحوري لما ينطوي عليه من جوانب متعددة تلعب دورًا كبيرًا في تحديد مدى قدرة الفرد على مواجهة أحداث الحياة الضاغطة، ومواقف الحياة المتتوعة، من هنا يكتسب مفهوم المرونة النفسية أهميته،

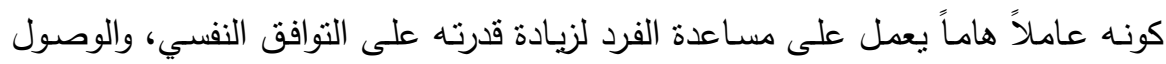
إلى قدر مناسب من الصحة النفسية.

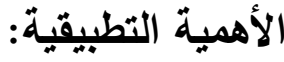

تساهم نتائج هذه الدراسة في توفير معلومات لوضع السياسات والخطط الخاصة من قبل

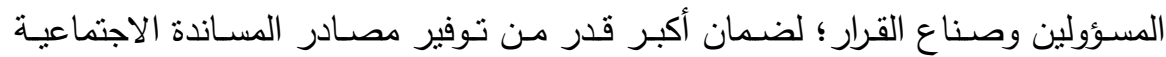
والدعم والخدمات لاولياء أمور الأطفال ذوي الاحتياجات الخاصة. 
بمكن لنتائج الدراسـة أن تساعد المعنيين بإعداد البرامج الإرشادية لأولياء أمور الأطفال

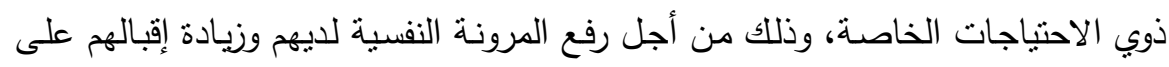

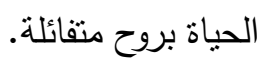

إعطاء مؤشرات لكل المسؤولين والمعنيين والمؤسسات وممن لهم علاقة بهذه الفئة بأن يُسخروا كل طاقاتهم، وأن يبذلوا كل جهدهم من أجل تمتعهم بالمرونة النفسية.

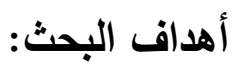

\section{تهاف الاراسة الحالية إلي التعرف علي:}

() طبيعة العلاقة بين المساندة الاجتماعية من قبل الأسرة والأصدقاء والمعلومانية والإجرائية

أو المادية والمرونة النفسية بأبعادها المختلفة.

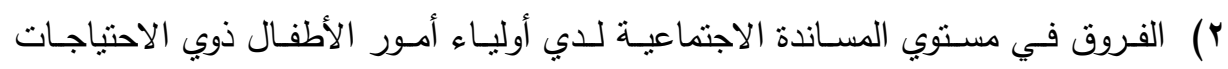

$$
\text { الخاصة تبعا لنوع الإعاقة. }
$$

r) الفروق في مستوي المرونة النفسية لدي أولياء أمور الأطفال ذوي الاحتياجات الخاصة

$$
\text { تبعا لنوع الإعاقة. }
$$

؛) مدي اسهام أبعاد المساندة الاجتماعية في التتبؤ بالمرونة النفسية لدى أولياء أمور الأطفال

ذوي الاحتياجات الخاصة.

\section{منهج الاراسة:}

تدرس البحوث الوصفية الارتباطية العلاقة بين المتغيرات، أو تتتبأ بحدوث متغيرات من

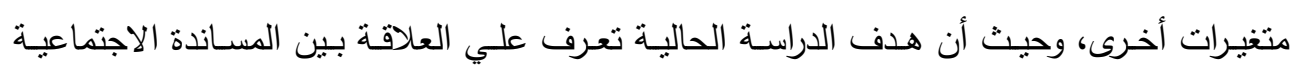

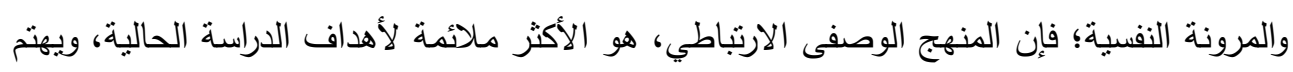

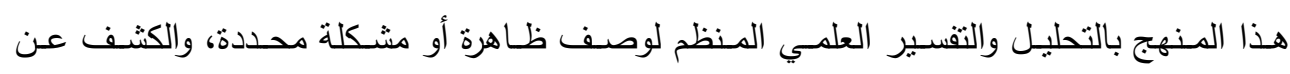
العلاقات بين متغيرين أو أكثر لمعرفة مدى الارتباط بين هذه المتغيرات والتعبير عنها بصورة رقمية لعنية

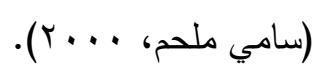


تتحدد هذه الدراسة بالحدود التالية:

الحد الموضسوعي: تتحدد هذه الدراسـة بموضوعها الذي يبحث في العلاقة بين متغيري

المساندة الاجتماعية و المرونة النفسية.

الحـد البشـري: بلـغ عدده (rVA) ولي أمر من أولياء أمور الأطفال ذوي الاحتياجات

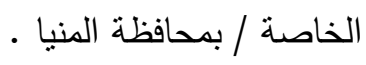

الحد المكاني: مدراس ومراكز التربية الخاصة بمحافظة المنيا.

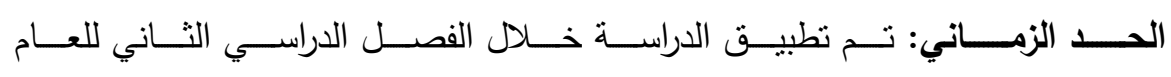

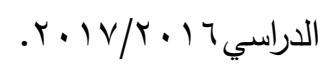

مصطلحات الاراسةة: - n

\section{: Social Support المساندة}

يعرفها كل من Cheng \& Chan (2004,1360 بأنها أساليب المساعدة المختلفة التىى

ينلقاها الفرد من الأسرة والأصدقاء والآخرين ذو العلاقة القوية به، والتى تتثثل فى تقديم المساعدة

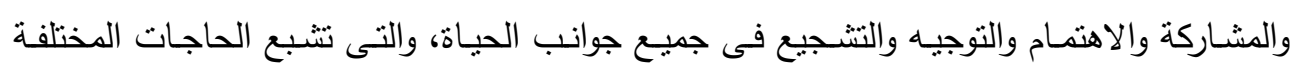
للفرد، وتتشعره بالأمن وتزيد من ثقته بنفسه وإمكانياته، وتساعده على تكوين ولثين علاقات اجتماعية جيدة.

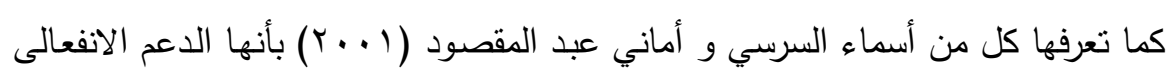

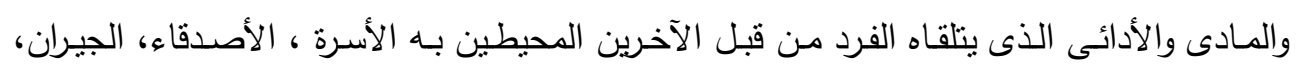

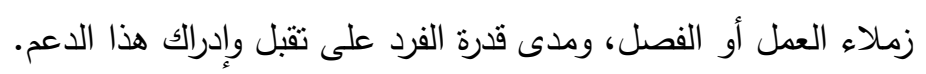

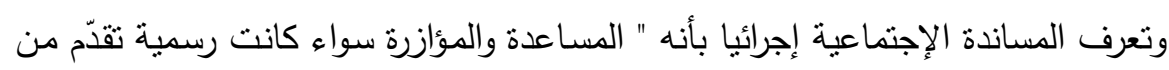

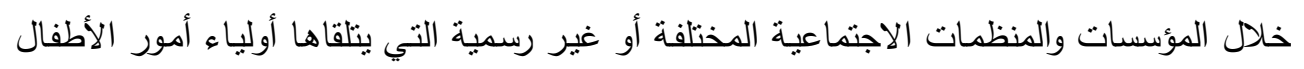
ذوي الاحتباجات الخاصة من الأسرة أو الأصدقاء أو في صورة معلوماتية أو إجرائية مادية. 


$$
\text { وتتمثل في أريع صور هي: }
$$

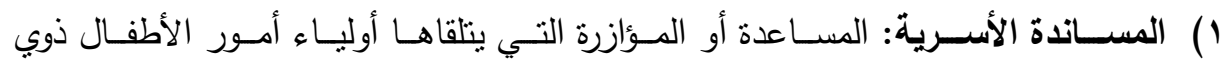
الاحتياجات الخاصة من أسرهم سواء الصغيرة أو الكبيرة.

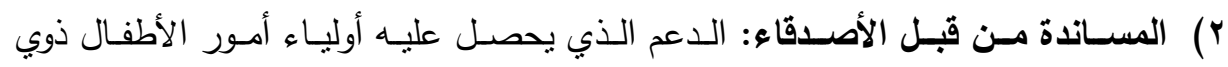

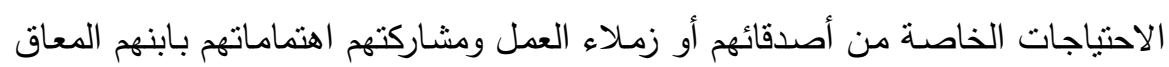

$$
\text { وتقديم المساعدة عند الضرورة. }
$$

r) المسـاندة المطلوماتيـة: إمداد أولياء الأمور بكم من المعلومات والنصائح عن الإعاقة، وكيفية الكثف المبكر عنها، والعلاج، و كيفية التعامل السليم مع الطفل ذو الاهنهاه الاحتياجات

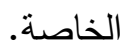

§) المساندة الإجرائية المادية: تقديم العون المالي والمادي والخدمات اللازمة لأسر الطفل ذو

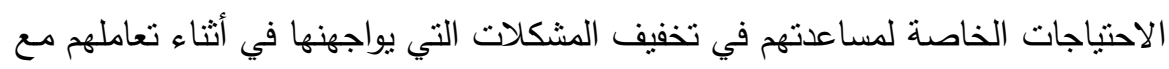
طفلهم، ويكون ذلك عن طريق المراكز المتخصصة أو الجمعيات الأهلية المنطوعة.

\section{المرونة النفسية Psychological Resilience:}

عرفها Walsh (1998 بأنها القدرة على تحمل المشقة والنهوض من المحن، وتصبح أكثر قوة ودهاءا.

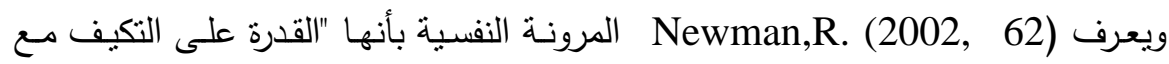
الأحداث الصادمة، المحن والمواقف الضاغطة المنواصلة، وهي عملية مستمرة يظهر من خلالهها الفرد سلوكاً تكيفياً إيجابياً في مواجهة الدحن، الصدمات ومصادر الضغط النفسي".

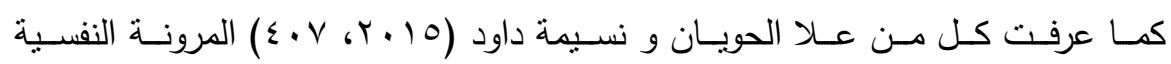
"Resilience" الذي يُجابه فيه مصاعب جمة أو صدمات أو مآسٍ. وتعرف المرونة النفسية إجرائيا بأنها " قدرة ولي أمر الطفل ذو الاحتياجات الخاصة علي التكيف الناجح والأداء الإيجابي مع الظروف الصعبة أو الاجهاد المزمن التي تواجه في أثناء تتشئة طفله." 


\section{أولياء أمور الأطفال ذوي الاحتياجات الخاصة: هم أم وأب طفل ذو احتياجات خاصة أو من ينوب عنهم. الأطفال ذوي الاحتياجات الخاصة: - الاصن}

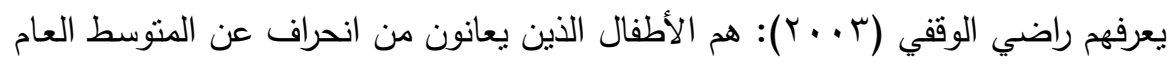

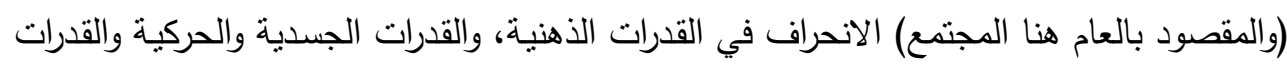

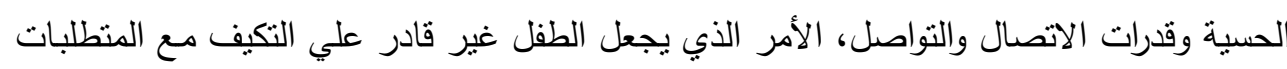

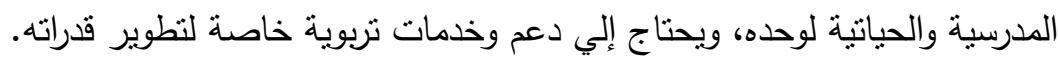

الأطار النظري للاراسة: - ماسن

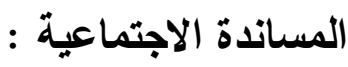

تعتبر المساندة الاجتماعية مصدرا هاما من مصادر الدعم النفسي الاجتماعي الفعال الذي

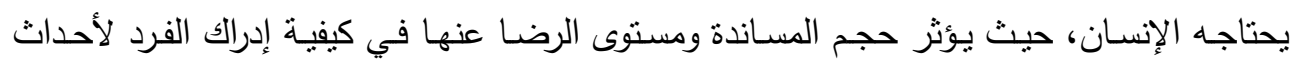
الحياة وأساليب التعامل معها وانعكاساتهما على صحته.

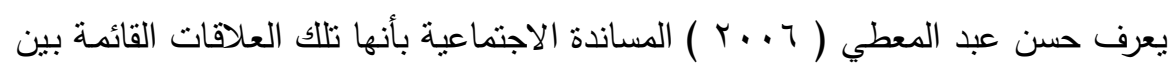

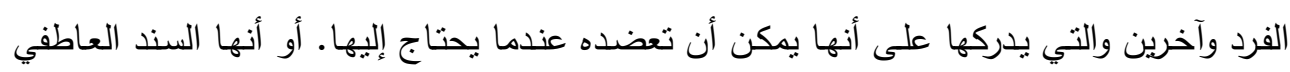

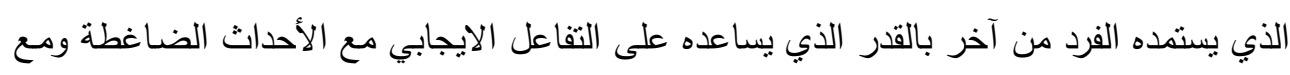

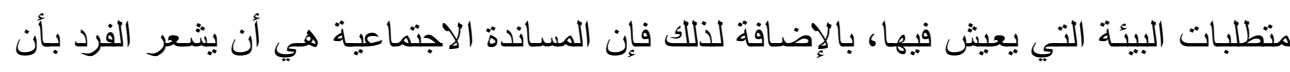

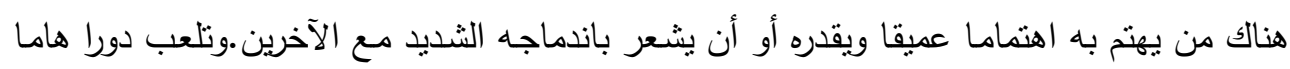

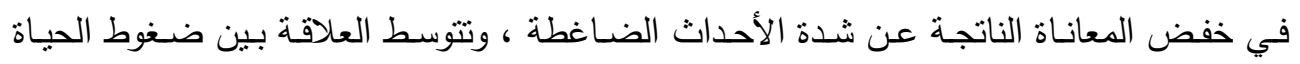
والانهيار الصحي أو النفسي.

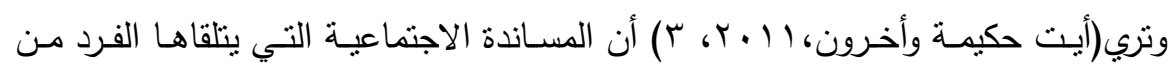
الآخرين سواء في الأسرة أو خارجها، تعد عاملا هاما في صحته النفسية، ومن ثم بمكن التتبؤ بأنه

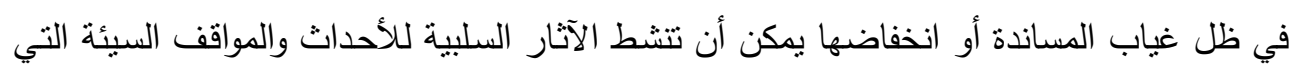
يتعرض لها الفرد، بما يؤدي إلى اختلال الصحة النفسية لديه 
وحددها Thoits (YAN19) في تلك المجموعة الفرعية من الأشخاص في الثبكة الكلية للعلاقات الاجتماعية للفرد، والذين يعتمد عليهم للمساعدة الاجتماعية العاطفية والمادية أو كليهها.

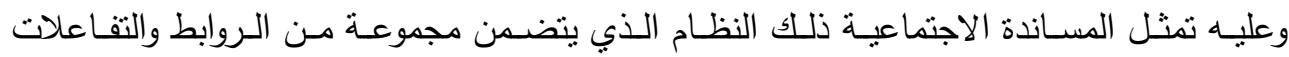

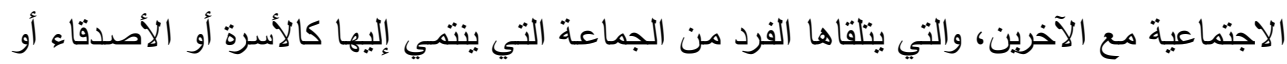

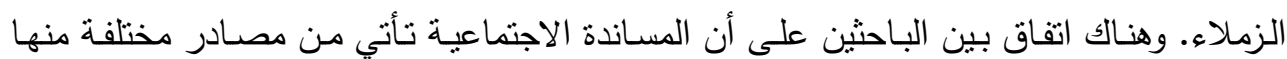
الأسرة ، الزوج أو الزوجة، الأصدقاء، الزملاء في العمل، الطبيب والمنظمات الاجتماعية.

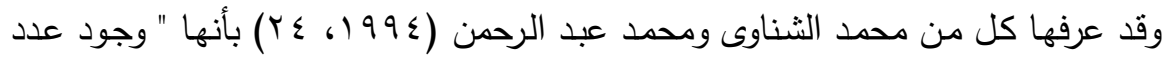

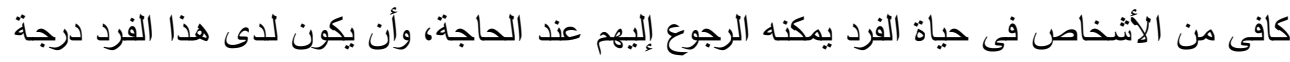
من الرضا عن هذه المساندة المتاحة له".

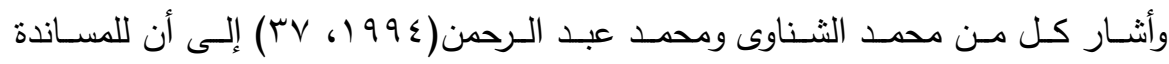

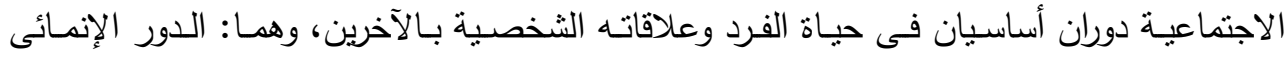

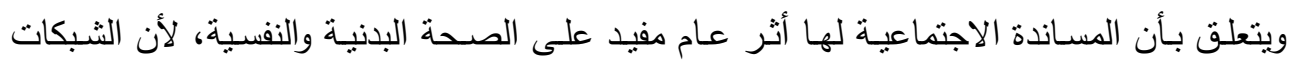

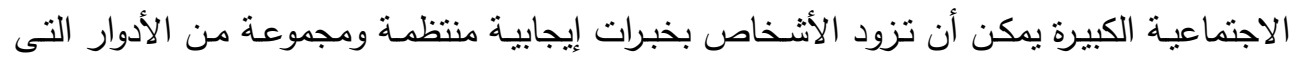

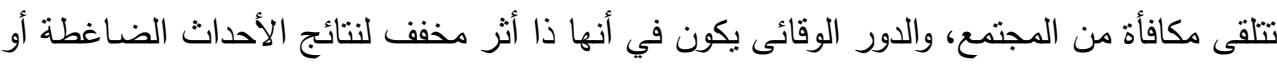

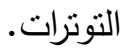

وهذا النوع من المساندة يمكن أن يرتبط بالمرونة النفسية حيث أنها تتمثل في قدرة الفرد

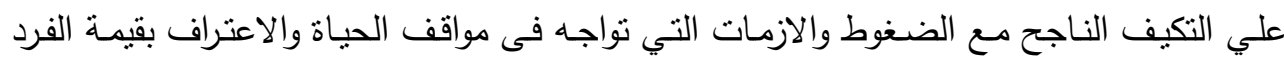
وأهميته ومساندة تقدير الذات.

وقد قسم كل من Wang \& Brown (2009) أنماط المساندة الاجتماعية للأسر التي لديها طفل يعاني من إعاقة تتموية، إلى نظامين رسمي وغير رسمي. وينظر إلى نظم المساندة

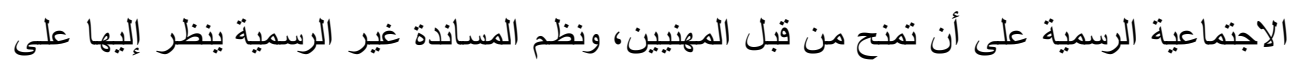

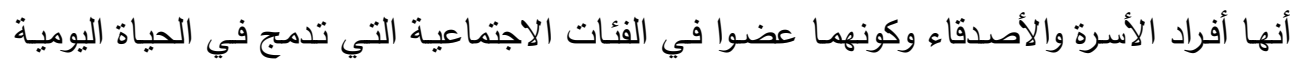
للأسرة. 


\section{أهمية المساندة الاجتماعية:}

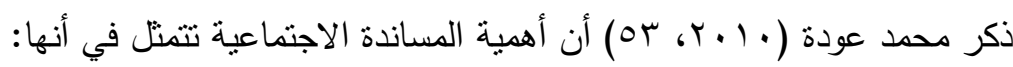

$$
\text { ( ) تؤثر بطريقة مباشرة على سعادة الفرد. }
$$

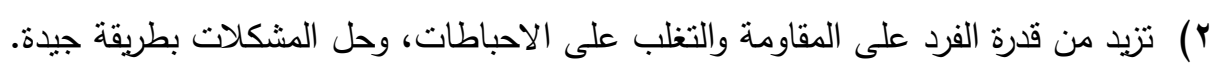

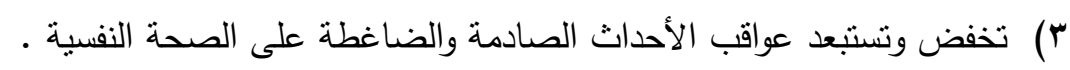
؛) نساعد الفرد على تحمل المسؤولية ، وتبرز الصفات القيادية له. له.

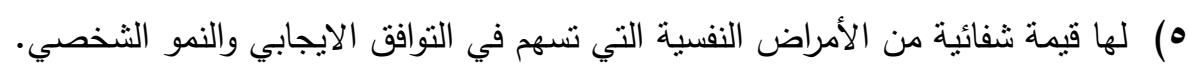

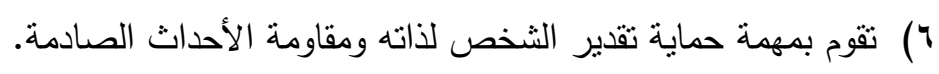
( ن تخفف من وقع الصدمات النفسية ، وتخفف من أعراض القلق والاكتئاب.

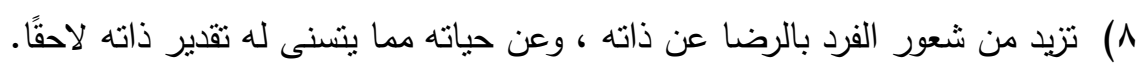
أشكال المساندة الاجتماعية:

ذكر كل من محمد الثناوى ومحمد عبد الرحمن( ؟991، ( 199 أنثكال المساندة الإجنماعية فيما

$$
\text { يلي: }
$$

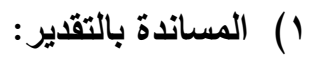

تعني التعبير للآخرين أنهم قادرون لقيمهم الذاتية وخبراتهم، وأنهم مقبولون بالرغم من

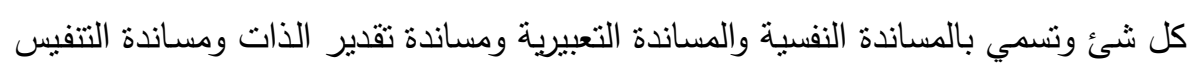

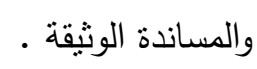

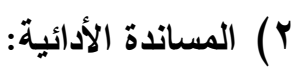

والتي تكون من خلال إلحاق الثخص المسند بعدل يتتاسب مـع امكانياته وقدراته، وكما تشمل على محاولة أن يحل الفرد مشكلاته عن طريق تزويده ببعض النقود أو الهدايا

$$
\text { الملموسة. }
$$

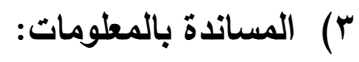

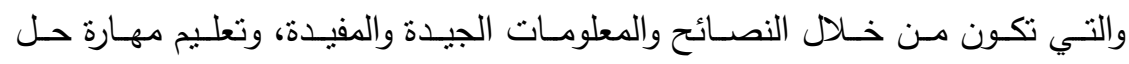

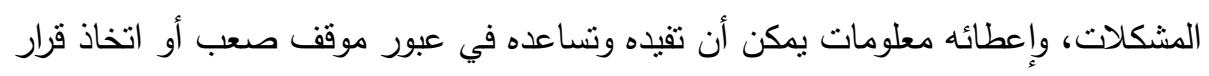

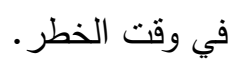


؟ ) المساندة الأدائية أو الإجرائية:

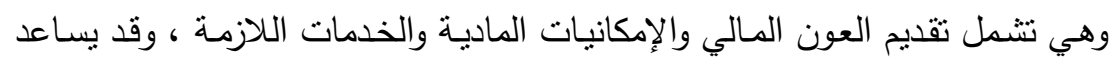

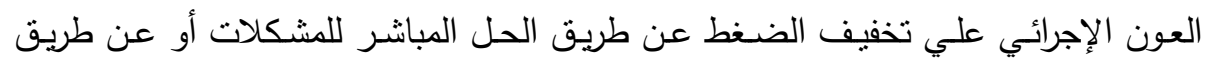

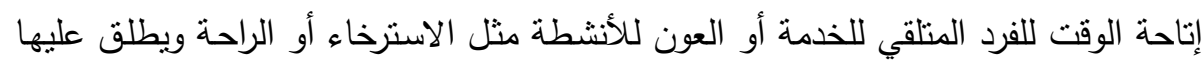
أيضا المساندة المادية والملموسة. وقد أضاف إليهم عماد عبد الرازق (99191، 7 (1)

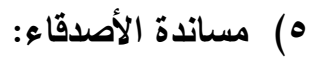
والتي تتطوي علي ما يمكن أن يقدمه الاصدقاء لبعضهم البعض وقت الثدة .

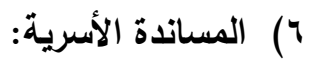

والتي تتمثل في قيام الأسرة بتقديم جميع جوانب وأثكال المساندة للفرد من خـلال الحديث معه، وتقديم المعلومات له، وزيادة تقته بنفسه.

كما أنثار ناجي الخشاب (r . . r) إلي ثناثة أبعاد للمساندة الاجتماعية وهي : ( المساندة الذاتية: ويقصد بها دعم معنوي يستطيع الفرد منحه لنفسه، وذلك بهدف التغلب علي المشكلات التي يواجهها. ^) المسـاندة الاجتماعيـة: ويقصد بها أي دعم معنوي أو إجرائي يقدم من المحيطين بالفرد

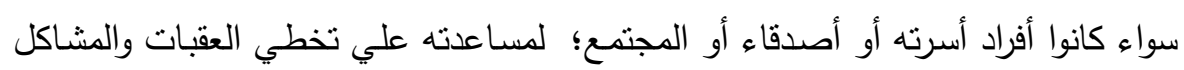
التي يواجهها.

9) المساندة المادية: ويقصد بها أي دعم مادي يقدم من المحيطين بالفرد أو المجتمع بطريق

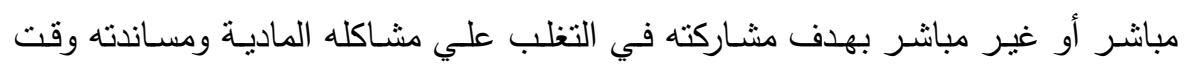
الثدة.

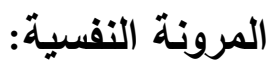

عرفها كل من DeHaan \& Hawley(1996, 284 بأنها "القدرة على الارتداد الخلفي أو العودة إلى طريقة العمل السابقة". 


\section{المجلة العلمية لكلية رياض الاطفال - جامعة اسيوط}

American Psychological تعرف الجمعية الأمريكية لعلم النفس المرونة النفسية

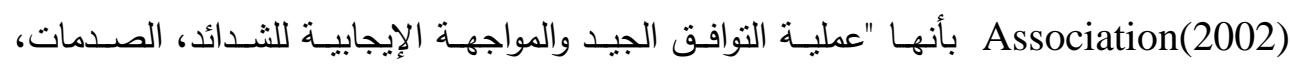

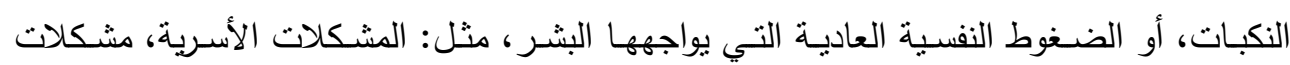
العلاقات مع الآخرين، المشكلات الصحية الخطيرة، وضغوط العمل والمشكلات المالية".

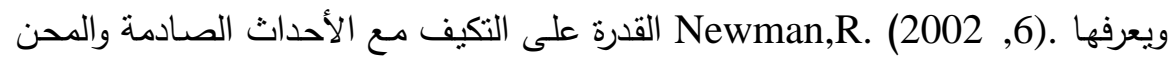

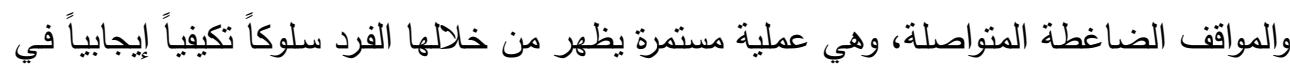
مواجهة المحن و الصدمات ومصادر الضغط النفسي.

كما عرض Lee, I., et al (2004, 636 مفهوما للمرونة النفسية للأسرة بأنها قوة دائمة

تدفع الأسرة إلى تغيير ديناميات عملها من أجل حل المشاكل المرتبطة بالضغوط الني تواجهها. يري كل من Lee \& Cranford ( 2008, 213 ) أن المرونة النفسية هي " قدرة الأفراد على التعامل بنجاح مع تغير كبير أو محنة أو خطر. ويعرفها كل من (2013) Fletcher, D. \& Sarkar, M. بأنها هي القدرة المطلوبة على الصمود استجابة لمختلف المحن، بدءا من المتاعب اليوميـة الجاريـة إلي وأحداث الحياة الرئيسية.

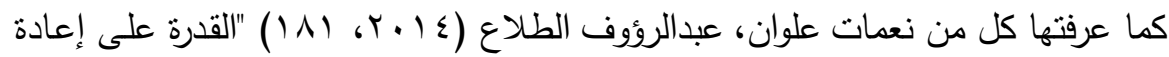

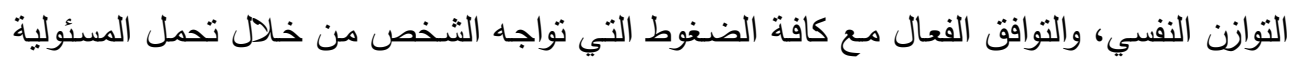

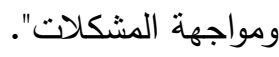

وقد حدد (1995) Grotberg, E. ثلاثة مصادر تأتي منها المرونة تتمثل في: الدعم

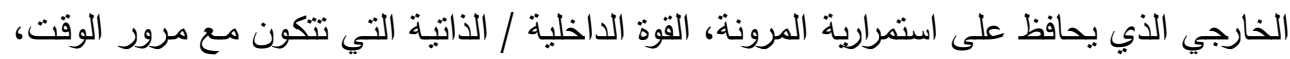
وامتلاك مهارة حل المشكلات التي تساعد الفرد على مواجهة المحن والثدائد.

وقد أورد Heiman, T. ثلاثة عوامل رئيسية تمكن أولياء أمور الأطفال ذوي

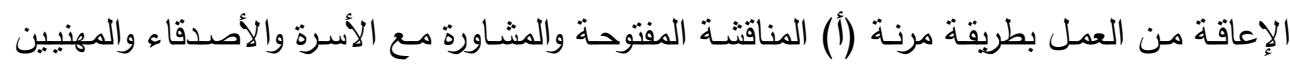
(ب) وجود علاقة إيجابية بين الوالدين تدعمهم وتقويهم (ج) دعم تعليمي وعلاجي ونفسي مستمر ومكثف لأفراد الأسرة. 
كما قام (Walsh,2003) بتحديد العوامل الرئيسية التي تساهم في قدرة الأسرة على التمتع بالمرونة النفسيةة ما يلي: (1) خلق معنى للثدائد، (Y) تأكيد القوة والحفاظ على النى النظرة الإيجابية

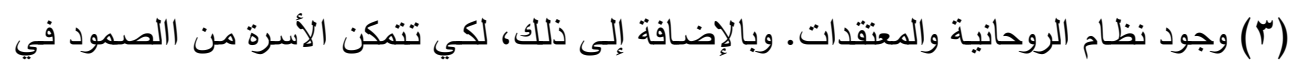

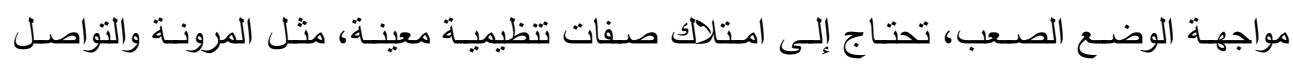
والاتصال والقدرة على استخدام الموارد أو المصادر . لمعاد.

وقد استعرض (Van Galen, et al, 2006,6) سمات الأفراد ذوي المرونـة التفسية

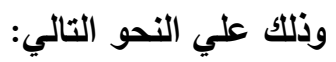

( ) لديهر علاقات جيدة مع الآخرين والقدرة علي استقبال المساندة الاجتماعية.Social support.

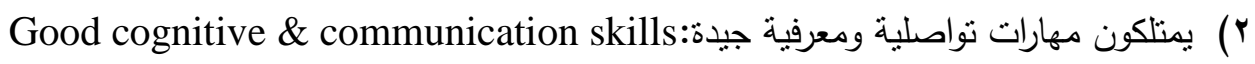

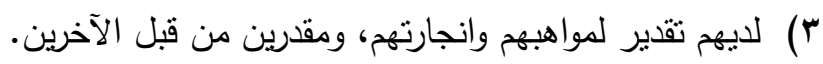

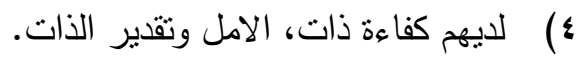
( ) الاحساس بالهدف من الحياة. 7) التدين والثعور بالانتماء. ( المساهمة في الحياة الاجتماعية. ^) تعزيز الذات. 9 ( ) ل لديهم القدرة علي استخدام أساليب تكيف منوافقة ومتتاسبة مع الموقف والفرد. • 1 اليتمتعون بالعاطفة الايجابية و روح الدعابة.

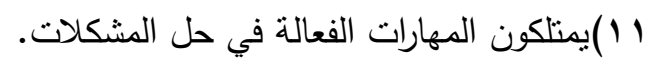
r باؤمنون بأن الضغوط يمكن أن تزيد الفرد قوة.

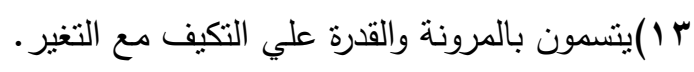
؛ ا (1) القبول المشاعر السلبية. ه 1) لايهم قدرة علي التعامل الجيد مع الضغوط، ورؤية الضغوط علي أنها تحديات.

\section{American psychological وقـــ حـدت الجمعيـة الأمريكيـة لعــم الـنفس} association (2002) 1) إقامـة العلاقات: إن العلاقات الجيدة مـع أفراد العائلـة المقربين أو الأصدقاء أو الآخرين

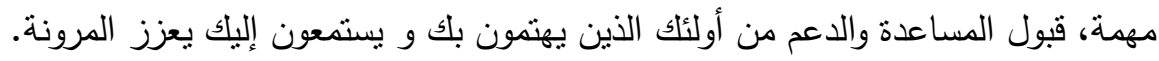




\section{المجلة العلمية لكلية رياض الاطفال - جامعة اسيوط}

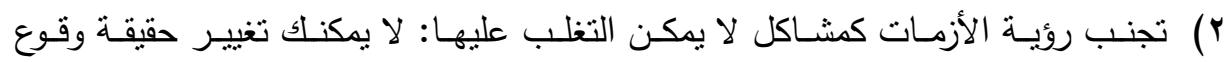

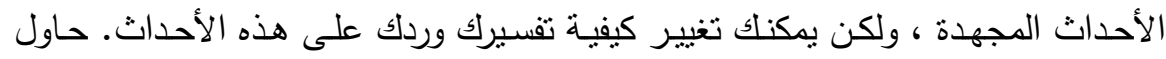
النظر إلى ما هو أبعد من الحاضر لكيف بمكن أن تكون الظروف المستقبلية أفضل

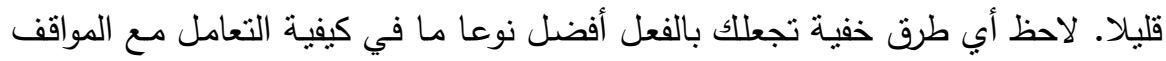

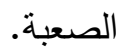
r) تقبل أن التغيير هو جزء من الحياة: قد لا يمكن تحقيق بعض الأهداف نتيجة للأوضاع

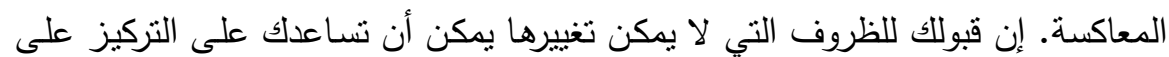
الظروف التي يمكنك تغييرها. ؛) النحرك نحو أهدافك: تطوير بعض الأهداف الواقعية. فعل شيئا بانتظام - حتى لو كان

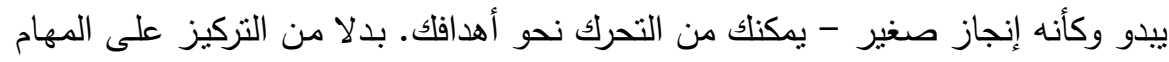

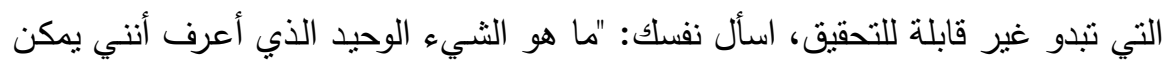

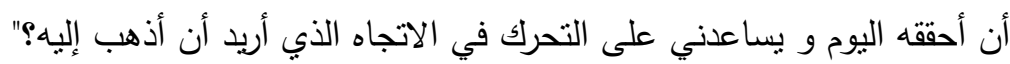

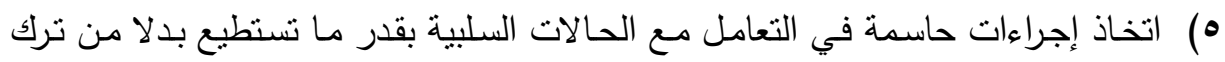
المشاكل والضغوط، منمنيا أنها سوف تنتهي من تلقاء نفسها. 7) ابحث عن فرص لاكتثاف ذاتك. ت تنبي وجهة نظر إيجابية عن نفسك: تطوير الثقة في قدرنك على حل الشاكل يساعدك على بناء القدرة على المرونة.

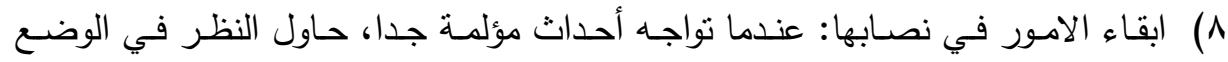
المجهد في حجمه الطبيعي بدلاً من التضخيم من المشكلة.

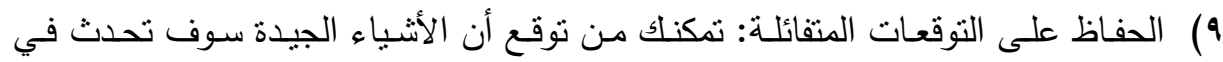
حياتك. حاول تصور ما تريد، بدلا من القلق بشأن ما تخشاه.

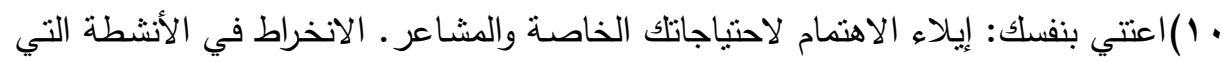
تمتعك وتجد فيها الاسترخاء. اتمرن بانتظام علي رعاية نفسك يساعدك على إبقاء عقلك الك الكا

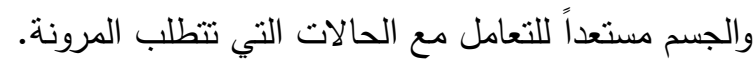
الركائز السبعة للمرونة النفسية:

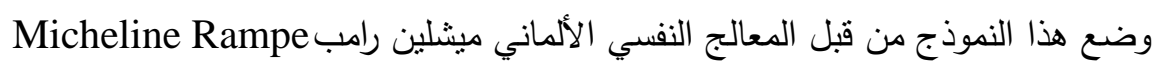

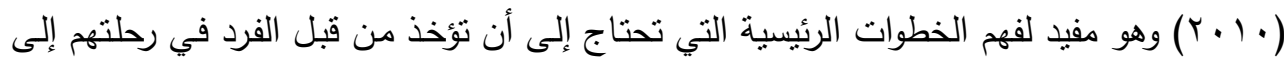


التمتع بالمرونة النفسية، والعديد من الاستراتيجيات التي وصفها رامب ( • • ب) متوافقة مع النهج

$$
\text { هذه الركائز السبعة هي في أدب علم النفس الإيجابي. }
$$

1) تطوير التفاؤل (مما يؤدي إلى توقعات إيجابية تمكن الثخص من اتخاذ إجراءات إيجابية.

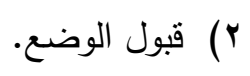

r ( التركيز على الحلول المحتملة.

؛ ) تحمل المسؤولية عن الحياة الخاصة.

$$
\text { •) الهروب من دور ضحية للظروف. }
$$

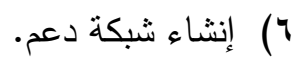

\section{(V تخطيط استراتيجية مرنة للتعامل مع التحديات المستقبلية}

وتوفر هذه الركائز خطوات أساسية تعطي الفرد الأدوات اللازمة للتعامل مع المحن بطريقة

$$
\text { إيجابية وبناءة. }
$$

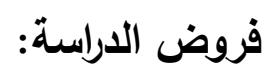

( ) نوجد فروق ذات دلالـة احصـائية في المرونـة النفسية لدي أوليـاء أمسور الأطفال ذوبي الاحتياجات الخاصة تبعا لنوع الإعاقة.

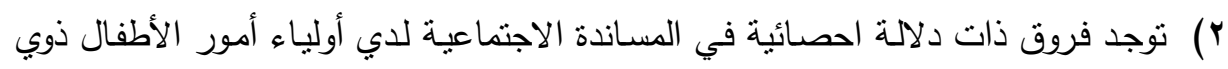
الاحتياجات الخاصة تبعا لنوع الإعاقة.

r) توجد علاقة ارتباطية بين المساندة الاجتماعية والمرونة النفسية لدي أولياء أمور الأطفال

$$
\text { ذوب الاحتياجات الخاصة. }
$$

؛) تسهم بعض أبعاد المساندة الاجتماعية اسهاما دالا في المرونة النفسية لادي أولياء أمور

$$
\text { الأطفال ذوي الاحنياجات الخاصة. }
$$

$$
\text { أدوات الدراسةة: - n }
$$

1- مقياس المسـاندة الاجتماعيـة لأولياء أمسور الأطفال ذوي الاحتياجـات الخاصـة (إعداد

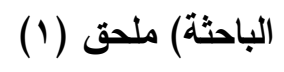

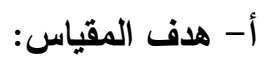

يهـدف هذا المقيـاس إلى قيـاس المسـاندة الاجتماعيـة لـدي أوليـاء أمسور الأطفال ذوي

$$
\text { الاحنباجات الخاصة. }
$$




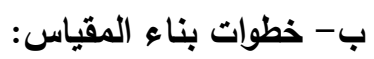

لإعداد مقياس المساندة الاجتماعية لأولياء أمور الأطفال ذوي الاحتياجات الخاصة قامت

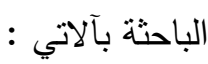

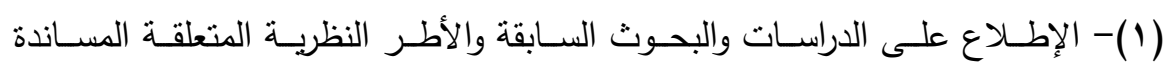

الاجتماعية .

(r) - تم تحليل بعض المقاييس والاستبيانات الخاصة بالمساندة الاجتماعية بوجه عام من

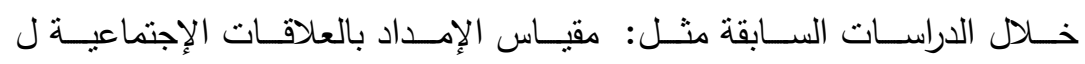

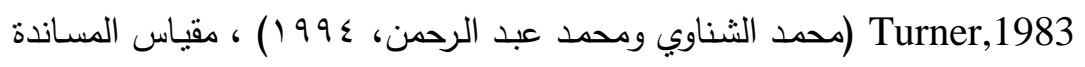

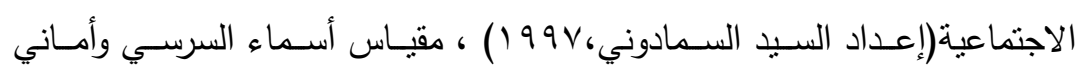

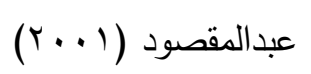

ج- وصف المقياس :

يتكون مقياس المساندة الاجتماعيـة من (rr) اثثان ثلاثون عبارة مقسمين علي أربع

ذأبعاد، وقد روعي وضوح العبارات ودقتها في وصف المساندة الاجتماعية لاي أولياء أمور الأطفال

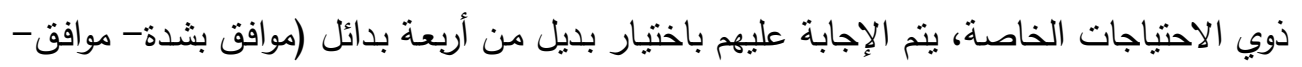
موافق إلي حد ما- غير موافق).

جدول (1)

أبعاد المساندة الاجتماعية والعبارات التي تقسيها

\begin{tabular}{|c|c|}
\hline العبارات التي تقيسها & أبعاد المساندة الاجتماعية \\
\hline$\wedge-1$ & المساندة الأسرية \\
\hline $17-9$ & مساندة الأصدقاء \\
\hline$r \varepsilon-1 V$ & المساندة المعلوماتية \\
\hline Tr TO & المساندة الإجرائية المادية \\
\hline
\end{tabular}

د - طريقة التطبيق والتصحيح.

يتم تطييق المقياس بطريقة جماعية، حيث يقوم ولي الأمر بملء البيانات الخاصة به، ولا

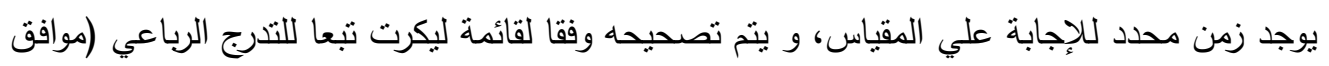

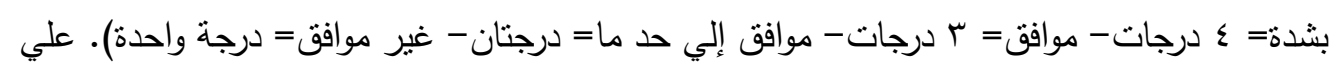


أن يتم عكس هذه الميزان في حالة الإجابات السالبة. وجميع عبارات المقياس موجبة باستثناء العبارات

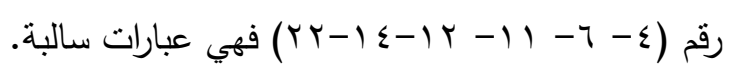

هـ - حسـاب صـلق مقيـاس المسـاندة الاجتماعيـة للدي أوليـاء أمسور الأطفـال ذوي الاحتياجـات

( ) (ستطلاع أي السادة المحكمين

للتأكد من صلاحية الصورة المبدئية المقياس نت عرضه علي مجموعة من السادة

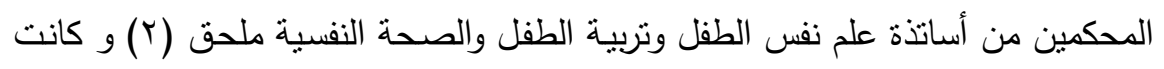

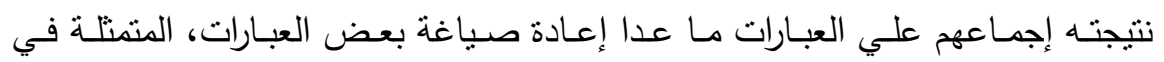
استبدال كلمة ابني المعاق بابني ذو الاحتياجات الخاصة، وقد نم إجرائها.

r

تم حساب التجانس الداخلي كمؤشر للصدق وذلك بحساب معاملات الارتباط بين

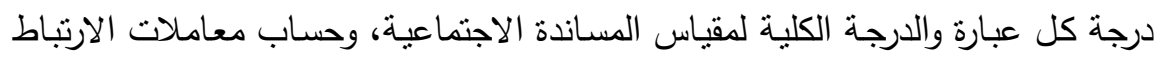
بين درجة العبارة بالدرجة الكلية للبعد المنتمية إليه، وكذلك حساب معاملات الارتباط بين الإني

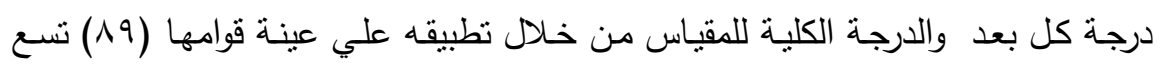

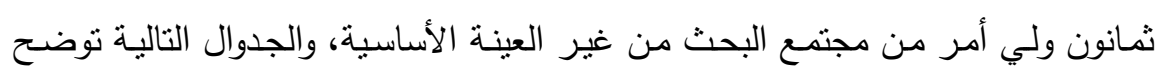
نتائج صدق الاتساق الداخلي للمقياس. 
المجلة العلمية لكلية رياض الاطفال - جامعة اسيوط

جدول (r) ( )

معاملات الارتباط بين درجة كل عبارة والدرجة الكلية لمقياس المساندة الاجتماعية (ن= ^9)

\begin{tabular}{|c|c|c|c|c|c|c|c|c|}
\hline \multicolumn{9}{|c|}{ العبارات } \\
\hline$\wedge$ & $v$ & 7 & 0 & $\varepsilon$ & $r$ & r & 1 & رقبرة \\
\hline **...Tr & $* * .0 r$ &. $.1 \mathrm{~V}$ & $" * \ldots .04$ & .r. & $* * . . \mathrm{VV}$ & ***. . $0 \leqslant$ & $* * . .09$ & الإرتباط معامل \\
\hline 14 & 10 & $1 \varepsilon$ & 14 & ir & 11 & 1. & 9 & رقبر \\
\hline .r. & ***. . & *..r & $* * \ldots$ * & ***.. & *..ro & $* * \ldots$ \% & $* * \ldots$ * & الإرتباط \\
\hline$r \varepsilon$ & rr & rr & r) & r. & 19 & 11 & IV & رقبر \\
\hline r". & $* * . .71$ & **...rY & **.or & $* * . .89$ & $* * . .44$ & ***.. & $* * \ldots$ * V & الإرتباط \\
\hline rr & r & r. & rq & rA & $r v$ & Y & ro & رقبر \\
\hline$* * \ldots$ & \& & $* * . . r r$ & *** & $* * \ldots . .89$ & *** & ***.. \&0 & ** . . $\{\Lambda$ & الإرتباط \\
\hline
\end{tabular}

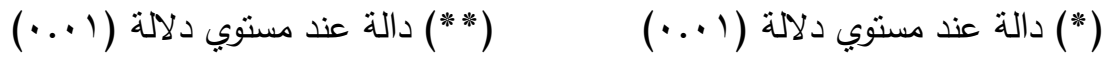

$$
\text { يتضح من جدول (r) ما يلي : (r) }
$$

تراوحت معاملات الارتباط بين درجة كل عبارة من عبارات المقياس والدرجة الكلية له ما

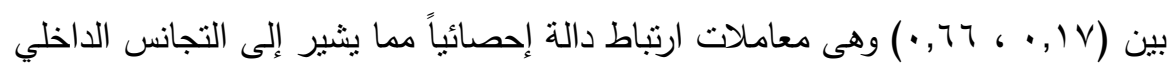

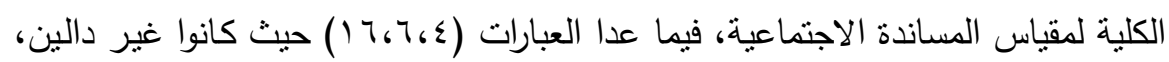

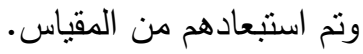




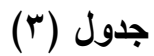

معاملات الارتباط بين درجة كل عبارة ودرجة البعد المنتمية إليه لمقياس المساندة الاجتماعية

$(\wedge q=\dot{0})$

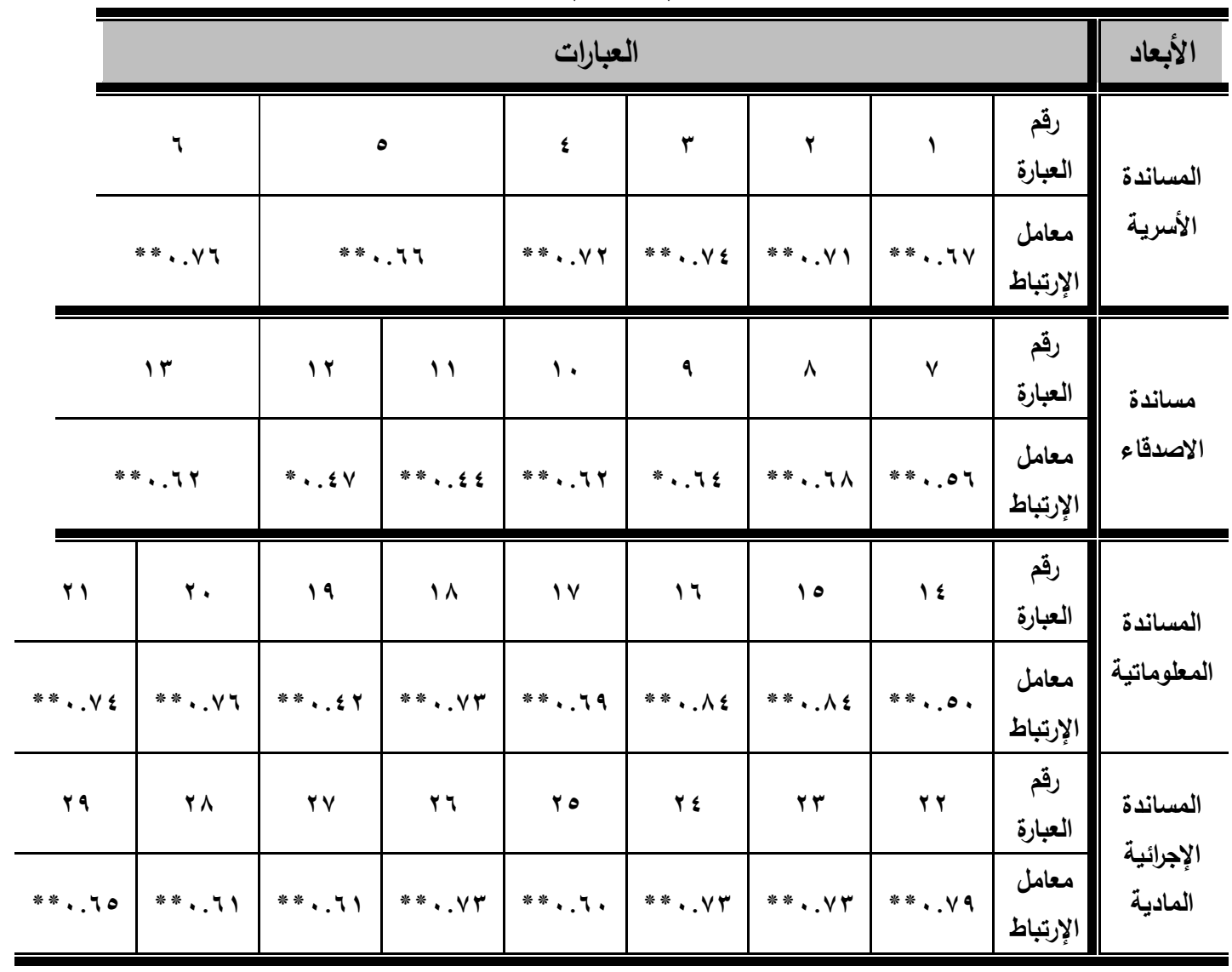

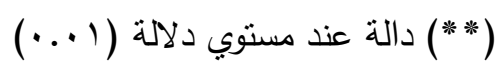

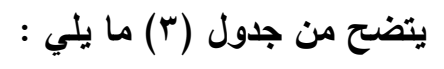

تزاوحت معاملات الارتباط بين درجة كل عبارة من عبارات مقياس المساندة الاجتماعية

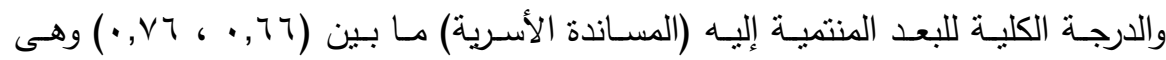

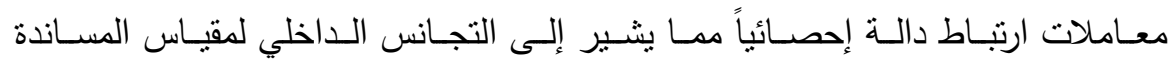
الاجتماعية لدي أولياء أمور الأطفال ذوي الاحتياجات. 


\section{المجلة العلمية لكلية رياض الاطفال - جامعة اسيوط}

تزاوحت معاملات الارتباط بين درجة كل عبارة من عبارات مقياس المساندة الاجتماعية

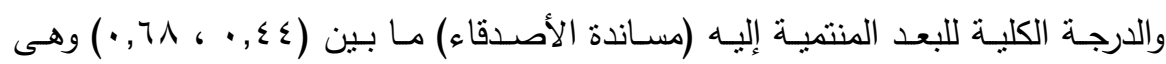

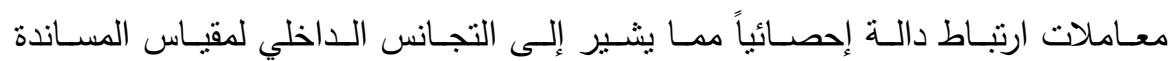
الاجتماعية لدي أولياء أمور الأطفال ذوي الاحنياجات.

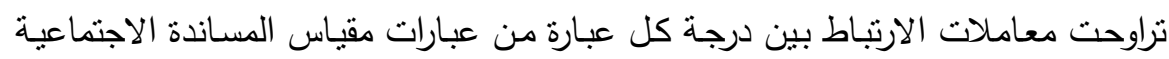

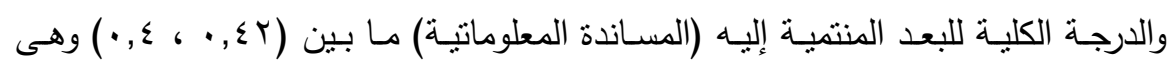

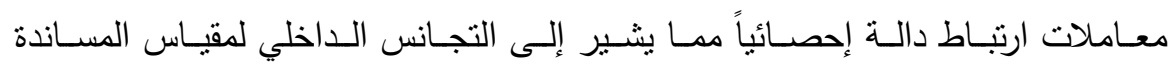
الاجتماعية لدي أولياء أمور الأطفال ذوي الاحتباجات. تراوحت معاملات الارتباط بين درجة كل عبارة من عبارات مقياس المساندة الاجتماعية

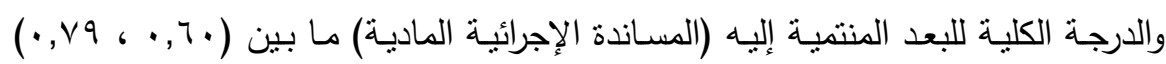

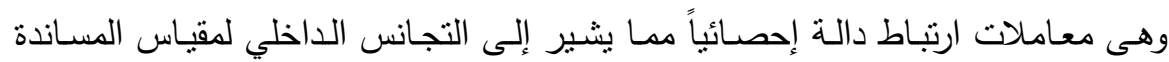

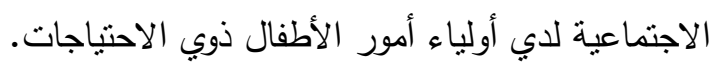

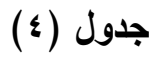

معاملات الإرتباط بين درجة كل بعد واللارجة الكلية لمقياس المساندة الاجتماعية (ن = ^ ^)

\begin{tabular}{|c|c|}
\hline معامل الإرتباط & أبعاد المقياس \\
\hline$* * . V Y$ & المساندة الأسرية \\
\hline$* * . .71$ & مساندة الأصدقاء \\
\hline$* * . . \wedge 1$ & المساندة المعلوماتية \\
\hline$* * . .7 \mathrm{~V}$ & المساندة الإجرائية المادية \\
\hline
\end{tabular}

$$
\begin{aligned}
& \text { (***) دالة عند مستوي دلالة (1 ...) } \\
& \text { يتضح من الجدول (؛) ما يلي : }
\end{aligned}
$$

تزاوحت معاملات الإرتباط بين درجة كل بعد من أبعاد مقياس المساندة الاجتماعية لدي

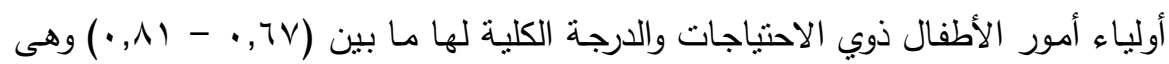

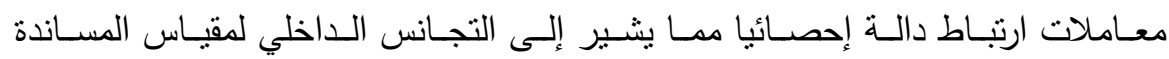

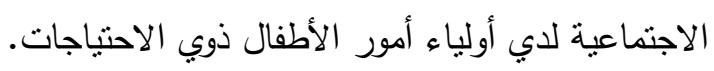


ز - حساب ثبات مقياس المساندة الاجتماعية لدي أولياء أمور الأطفال ذوي الاحتياجات الخاصة.

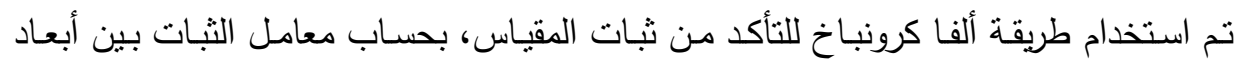

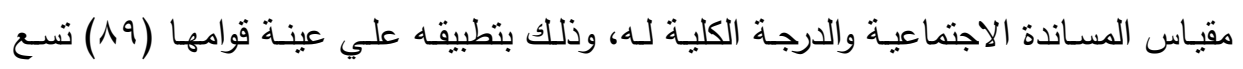

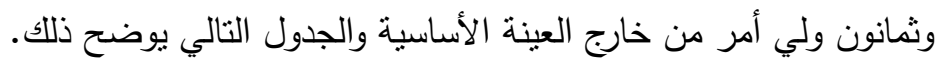

\section{جدول(0)}

معاملات ثبات ألفا كرونباخ لمكونات مقياس المساندة الاجتماعية (ن = ^9)

\begin{tabular}{|c|c|}
\hline معامل ألفا & أبعاد المقياس \\
\hline$* * . .10$ & المساندة الأسرية \\
\hline$* * \ldots$ * & مساندة الأصدقاء \\
\hline 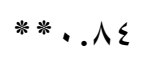 & المساندة المعلوماتية \\
\hline$* * . . \wedge r$ & المساندة الإجرائية المادية \\
\hline$* * \ldots \wedge$ & الكلي \\
\hline
\end{tabular}

$$
\begin{aligned}
\text { يتضح من الجدول(ه) ما يلي: دالة عند مستوي دلالة (1.*.) } &
\end{aligned}
$$

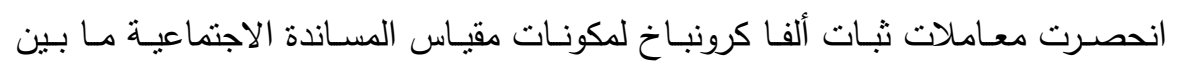

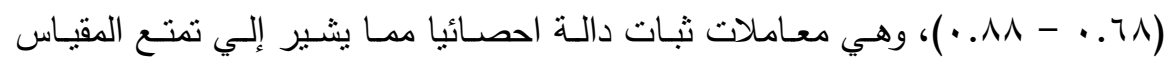

$$
\text { بمعاملات ثبات مرتفعة. }
$$

ح- وصف المقياس في صورته النهائية :

نم التوصل إلي الصورة النهائية للمقياس، وذلك بعد أن نم حساب الصدق والثبات التهات للمقياس

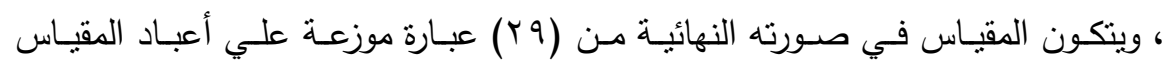

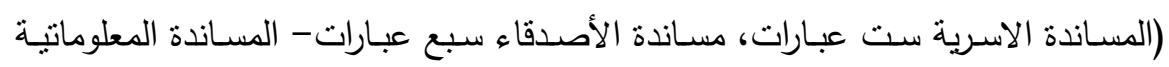
ثماني عبارات-المساندة المادية أو الإجرائية ثماني عبارات). 
r) مقياس المرونـة النفسبة لأولياء أمور الأطفال ذوي الاحتياجات الخاصة. (إعداد الباحثة)

ملحق (ب)

أ- هدف المقياس: (r)

يهـدف إلـى قيـاس المرونـة النفسـية لـدي أوليـاء أمـور الأطفـال ذوي الاحتباجـات

الخاصة.

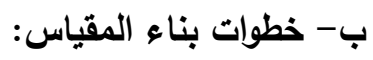

لإعداد مقياس المرونة النفسية لأولياء أمور الأطفال ذوي الاحتياجات الخاصة قامت

الباحثة بآلاتي : (1) - (1)

(1) الإطلاع على الدراسات والبحوث السابقة والأطر النظرية المتعلقة بالمرونة النفسية.

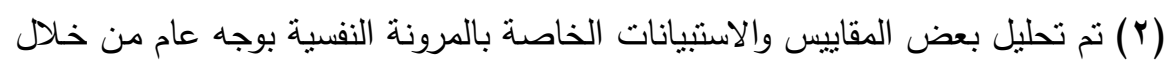
الدراسات السابقة مثل: مقياس كونور -دافيدسون

Connor-Davidson Resilience Scale

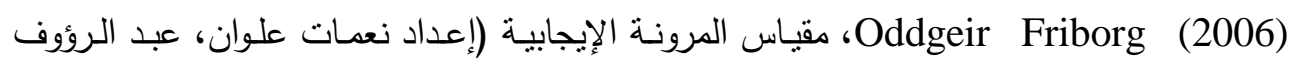

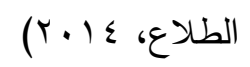

ج- وصف المقياس:

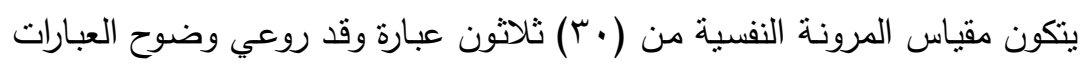

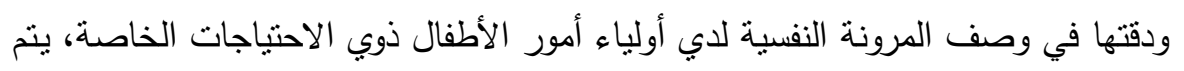

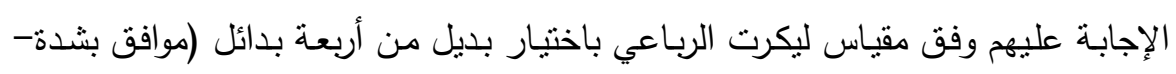

$$
\text { موافق - موافق إلي حد ما- غير موافق). }
$$

د- طريقة التطبيق والتصحيح.

يتم نطبيق المقياس بطريقة جماعية، حيث يقوم ولي الأمر بملء البيانات الخاصـة

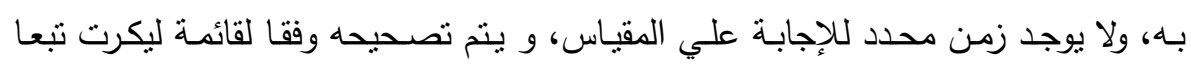

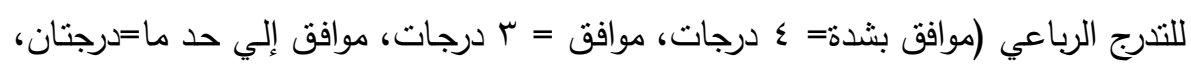

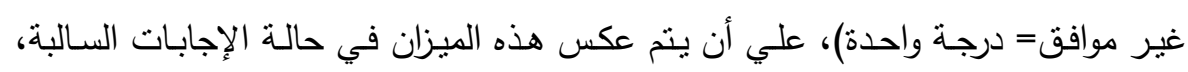

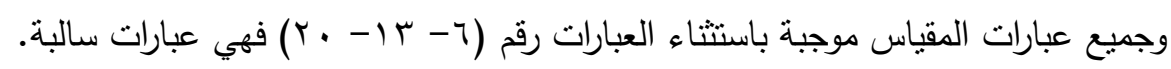


هـ - حسـاب صـاق مقيـاس المرونـة النفسية لـدي أوليـاء أمسور الأطفـال ذوي الاحتياجـات

الخاصة.

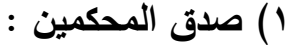

للتأكد من صسلاحية الصورة المبدئية للمقياس تم عرضـه علي مجموعة من السادة

المحكمين من أسـاتذة علم نفس الطفل وتربية الطفل والصحة النفسية ملحق (Y) وعلي

$$
\text { ضوء أرائهم نم إعادة صياغة بعض من العبارات . }
$$

جدول (7)

تعديلات السادة المحكمين علي مقياس المرونة النفسية

\begin{tabular}{|c|c|}
\hline العبارات بعد التعديل & العبارات قبل التعديل \\
\hline استطيع ضبط انفعالاتي عندما أنضايق لأمر من الأمور & اسنطيع اخفاء انفعالي عندما أتضايق لأمر من الأمور \\
\hline أضع الأمور في سياقها وحجمها الطبيعي في أي مشكلة & أضع الأمور في سياقها وحجمها الطبيعي. \\
\hline انظر إلي الأثياء أو الأمور التي تحدث في حياتي & انظر إلي الأثياء أو الأمور بايجابية \\
\hline راضية عن نفسي وبما حققته في حياتي من انجازات. & أفخر بنفسي وبما حققته في حياتي من انجازات. \\
\hline
\end{tabular}

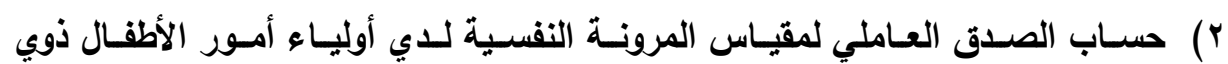

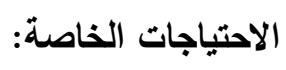

يعد التحليل العاملي شكلاً متقدماً من أشكال الصدق ، وقد تم إجراء التحليل العاملي

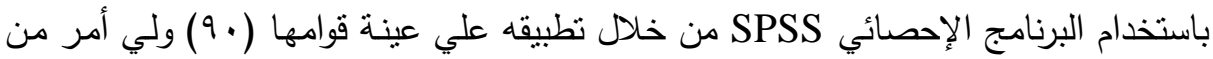

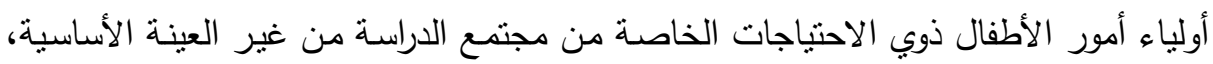

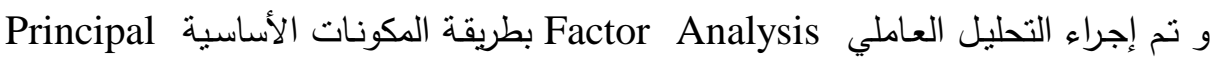
Component التثبعات الدالة فقد تم اختيار العبارات التى تثبعت على أكثر من عامل بقيم غير منقاربة

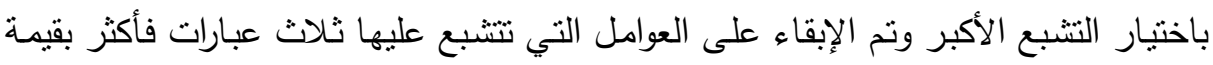

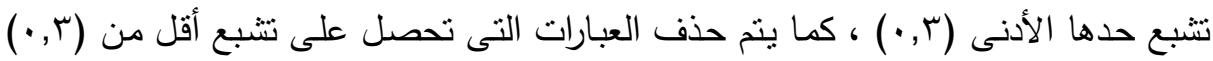

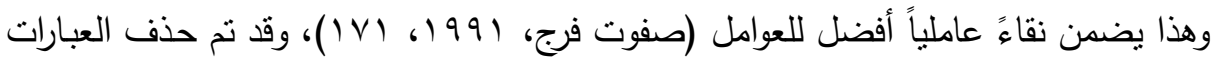

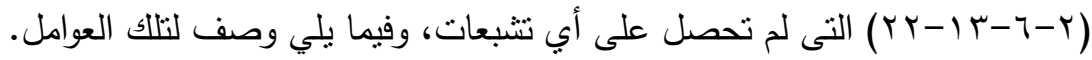




\section{المجلة العلمية لكلية رياض الاطفال - جامعة اسيوط}

جدول (v)

مصفوفة العوامل قبل التدوير لمقياس المرونة النفسية لاي أولياء أمور الأطفال ذوي الاحتياجات الخاصة.

\begin{tabular}{|c|c|c|}
\hline العامل الثاني & العامل الأول & رقم البند \\
\hline .256 & .542 & 1 \\
\hline$-.100-$ & .161 & $r$ \\
\hline .241 & .282 & $r$ \\
\hline .232 & .311 & $\varepsilon$ \\
\hline$-.126-$ & .441 & 0 \\
\hline .335 & .025 & 7 \\
\hline$-.207-$ & .474 & $\mathrm{~V}$ \\
\hline .197 & .612 & $\wedge$ \\
\hline .412 & .295 & 9 \\
\hline .233 & .417 & 1. \\
\hline .018 & .638 & 11 \\
\hline$-.341-$ & .592 & ir \\
\hline .131 & .197 & ir \\
\hline .111 & .444 & $1 \varepsilon$ \\
\hline .416 & .461 & 10 \\
\hline .078 & .591 & 17 \\
\hline .319 & .676 & iv \\
\hline .239 & .530 & 11 \\
\hline .201 & .290 & 19 \\
\hline .142 & .064 & $r$. \\
\hline-.249 & .320 & MI \\
\hline .396 & .202 & rr \\
\hline$-.132-$ & .697 & rr \\
\hline$-.323-$ & .531 & $r \leq$ \\
\hline$-.212-$ & .696 & ro \\
\hline .045 & .591 & $r y$ \\
\hline$-.352-$ & .393 & rV \\
\hline$-.243-$ & .616 & $r \wedge$ \\
\hline$-.527-$ & .280 & rq \\
\hline$-.251-$ & .680 & $r$. \\
\hline
\end{tabular}


جدول (^)

مصفوفة العوامل بعد التدوير لمقياس المرونة النفية لاي أولياء أمور الأطفال ذوي الاحتياجات الخاصة

\begin{tabular}{|c|c|c|c|}
\hline الاشتراكيات & العامل الثاني & العامل الأول & رقم البند \\
\hline .359 & .537 & .265 & 1 \\
\hline .036 & .021 & .189 & r \\
\hline .138 & .364 & .071 & $r$ \\
\hline .150 & .375 & .099 & $\varepsilon$ \\
\hline .210 & .175 & .424 & 0 \\
\hline .113 & .278 & $-.188^{-}$ & 7 \\
\hline .268 & .133 & .500 & v \\
\hline .413 & .535 & .357 & $\wedge$ \\
\hline .257 & .506 & $-.025-$ & 9 \\
\hline .228 & .441 & .182 & 1. \\
\hline .407 & .411 & .489 & 11 \\
\hline .466 & .101 & .676 & IT \\
\hline .056 & .225 & .073 & $1 T$ \\
\hline .210 & .363 & .279 & $1 \varepsilon$ \\
\hline .386 & .612 & .103 & 10 \\
\hline .355 & .428 & .414 & 17 \\
\hline .559 & .670 & .332 & IV \\
\hline .338 & .517 & .266 & 11 \\
\hline .124 & .337 & .102 & 19 \\
\hline .024 & .151 & $-.038-$ & $r$. \\
\hline .164 & .004 & .405 & r) \\
\hline .198 & .436 & $-.087-$ & rT \\
\hline .503 & .330 & .628 & rT \\
\hline .386 & .077 & .617 & $r \varepsilon$ \\
\hline .530 & .267 & .677 & ro \\
\hline .351 & .402 & .435 & T \\
\hline .279 & $-.032-$ & .527 & TV \\
\hline .439 & .193 & .634 & rA \\
\hline .356 & $-.239-$ & .546 & rq \\
\hline .525 & .226 & .689 & r. \\
\hline
\end{tabular}


المجلة العلمية لكلية رياض الاطفال - جامعة اسيوط

جدول (9)

مصفوفة العوامل بعد التدوير وحذف التثبعات الأقل من ؟ّ, · لمقياس المرونة النفسية لاي

أولياء أمور الأطفال ذوي الاحتياجات الخاصة.

\begin{tabular}{|c|c|c|c|}
\hline الإشتراكيات & العامل الثاني & العامل الأول & رقم البند \\
\hline .359 & $.0 \mathrm{OrV}$ & & 1 \\
\hline .138 &.$\pi 7 \varepsilon$ & & $r$ \\
\hline .150 & $\therefore$ rVo & & $\varepsilon$ \\
\hline .210 & & $. . \leqslant r \leqslant$ & 0 \\
\hline .268 & &. $.0 \ldots$ & $v$ \\
\hline .413 & .0 . & . rov & $\wedge$ \\
\hline .257 & .0 .7 & & 9 \\
\hline .228 & .. $\leqslant \leqslant 1$ & & 1. \\
\hline .407 & ..211 & $\therefore \varepsilon \wedge q$ & 11 \\
\hline .466 & & . $.7 V 7$ & Ir \\
\hline .210 & שדא.. & & $1 \varepsilon$ \\
\hline .386 & . . & & 10 \\
\hline .355 &..$\leqslant Y \wedge$ & $. . \varepsilon 1 \leqslant$ & 17 \\
\hline .559 & $\therefore 7 V$. & . . & IV \\
\hline .338 & $.01 \mathrm{~V}$ & & 11 \\
\hline .124 &.$r T V$ & & 19 \\
\hline .164 & & $\therefore \varepsilon .0$ & r) \\
\hline .198 & $\therefore \varepsilon r q$ & & rY \\
\hline .503 & . &. $.7 \% \Lambda$ & $r$ \\
\hline .386 & &. $.71 \mathrm{~V}$ & $r \varepsilon$ \\
\hline .530 & & $.71 \mathrm{~V}$ & ro \\
\hline .351 & .E.Y & $\therefore \varepsilon T_{0}$ & $r_{4}$ \\
\hline .279 & & $.0 Y Y$ & TV \\
\hline .439 & & 两 & ru \\
\hline .356 & & $.0 \leq 4$ & rq \\
\hline \multirow[t]{3}{*}{.525} & &. .719 & $r$. \\
\hline & r.A & $\$ .90$ & الجذور الكامنة \\
\hline & $1 Y .9 \varepsilon$ & 17.89 & النسبة المئوية للتباين \\
\hline
\end{tabular}




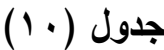

يوضح التشبعات الجوهرية للعامل الأول لمقياس المرونة النفسية لدي أولياء أمور الأطفال ذوي

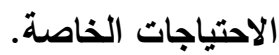

\begin{tabular}{|c|c|c|}
\hline درجة التشبع & مضمون البند & 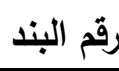 \\
\hline$\cdot . \leqslant Y \leqslant$ & استطيع ضبط انفعالاتي عندما أنضايق لأمر من الأمور & • \\
\hline. .0. & انظر إلي الأثياء أو الأمور التي تحدث في حباتي بايجابية & $\checkmark$ \\
\hline. rov & لا لا استسلم بسهولة للفنثل. & $\wedge$ \\
\hline$\because \leqslant \wedge 9$ & راضية عن نفسي وبما حقتته في حياني من انجازات. & 11 \\
\hline $.7 \vee 7$ & أحرص علي أن أكون هادئا ومتماسكا في المواقف الحرجة. & ir \\
\hline$\cdot \varepsilon \cdot 0$ & لدي القدرة علي اتخاذ قرارات صعبة ومصيرية في حياتي. & r \\
\hline. $.7 r \wedge$ & أعمل علي تحقيق أهدافي مهما واجهني من عقبات & rr \\
\hline. $.71 \mathrm{~V}$ & أستطيع أن أفكر وأركز جيدا تحت الضغط. & $r \varepsilon$ \\
\hline. $.71 \mathrm{~V}$ & أحب التحديات. الت & ro \\
\hline.$\leqslant$ r & أبادر بحل المشاكل التي تواجهني قبل تفاقمها. & r \\
\hline. $.0 Y V$ & لا استشلم للأكور حتي لوكانت ميؤوس منها. & rv \\
\hline $.7 r \leq$ & أسيطر علي أمور حياتي بفاعلية. & rı \\
\hline $.0 \leq 7$ & أتاقلم مع الضغوط التي تواجهني في حياتي. & rq \\
\hline. $.7 \wedge 9$ & لدي القدرة علي مواجهة المواقف وحل المشكلات التي & $r$. \\
\hline
\end{tabular}

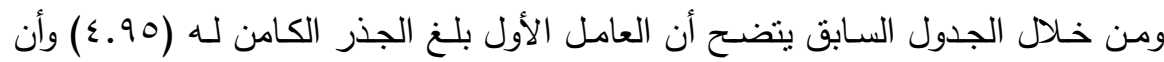

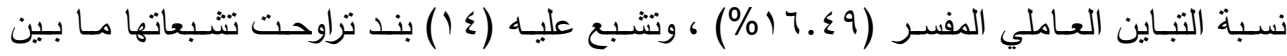

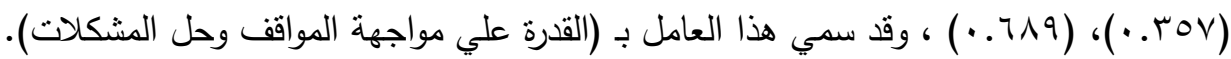




\section{المجلة العلمية لكلية رياض الاطفال - جامعة اسيوط}

جدول (11)

التشبعات الجوهرية للعامل الثاني لمقياس لمقياس المرونة النفسية لاي أولياء أمور الأطفال ذوي الاحتياجات الخاصة

\begin{tabular}{|c|c|c|}
\hline درجة التشبع & 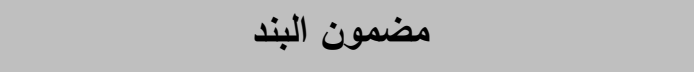 & 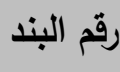 \\
\hline $.0 \mathrm{orr}$ & للدي علاقات اجتماعية كثيرة مع الاخرين. & 1 \\
\hline 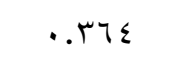 & أتعلم من اخطائي بدلا من أن ألوم نفسي. & $r$ \\
\hline .rvo & أؤمن بمقولة ان كل مشكلة ولها حل. & $\varepsilon$ \\
\hline .0 .7 & أؤمن بأن هناك حكمة في الأثياء التي تحدث في حياتي. & 9 \\
\hline$\cdot . \leqslant \varepsilon 1$ & اتمتع بروح الدعابة. الدابة & 1. \\
\hline 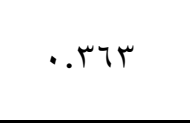 & أضع الأمور في سياقها وحجمها الطبيعي في أي مشكلة & $1 \varepsilon$ \\
\hline $.71 \mathrm{r}$ & استمتع بعلاقات طيية مع الأخرين. & 10 \\
\hline$\cdot . \leqslant \uparrow \wedge$ & اعتتي بنفسي جيدا. & 17 \\
\hline. $.7 \%$ & أنشعر بالتفاؤل و الأمل في تحقيق أهدافي المتعلقة بابني. & iv \\
\hline. $.01 \mathrm{~V}$ & استفيد من تجارب وخبرات الآخرين في حل أي مشكلة & 11 \\
\hline.$r t r$ & أتقبل نقد الأخرين وأستقبد منه. & 19 \\
\hline 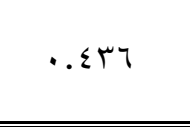 & اطلب الشورة والتوجيه من الاخرين في أي مشكلة & rr \\
\hline
\end{tabular}

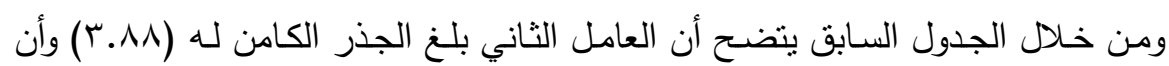

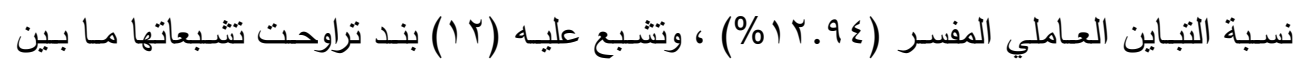

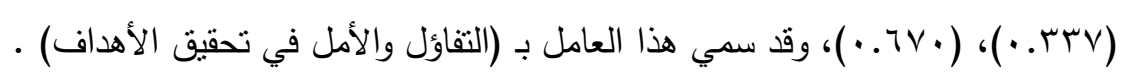

و - حساب ثبات مقياس المرونة النفسية لاي أولياء أمور الأطفال ذوي الاحتياجات الخاصة. تم استخدام طريقة ألفا كرونباخ للتأكد من ثبات المقياس، بحساب معامل الثبات بين أبعاد

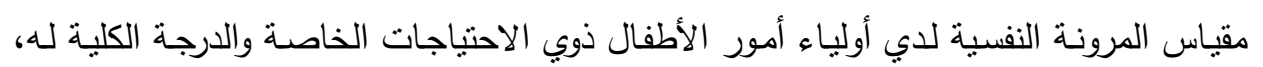


وذلـك بتطبيقهـ علـي عينـة قوامهـا (·9) تسـعون ولـي أمـر مـن أوليـاء أمسور الأطفـال ذوي

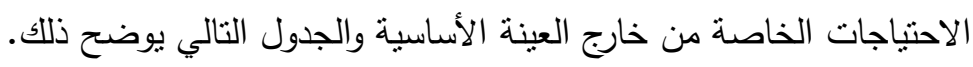

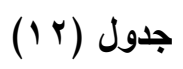

معاملات ثبات الفا كرونباخ لمقياس المرونة النفسية

\begin{tabular}{|c|c|}
\hline 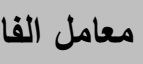 & أبعاد المقياس \\
\hline$* * . .10$ & القدرة علي مواجهة المواقف وحل المشكلات \\
\hline$* * . . \vee 0$ & التفاؤل والأمل في تحقيق الأهداف \\
\hline$* * . . \wedge \vee$ & الارجة الكلية \\
\hline
\end{tabular}

$$
\begin{aligned}
& \text { (***) دالة عند مستوي دلالة (1 (..) } \\
& \text { يتضح من جدول (r r) : }
\end{aligned}
$$

تراوحت معاملات ثبات الفا كرونباخ لأبعاد المقياس ما بين (0. . . : 10. ·) ، كما بلغ

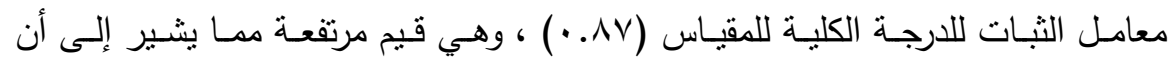

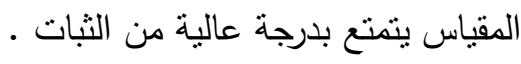

\section{ح- وصف المقياس في صورته النهائية :}

تم التوصـل إلـي الصـورة النهائيسة للمقيـاس، وذللك بعد أن تم حسـاب الصـدق والثبـات

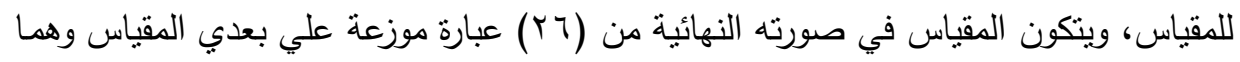
القرة علي مواجهة المواقف وحل المشكلات و التفاؤل والأمل في تحقيق الأهداف.

\section{عينة الدراسةة:}

تكونت عينة هذه الدراسة من أولياء أمور الأطفال ذوي الإحتياجات الخاصة والذين يتلقون

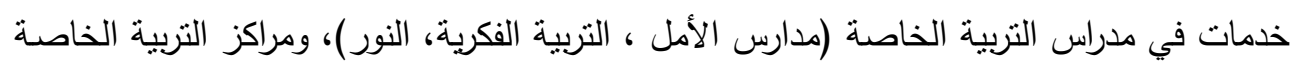

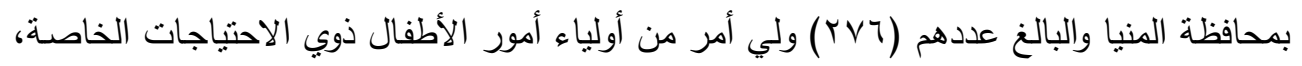
وجدول (r ا ) يوضح توزيع العينة. 
المجلة العلمية لكلية رياض الاطفال - جامعة اسيوط

$$
\text { جدول (1T) }
$$

توزيع أفراد العينة حسب نوع الإعاقة لاى الأبناء

\begin{tabular}{|c|c|c|}
\hline النسبة المئوية & 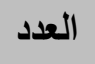 & نوع الإعاقة \\
\hline$\% \vee . r$ & $r \cdot$ & توحد \\
\hline$\% r \cdot . q$ & $0 \wedge$ & إعاقة عقلية \\
\hline$\% 4 . \wedge$ & 19 & إعاقة بصرية \\
\hline$\%$ \%.० & Ar & إعاقة سمعية \\
\hline$\% \vee . r$ & $r \cdot$ & اضطرابات نطق \\
\hline$\% 10.1$ & $\varepsilon r$ & إعاقة جسمية و حركية \\
\hline$\% 1 r . r$ & $r v$ & متعدد الإعاقة \\
\hline$\% 1 \ldots$ & tVA & المجموع \\
\hline
\end{tabular}

نتائج الدراسة:

يــص الفرض الأول علي انـه "'. أنــ "توجد فروق ذات دلالـة احصـائية في المرونـة

$$
\text { النفسية لدي أولياء أمور الأطفال ذوب الاحتياجات الخاصة تبعا لمتغير نوع الإعاقة." }
$$

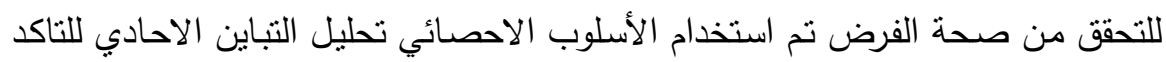

من وجود الفروق من عدمه وكانت النتائج كالأتي: 


\section{جدول (؛ ( )}

تحليل التباين الاحادي ONE- WAY-ANOVA لأبعاد المرونة النفسية لدي أولياء أمور الأطفال ذوي الاحتياجات الخاصة تبعا لمتغير نوع الإعاقة

\begin{tabular}{|c|c|c|c|c|c|c|}
\hline مستوي & ف & متوسط المربعات & درجات & المربعات & التباين & أبعاد المرونة \\
\hline \multirow{3}{*}{$\cdot 1 \cdot r$} & \multirow{3}{*}{$\begin{array}{l}1 . V \\
9\end{array}$} & Ar.l. & 7 & Eqr.TY & المجموعات & \multirow{3}{*}{ مواجهة المواقف } \\
\hline & & $\leq 0.91$ & rVI & $1 T \leq \leqslant 1.19$ & المجموعات & \\
\hline & & & TVV & IrqTr.Ar & الكلي & \\
\hline \multirow{3}{*}{$.7 V}$. & \multirow{3}{*}{$\begin{array}{r}\cdot 7 \\
1\end{array}$} & Y.$V$. & 7 & $1 \leqslant \Lambda . Y Y$ & المجموعات & \multirow{3}{*}{$\begin{array}{c}\text { ف - التفاؤل والأمل تحقيق } \\
\text { الأهداف }\end{array}$} \\
\hline & & r..01 & TVI & $991 T . \wedge \varepsilon$ & المجموعات & \\
\hline & & & TVV & $1 \cdots r r_{.} \cdot{ }^{\prime}$ & الكلي & \\
\hline \multirow{3}{*}{.71} & \multirow{3}{*}{$\begin{array}{l}\cdots V \\
0 .\end{array}$} & צr.V & 7 & $T \leq \varepsilon .1 T$ & المجموعات & \multirow{3}{*}{ الارجة الكلية } \\
\hline & & $1 \leqslant \mu$ & rVI & rAV & المجموعات & \\
\hline & & & TVV & r & الكلي & \\
\hline
\end{tabular}

$$
\text { يتضح لنا من الجدول (ء ) : }
$$

عدم وجود فروق ذات دلالة احصائية في المرونة النفسية لدي أولياء أمور الأطفال ذوي

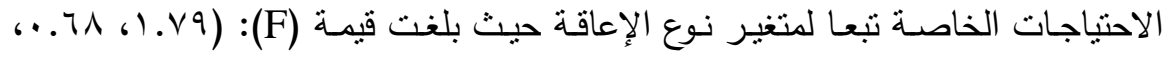

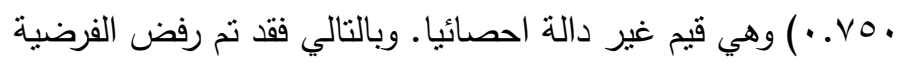

ويمكن ارجاع ذللك إلي أنه بالرغم من أن وجود طفل ذو احتياجات خاصـة هو مصدر

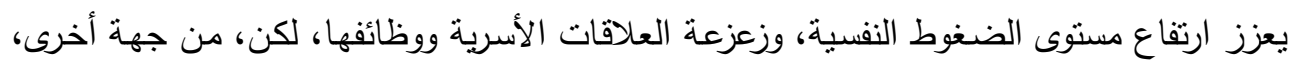




\section{المجلة العلمية لكلية رياض الاطفال - جامعة اسيوط}

وجود مستوى عـال من الضغط لدى أوليـاء الأطفال المعاقين لا يؤدي بالضـرورة إلى الاختلال

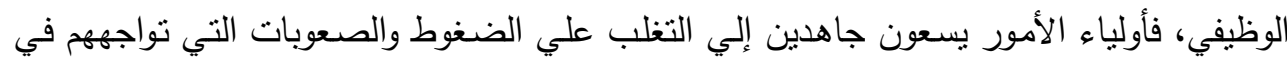

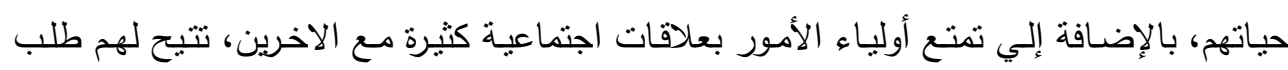

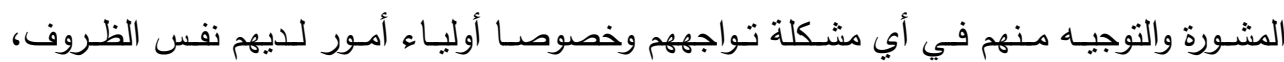

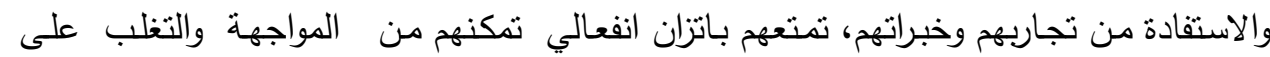
الصعوبات الانفعالية التي يتعرضون لها. إيمانهم بقدرات أطفالهم يقلل من قلقهم علي مستقبل أبنائهم، وجود الرعاية والمساندة الاجتماعية والتقة والتتجيع سواء من داخل العائلة أو من خارجها.

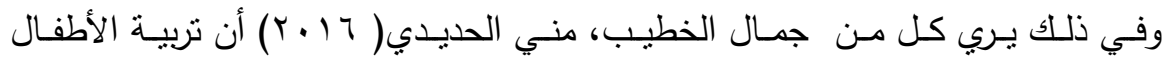
مسؤولية كبيرة وصعبة وشاقة، وتربية طفل ذو إعاقة أكثر صعوبة وأكثر مشقة، لما نواجهه الأسرة

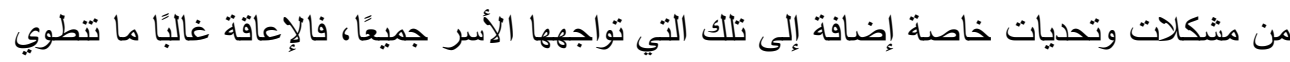

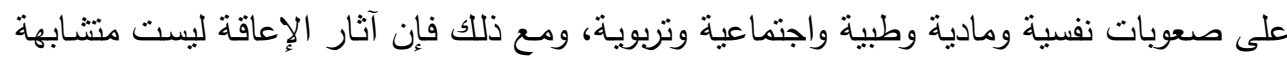

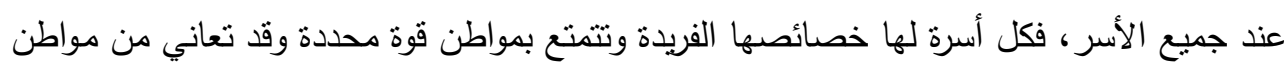
ضعف معينة.

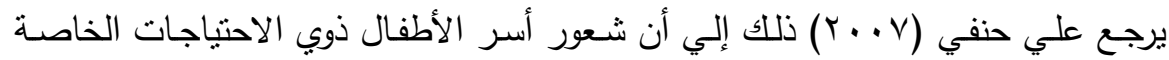

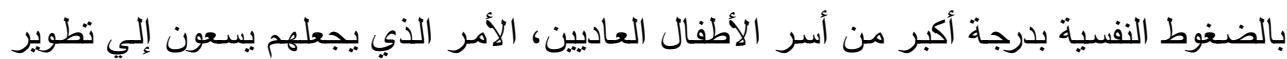

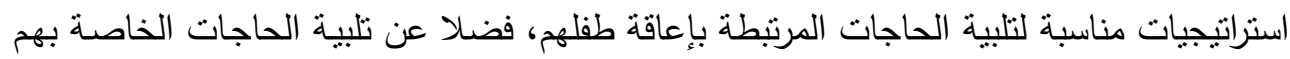
لمواجهة الضغوط النفسية الناجمة عن إعاقة الأبناء.

وهذا ما أكدته العديد من الدراسات (Skinner et al. 1999)، ( Scorgie\&Sobsey 2000)، (Taunt \& Hastings 2002)، (Hastings et al. 2005) أن العديد من الآباء تمكنوا من التكيف بشكل إيجابي مع وجود طفل معاق . ويرجع ذلك تمتعهم بعلاقات زواجية ناجحة، وقدرة أطفالهم علي التكيف الجيد مع الأطفال المعاقين وغير المعاقين.

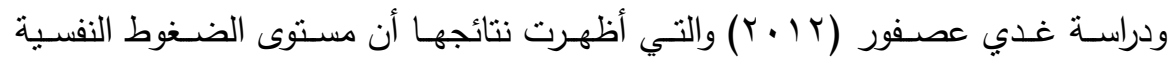

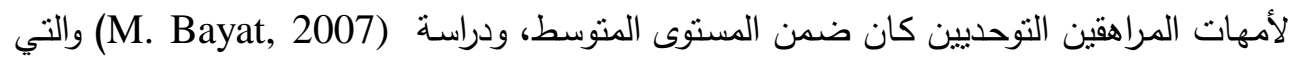

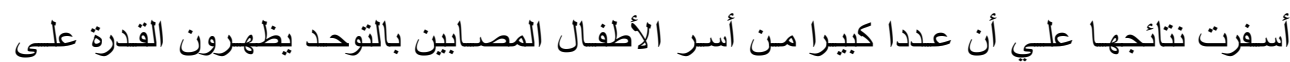

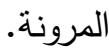


وكثفت دراسة كل من (Roach et al., 1999)؛ (2002) (Heiman, T. (2003 تمتع أسر الأطفال المعاقين بالقدرة على المرونة النفسية، والتي تتجلي مظاهرها في مشاعر التها الوالدين الإيجابية تجاه طفلهم، التكيف في العلاقات الأسرية و الحفاظ على حياتهم الروتينية، ووجود نظام للروحانيات والمعتقدات. وبالإضـافة إلى ذلك، لكي تتمكن الأسرة من الصمود في مواجهة الإنة

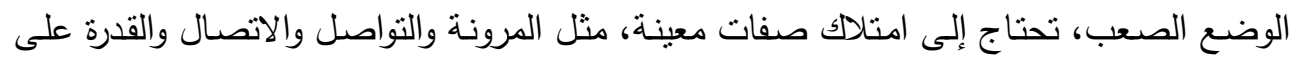

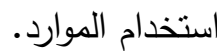

Taunt \& Hastings وكما اتفقت نتيجة هذه الفرضية مع ما كثفت عنه نتائج دراسة

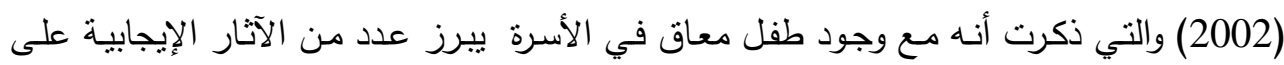

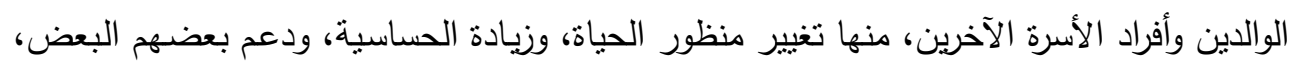

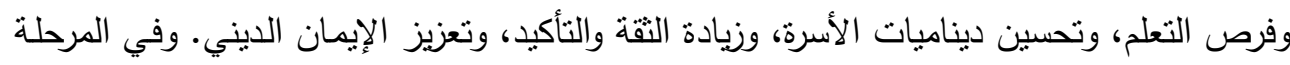

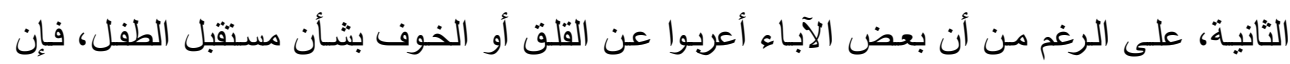
غالبية الأسر أعربت عموما عن مواقف إيجابية تجاه مسنقبل أطفالهم ذوي الإعاقة. بالإضافة إلي دراسة (2009) Gerstein, E, et al والتي أظهرت نتائجها أنه بالرغم

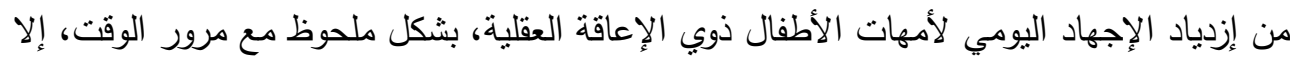

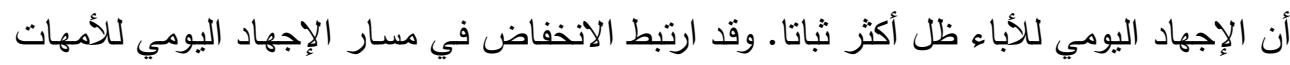

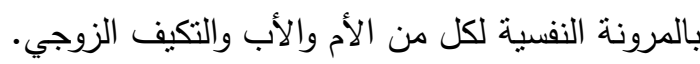

كما كثفت دراسة كل من (Rajan, A. \& John, R., 2017) عن قدرة الآباء على التحلي بالمرونة النفسية في سياق تربية طفل بعاني من إعاقة ذهنية. ينص الفرض الثاني علي أنه" توجد فروق ذات دلالة احصائية في المساندة الاجتماعبة

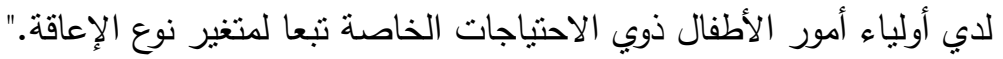
للتحقق من صحة الفرض تم استخدام الأسلوب الاحصائي تحليل التباين الاحادي للتاكد من وجود الفروق من عدمه وكانت النتائج كالأتي: 
المجلة العلمية لكلية رياض الاطفال - جامعة اسيوط

$$
\text { جدول (10) }
$$

تحليل التباين الاحادي ONE- WAY-ANOVA لأبعاد المساندة الاجتماعية لاي أولياء

أمور الأطفال ذوي الاحتياجات الخاصة تبعا لمتغير لنوع الإعاقة

\begin{tabular}{|c|c|c|c|c|c|c|}
\hline مستوي & ف & متوبط المربعات & الحرية & المربعوع & مصدر التباين & أبعاد المساتدة \\
\hline \multirow{3}{*}{. .01} & \multirow{3}{*}{$\cdot . \wedge \wedge$} & $1 \leq .1 \leq$ & 7 & $\wedge \Sigma . \wedge T$ & بين المجموعات & \multirow{3}{*}{ الأسساندة } \\
\hline & & $17 . . V$ & rVI & $\leqslant r 00.7$. & داخل المجموعات & \\
\hline & & & TVV & $\varepsilon \varepsilon \varepsilon \cdot . \leqslant T$ & الكلي & \\
\hline \multirow{3}{*}{.ATV } & \multirow{3}{*}{$\cdot . \leqslant 7$. } & A.Tr & 7 & $01 . V$. & بين المجموعات & \multirow{3}{*}{ الأصداندة } \\
\hline & & IN.Vr & rVI & $0 . V \varepsilon .11$ & داخل المجموعات & \\
\hline & & & TVV & 01 ro.AV & الكلي & \\
\hline \multirow{3}{*}{..$\wedge \wedge$} & \multirow{3}{*}{$1 . \wedge 71$} & $0 \wedge . \wedge \wedge$ & 7 & & بين المجموعات & \multirow{3}{*}{ المعلوماتدة } \\
\hline & & אד. ו" & rVI & NOVY.MI & داخل المجموعات & \\
\hline & & & TVV & N9r0.7. & الكلي & \\
\hline \multirow{3}{*}{$\cdots \cdots$} & \multirow{3}{*}{.171} & $99.9 \%$ & 7 & 099.7. & بين المجموعات & \multirow{3}{*}{ أو المساندة المادية } \\
\hline & & $r \varepsilon \ldots r$ & rVI & $70 \cdot \Lambda . \leqslant r$ & داخل المجموعات & \\
\hline & & & rVV & $v 1 \cdot \Lambda . \cdot r$ & الكلي & \\
\hline \multirow{3}{*}{$\because 9$} & \multirow{3}{*}{1.10} & MqV.r & 7 & 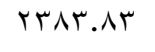 & بين المجموعات & \multirow{3}{*}{ الدرجة الكلية } \\
\hline & & rוo.r & YVI & q.T.M & داخل المجموعات & \\
\hline & & & rVV & T.VIT.rY & الكلي & \\
\hline
\end{tabular}

$$
\text { يتضح لنا من الجدول (10): }
$$

عدم وجود فروق ذات دلالة احصائية في المساندة الاجنماعية لاي أولياء أمور الأطفال

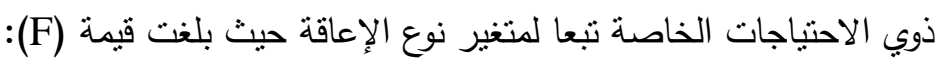

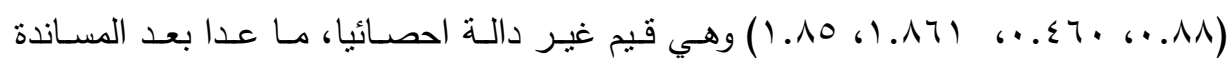

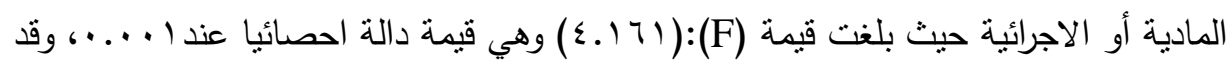


تم استخدام اختبار أقل فرق معنوي (L.S.D) للتعرف علي وجود الفروق بين كل إعاقة في

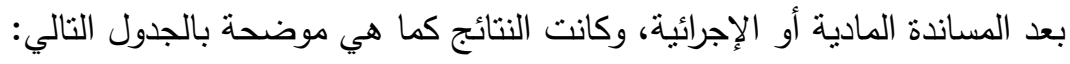
جدول (17)

نتائج اختبار أقل فرق معنوي (L.SD) بين الإعاقات المختلفة في المساندة المادية لدي عينة

\begin{tabular}{|c|c|c|c|c|c|c|c|c|}
\hline بصرية & الإعاقة & توحد & سمعية & جسمية & نطق اضطرات & إعلاقة & الإعاقات & المتغيرات \\
\hline & & & & & & & عقلية & \multirow{7}{*}{ 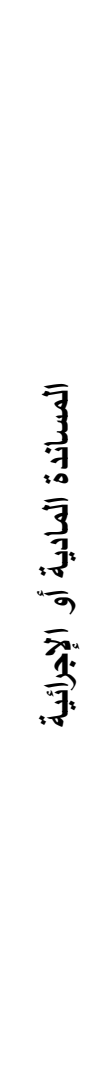 } \\
\hline & & & & & &..$- r_{0}$ & اضطقرابات & \\
\hline & & & & & $* r \ldots$ & *Y.VY & وحركية & \\
\hline & & & & $-1 . \vee 9$ & I.rY &. .91 & سمعية & \\
\hline & & &..$\leqslant V$ & $-1 . \mu 1$ & l.v. & $1 . \leqslant 0$ & توحد & \\
\hline & & r..A & *Y.०० &..$v v$ & *r.v^ & *r.or & متعلد & \\
\hline & $*-0 . r q$ & $*-r . r)$ & $*-$ r.V $\leqslant$ & * * & -1.01 & -1.87 & بصرية & \\
\hline
\end{tabular}

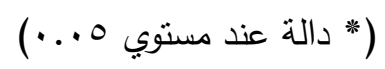




\section{يتضح من جدول (1 1 ) ما يلي:}

وجود فرق دال احصائيا بين أولياء أمور الأطفال ذوي الإعاقة العقلية وكل من أولياء

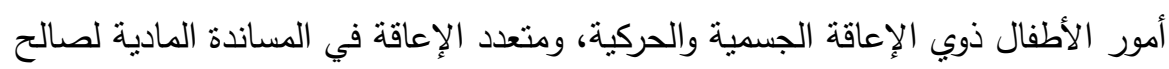

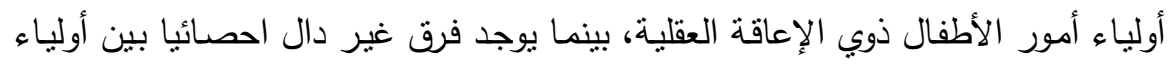

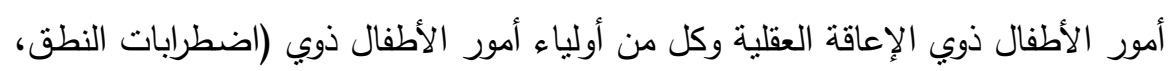
الإعاقة السمعية، النوحد والإعاقة البصرية).

وجود فرق دال احصائيا بين أولياء أمور الأطفال ذوي اضطرابات النطق وكل من أولياء

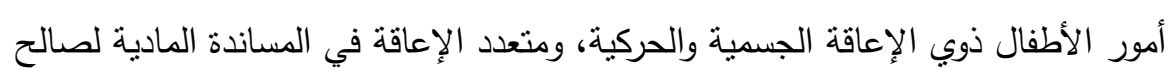

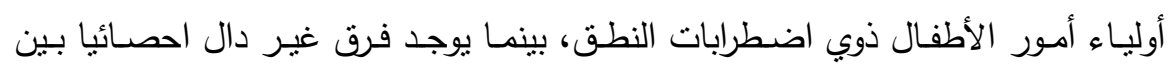

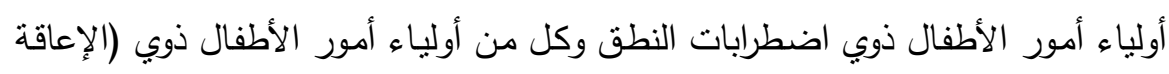
السمعية، النوحد و الإعاقة البصرية).

وجود فرق دال احصائيا بين أولياء أمور الأطفال ذوي الإعاقة الجسمية الحركية وأولياء

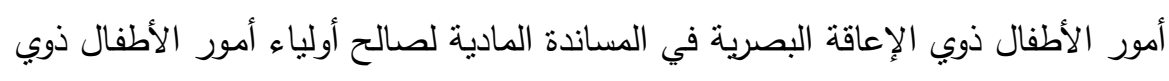

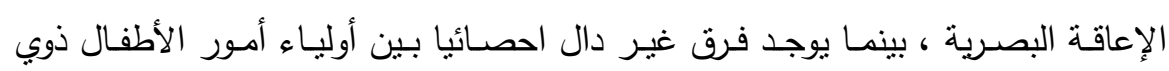

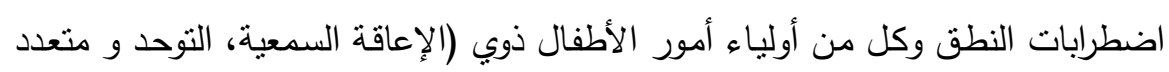
الإعاقة ). وجود فرق دال احصائيا بين أولياء أمور الأطفال ذوي الإعاقة السمعية و أولياء أمور

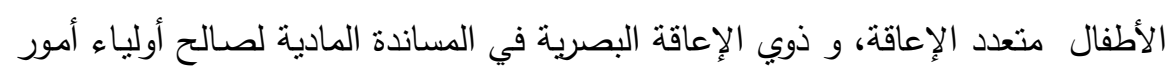

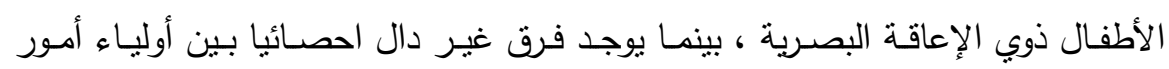
الأطفال ذوي الإعاقة السمعية وكل من أولياء أمور الأطفال ذوي (التوحد). وجود فرق دال احصـائيا بين أوليـاء أمسور الأطفال ذوب التوحد وكل مـن أوليـاء أمور

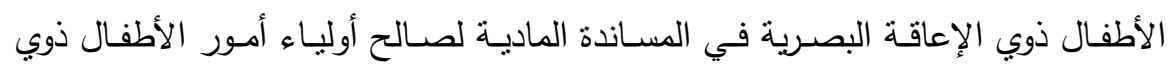

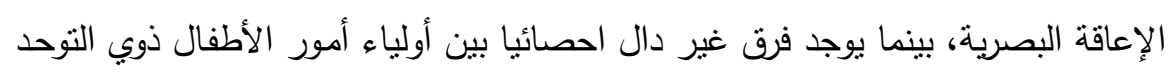
وكل من أولياء أمور الأطفال متعدد الإعاقة. 
وجود فرق دال احصـائيا بين أولياء أمور الأطفال ذوي التوحد وكل من أوليـاء أمور

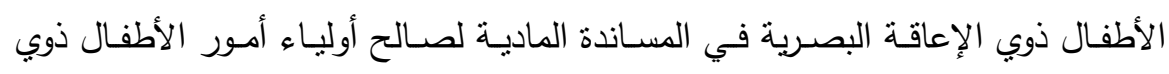
الإعاقة البصرية

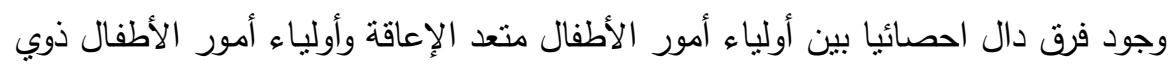

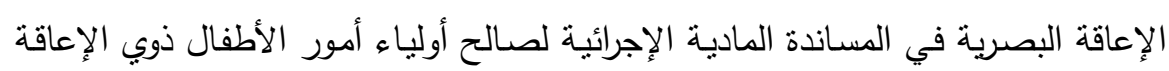
البصرية.

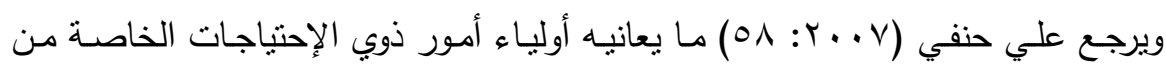

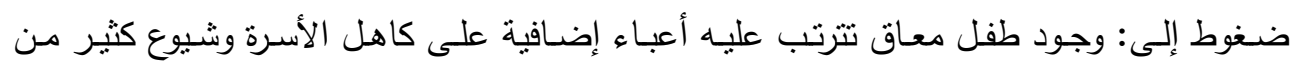
المشكلات الأسرية وإزدياد الأعباء المالية ، والعزلة والإرهاق المزمن والمشكلات الإنفعالية.

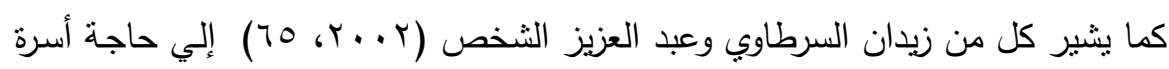

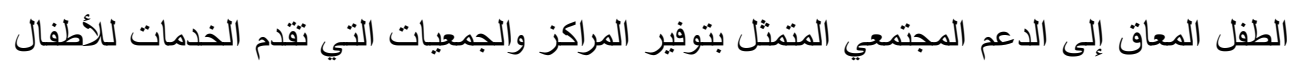

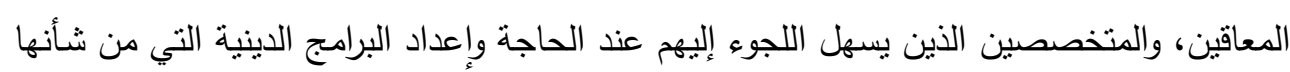

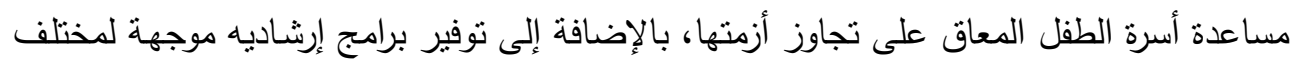
أفراد المجتمع حول كيفية التعامل مع أسر المعاقين.

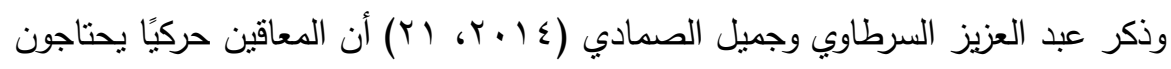

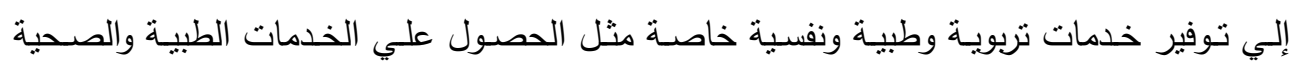

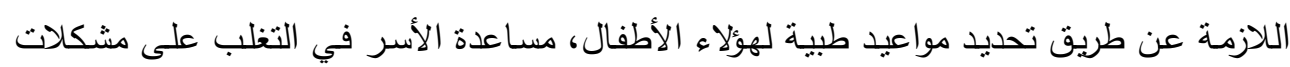

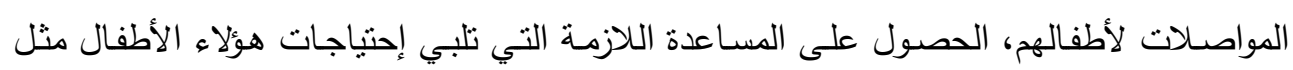

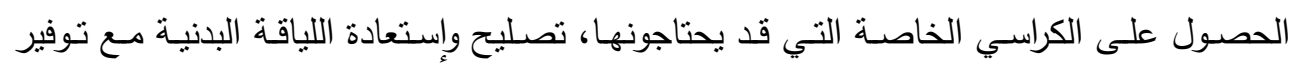

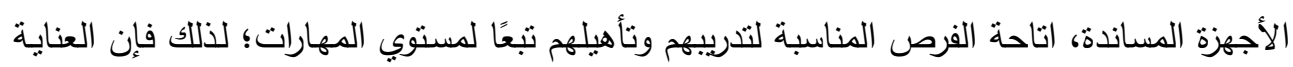
بالطفل المعاق جسميًا وصحيا تعتبر مكلفة، وتتطلب أموال كبيرة قد لا تسنطيع الأسرة تحملها.

وتنقت نتيجة هذه الفرضية مع ما أظهرته دراسة كل من ( Freedman \& Boyer,2000) عن مواجهة بعض أسر الأطفال ذوي الاحتباجات الخاصة صعوبات في المساعدة المالية وعدم كفاية

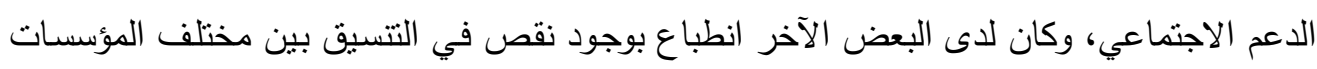




\section{المجلة العلمية لكلية رياض الاطفال - جامعة اسيوط}

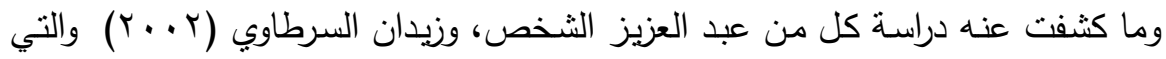

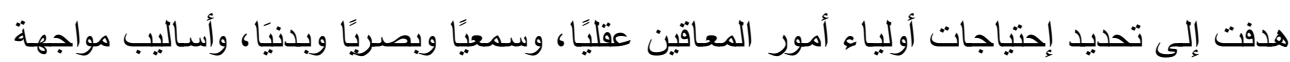

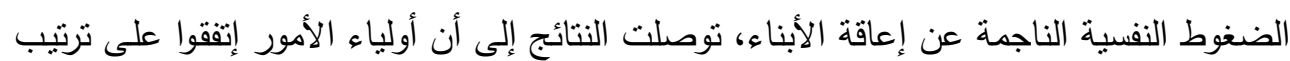

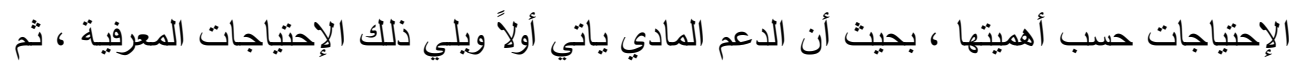

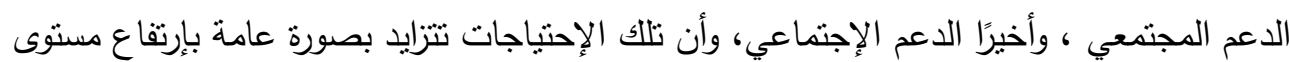
الضغط النفسي وبإرتفاع مستوى مواجهة الضغط النفيرعي.

واتفقت جزئيا مع دراسة أميرة بخش (r . . . التي نتاولت الضغوط الأسرية لاي أمهات

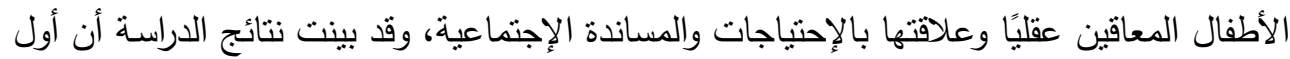

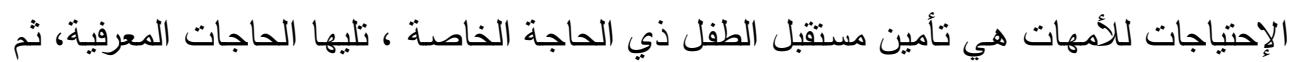
الحاجات المرتبطة برعاية الطفل، ثم الحاجات المرتبطة بالمجتمع، ثم الحاجات للخدمات المات المعاونة،

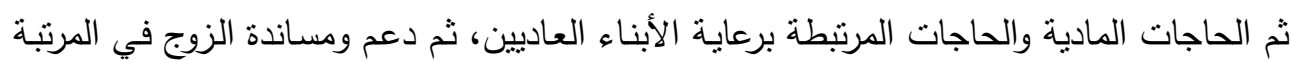

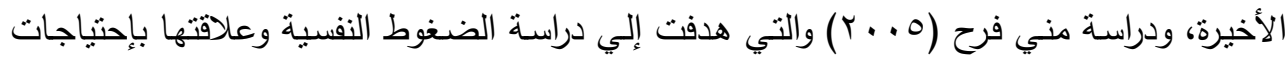
أولياء أمور غير العاديين (المعاقين حركيا)، حيث أظهرت النتائج وجود علاقة إنبة إرتباطية طردية بين

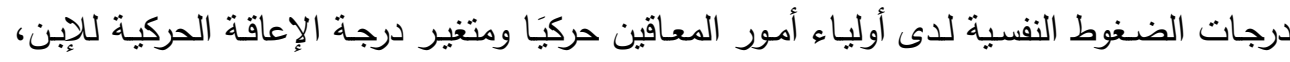

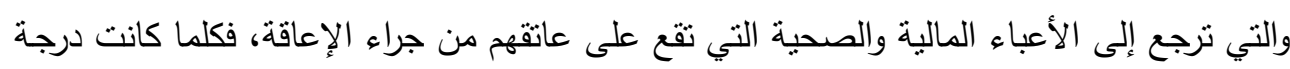

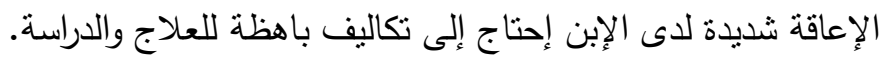

ينص الفرض الثالث علي أنه "توجد علاقة ارتباطية بين المساندة الاجتماعية والمرونة النفسية لدي أولياء أمور الأطفال ذوي الاحتياجات الخاصة".

وللتحقق من صحة هذا الفرض ووجود العلاقة بين المساندة الاجتماعية والمرونة النفسية

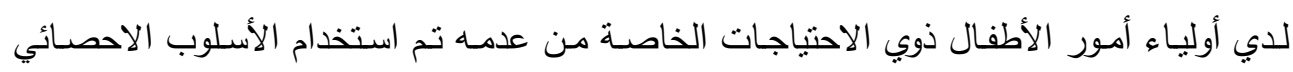

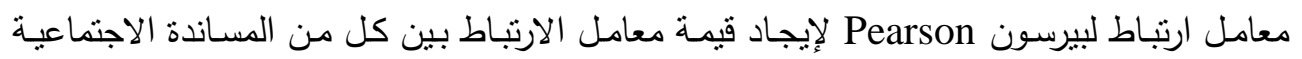
والمرونة النفسية، وكانت النتائج كالأتي: 


$$
\text { جدول (iv) }
$$

معاملات الارتباط بين كل من المساندة الاجتماعية والمرونة النفسية لاي أولياء أمور الأطفال

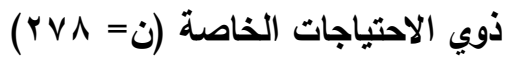

\section{المرونة النفسية}

\begin{tabular}{|c|c|c|c|c|}
\hline المرونة النفسية & تحقيق الأهداف الأفل في & المواقف وحل المشرة علي مواجهةت & & \\
\hline$* * . r V$ & ***. & **. & المساندة الأسرية & \\
\hline ***..rT & $* * ., r$ & $* * . . r T$ & مساندة الأصدقاء & 言 \\
\hline ***..rT & $* * . r q$ & $* * . . \mu$ & المعلوماتية & 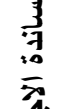 \\
\hline$* * . .19$ & $* * . .17$ & $* * . .19$ & المساندة الإجرائية & $\vec{g}$ \\
\hline$* * . r V$ & *TH & **.. & المساندة كلي & \\
\hline
\end{tabular}

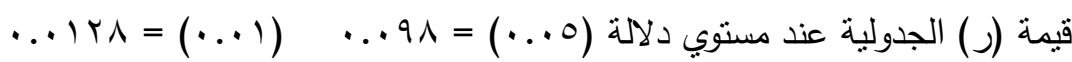
** دالة عند مستوى ا +...

$$
\text { يتضح من جدول (IV) ما يلي : }
$$

توجد علاقة ارتباطية طردية دالة إحصائياً بين المساندة الاجتماعية والمرونة النفسية لدي أولياء أمور الأطفال ذوي الاحتباجات الخاصة.

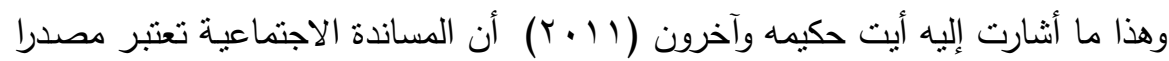
هاما من مصادر الدعم النفسي الاجتماعي الفعال الذي يحتاجه الإنسان، حيث يؤثر حجم المساندة

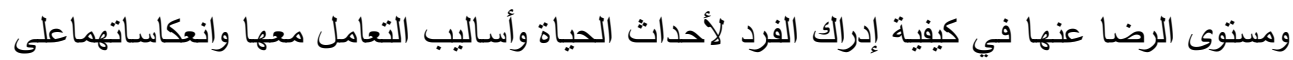
صحته.

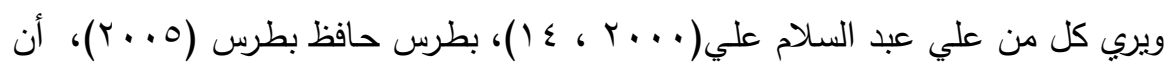
المساندة الاجتماعية تعتبر مصدرا مهما من مصادر الدعم الاجتماعي الفاعل الذي يحتاجه الفرد، و يؤثر حجمها ومستوى الرضا عنها في كيفية إدراك الفرد لضغوط الحياة المختلفة ، وأساليب مواجهته 


\section{المجلة العلمية لكلية رياض الاطفال - جامعة اسيوط}

وتعامله مع هذه الضغوط ، كما تلعب دورا هاما في إثباع الأمن النفسي، وخفض مستوى المعاناة

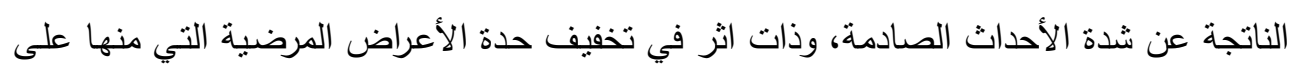
سبيل المنل: القلق، والاكتئاب.

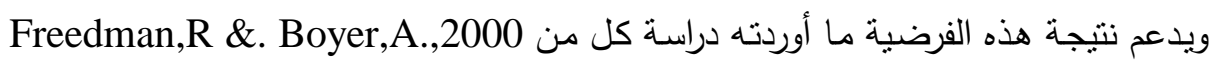

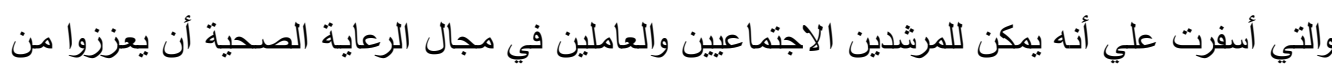

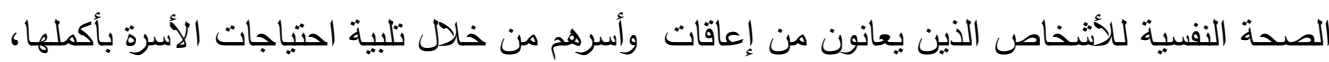

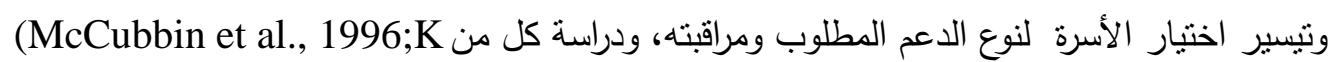
(,Walsh, 2003

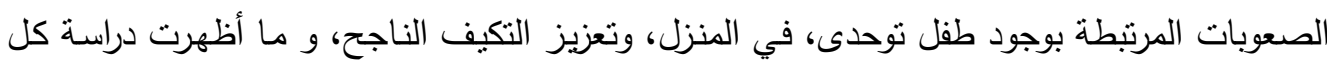

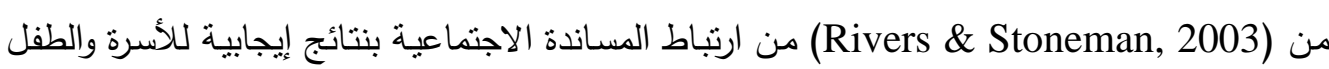
وخاصة في الأسر التي لديها طفل مصاب بالتوحد.

وما كثفت عنه نتائج دراسة ( Yusoff,Y, 2012 ) , أن المساندة الاجتماعية (المساندة من الأصدقاء والآخرون) له علاقة جوهرية بالتوافق النفسي.

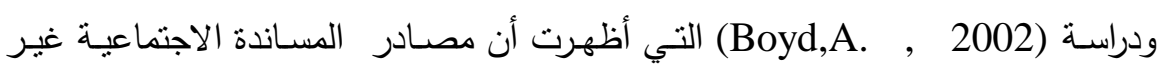

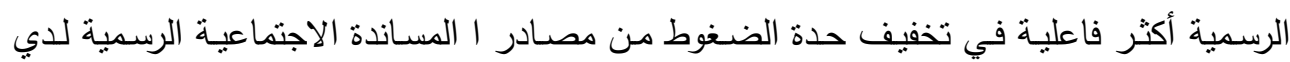
أمهات الأطفال الذين يعانون من التوحد.

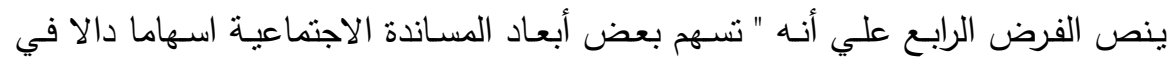

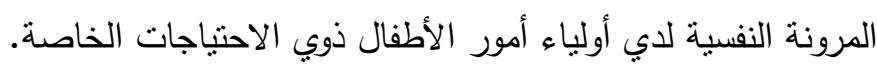
وللتحقق من صحة الفرض تم حساب تحليل الانحدار المتدرج (Stepwise Regression) للتعرف علي أكثر أبعاد المساندة الاجتماعية اسههاما في المرونة النفسية لدي أولياء أمور الأطفال

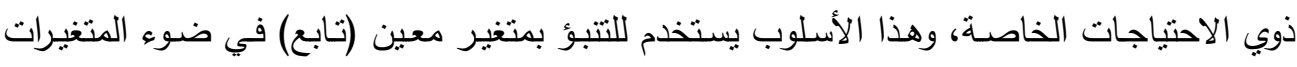

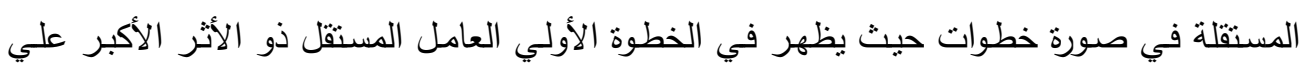

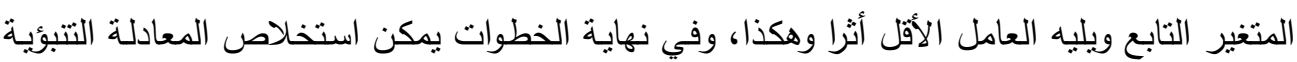
بدلالة المتغيرات ذات معاملات الانحدار الدالة فقط.

وفي البحث الحالي تم إجراء تحليل الانحدار المتدرج لدرجات عينة البحث الأساسية في

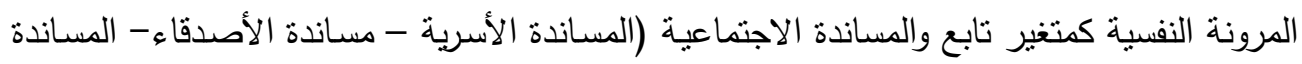
المعلوماتية- المساندة المادية أو الإجرائية) كتغيرات مستقلة وكانت النتائج كالآتي: 


$$
\text { جدول (11) }
$$

نتائج تحليل الانحار المتدرج الخطوات للمرونة النفسية كمتغير تابع ويعض أبعاد المساندة الاجتماعية كمتغيرات مستقلة

\begin{tabular}{|c|c|c|c|c|c|c|c|c|c|c|}
\hline الدلالة & قيمة & $\begin{array}{l}\text { الانحدار } \\
\text { المعياري } \\
\text { Beta }\end{array}$ & قالاندار & قيمة الثابت & للارتباطئية & لكليمة & المشترك & $\begin{array}{c}\text { الارتباط } \\
\text { Rعلمل } \\
\text { R }\end{array}$ & المستقل & النموذج \\
\hline,., 1 & ת ז, & צז, • & , 9. & $\sum 9,9$ Y & $\cdot, \cdot 1$ & $\varepsilon \cdot, \cdot q$ & . & צז, & مساندة & 1 \\
\hline $\begin{array}{l}\cdot, \cdot 1 \\
., \cdot 1\end{array}$ & $\begin{array}{l}\varepsilon, A Y \\
\varepsilon, .0\end{array}$ & $\begin{array}{l}\cdot, r q \\
\cdot, r \leqslant\end{array}$ & $\begin{array}{l}\cdot, v 1 \\
\cdot, \leq q\end{array}$ & $\{0, \lambda \Gamma$ & $\cdot, \cdot 1$ & $r q, \varepsilon$. & $\cdot, 1 \wedge$ & $\cdot, \varepsilon r$ & مساندة مسرية & $r$ \\
\hline
\end{tabular}

يتضح لنا من الجدول (1) أنه قد تم التحليل في خطوتين كالاتي:

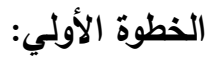

تحددت المساندة الأسرية علي أنها أعلي المتغيرات المستقلة ارتباط بالمتغير التابع المرونة

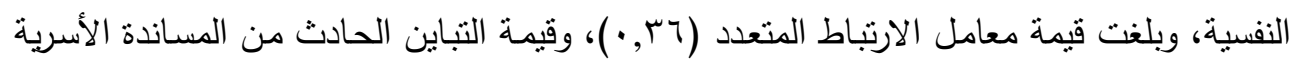

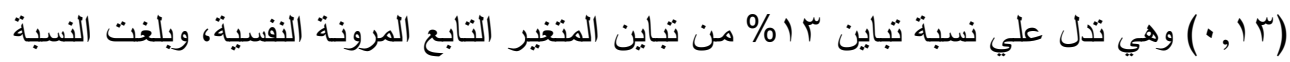

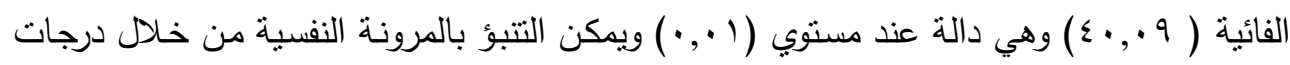
أولياء الأمور بالمساندة الأسرية من خلال المعادلة الأثية:

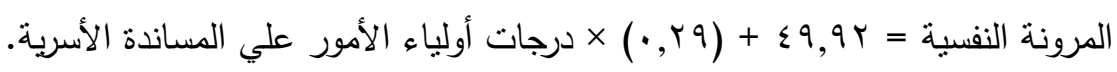

وقد كان معامل الانحدار موجبا مما يدل علي أن ارتفاع المساندة الأسرية من مؤشرات

$$
\text { المرونة النفسية لدي عينة البحث الأساسية. }
$$


الخطوة الثانية:

تم إضافة المتغير المستقل (المساندة المعلومانية) علي أنه المتغير الثاني الأكثر أهمية

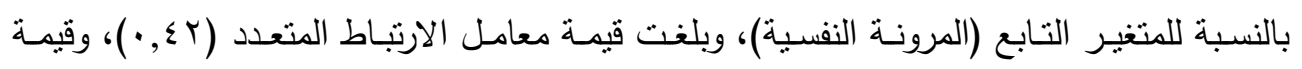

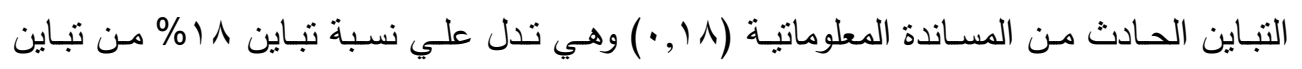

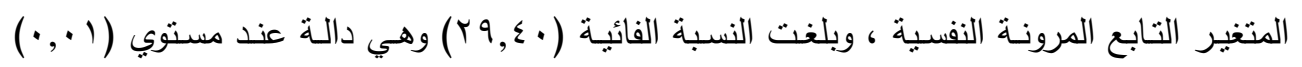

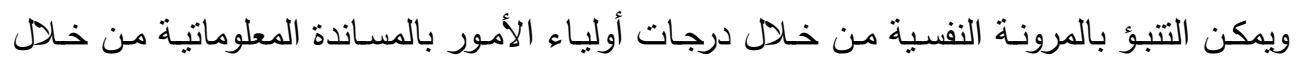

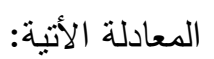

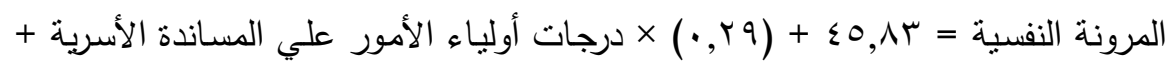
( وقد كان معامل الانحدار موجبـا ممـا يـل علي أن ارتفاع المسـاندة الأسـرية و المسـاندة المعلوماتية من مؤشرات المرونة النفسية لدي عينة البحث الأساسية. ثم تم استخدام أسلوب تحليل المسار (Path Analysis) للتعرف علي الأثار المباشرة وغير المباشـرة لأبعـاد (المسـاندة الأسـرية - مسـاندة الأصـدقاء- المسـاندة المعلوماتيـة- المسـاندة المادية أو الإجرائية) في المرونة النفية لائي عينة البحث الأساسية. ويبدأ التحليل في هذا الأسلوب بتحديد النموذج السببي الذي من خلاله يتم التحليل،وقد

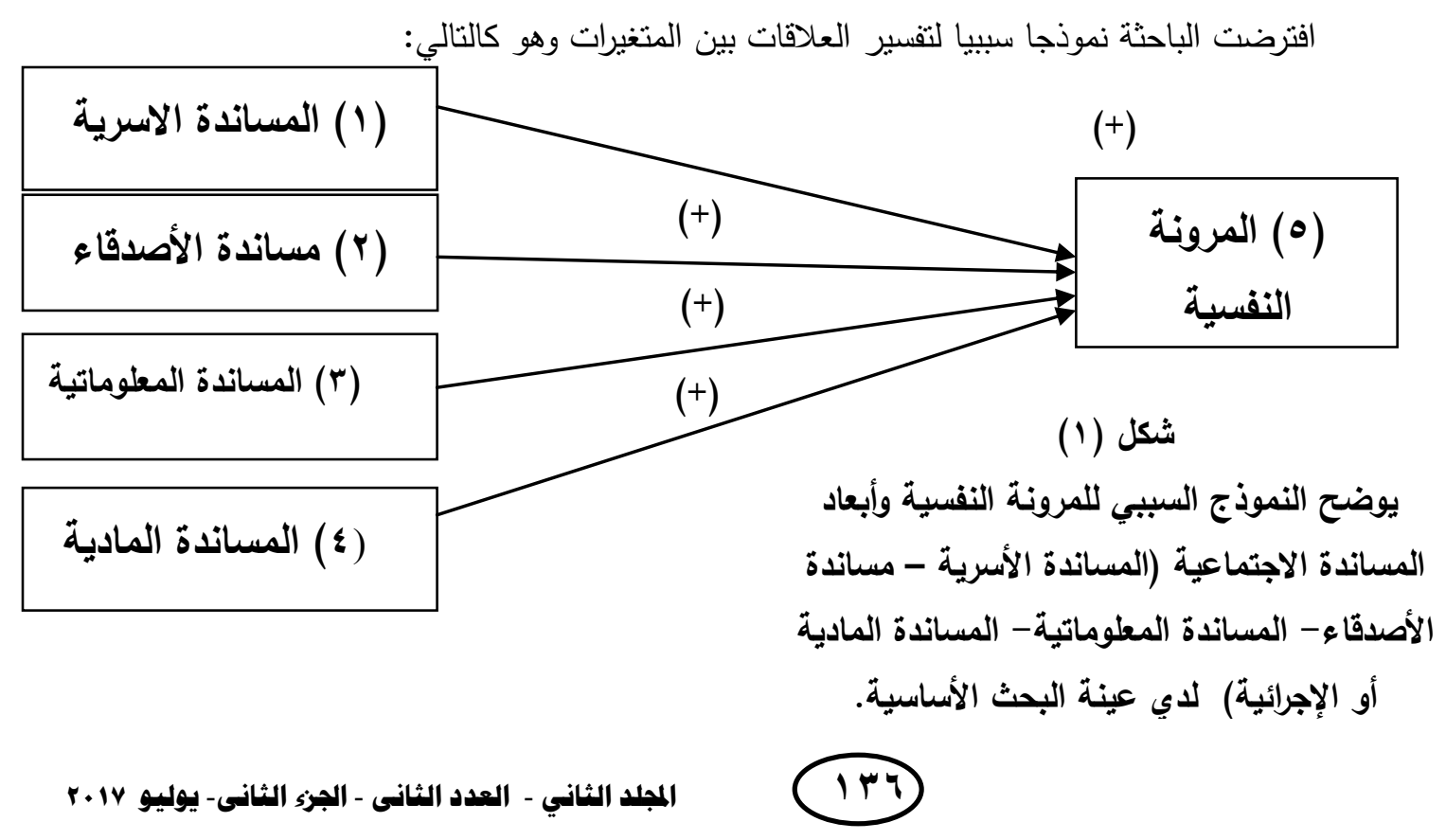


ووفقا للنمـوذج المقترح تعتبر أبعـاد (المسـاندة الأسـرية - مسـاندة الأصدقاء- المسـاندة

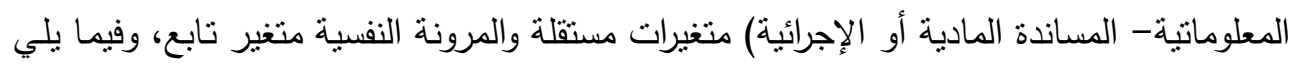
نتائج تحليل المسار للمتغيرات موضع البحث وهي كالآتي:

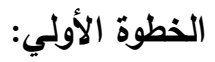

ايجـاد المصـفوفة الارتباطيـة بــين المتغيـرات المسـتقلة (المســاندة الأسـرية - مسـاندة

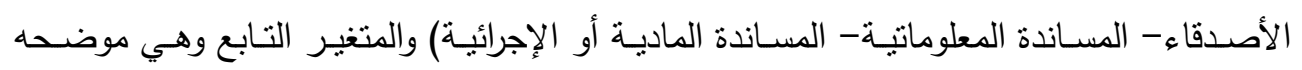
بالجدول التالي.

\section{جدول (19)}

المصفوفة الارتباطية بين المتغيرات المستقلة (المساندة الأسرية - مساندة الأصدقاء- المساندة

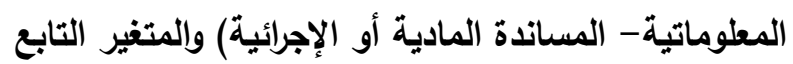

\begin{tabular}{|c|c|c|c|c|c|}
\hline النفرونة & المادية & المطوماتية & الأصدقاء & الأسرية & العوامل \\
\hline & & & & & المساندة الأسرية \\
\hline & & & & $* * *, \Sigma)$ & مساندة الأصدقاء \\
\hline & & & $* *, r<0$ & $* *$ * ro & المعلوماتية \\
\hline & & $* * \cdot, T Y$ & $* *, Y \wedge r$ & $* * *, r \cdot$ & المساندة المادية \\
\hline & $* *,, 1 \wedge \wedge$ & ד & $* *, r T$ & $* *, r 40$ & المرونة النفسية \\
\hline
\end{tabular}

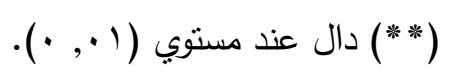

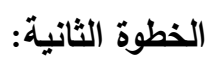

حيث إن معاملات المسار = أوزان الانحدار المعيارية، فإن الخطوة التالية من التحليل

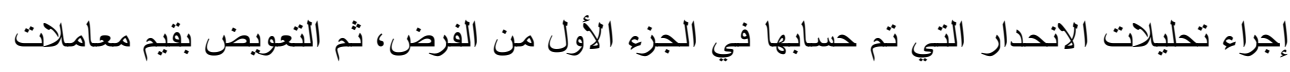


المسار في النموذج السببي الذي تقترضه الباحثة لتفسير العلاقات، وكذلك قبم معاملات الارتباط

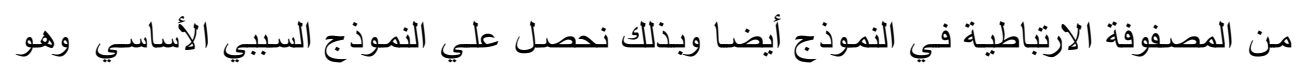
كالنالي

$1 \wedge, \cdot \mathrm{R} 2=$

$\cdot, 91=0^{0}$

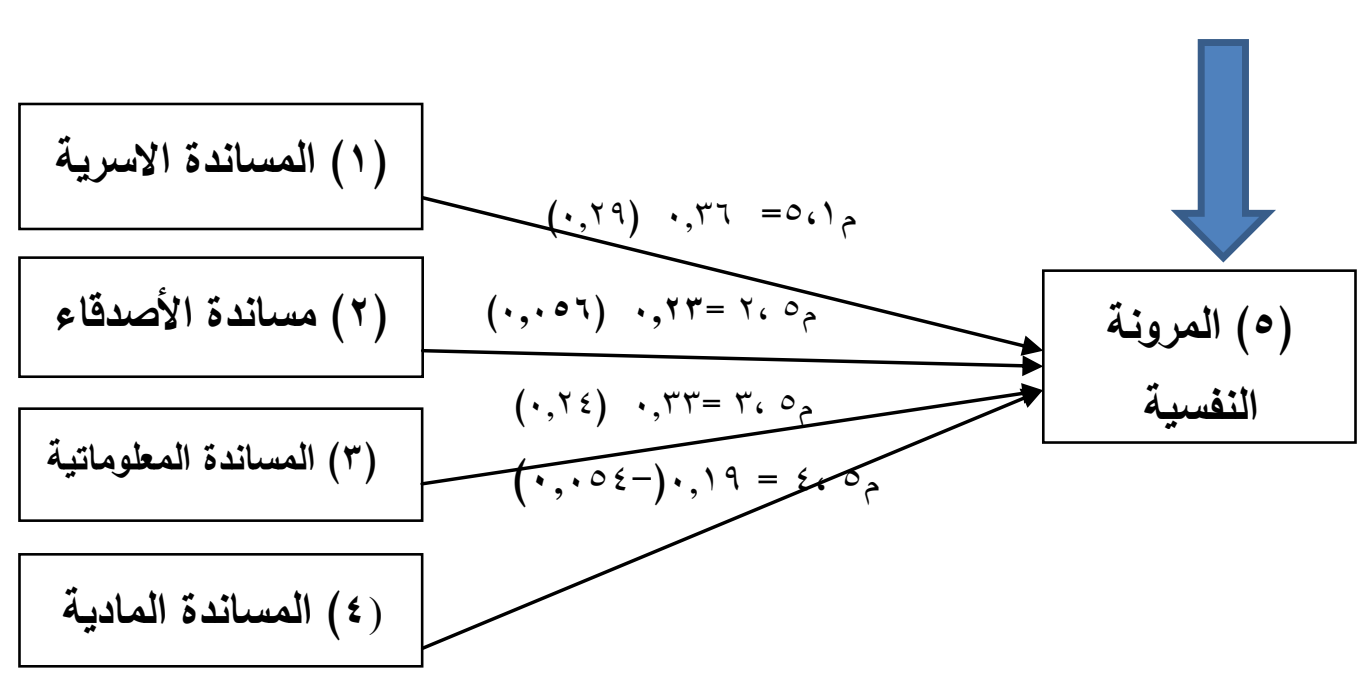

شكل (r)

النموذج السبي الأساسي للمرونة النفسية وأبعاد المساندة الاجتماعية

(المساندة الأسرية - مساندة الأصدقاء- المساندة المعلوماتية- المساندة المادية أو الإجرائية)

* معامل الارتباط خارج الاقواس ، معامل المسار داخل الأقواس •

وبالرغم من أن المعادلـة الانحداريـة للتتبؤ بالمرونـة النفسية عن طريق أبعاد المساندة

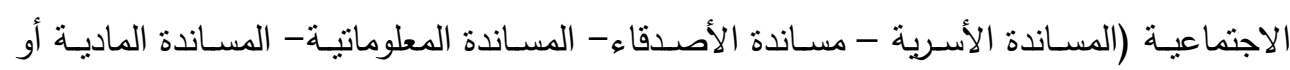

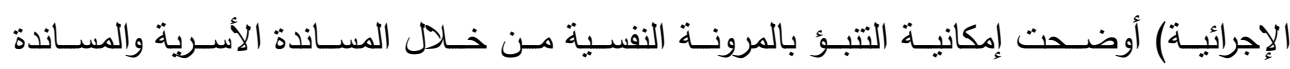

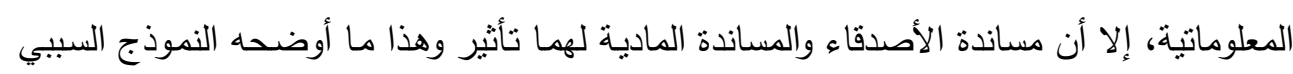

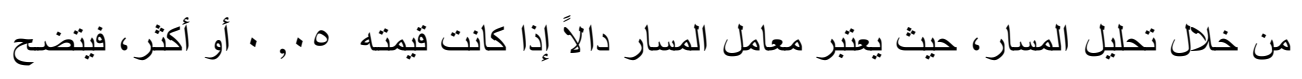

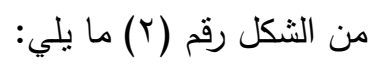


بلغت قيمة معامل المسار للمساندة الأسرية علي المرونة النفسية (9 r, •) وهي قيمة دالة

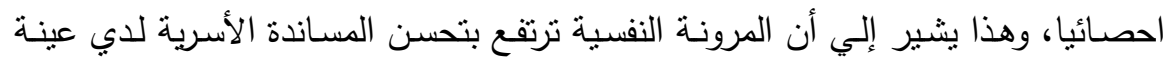
البحث الأساسية. بلغت قيمة معامل المسار للمساندة المعلوماتية علي المرونة النفسية (ع ب, ·) وهي قيمة

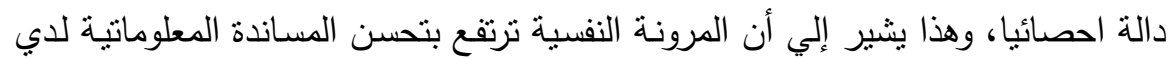

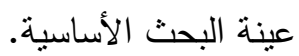
بلغت قيمة معامل المسار لمساندة الأصدقاء علي المرونة النفسية (07. . ••) وهي قيمة

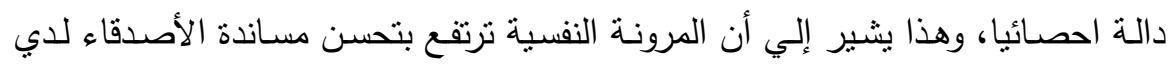
عينة البحث الأساسية.

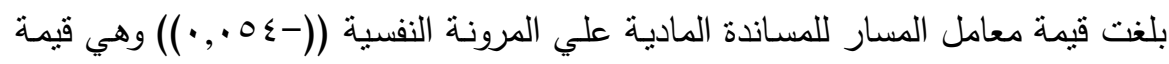

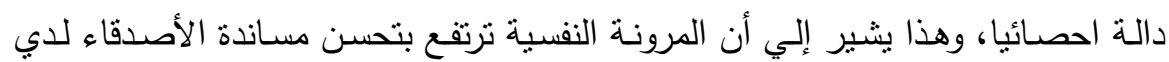
عينة البحث الأساسية.

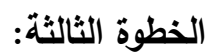

يتتم حسـاب مسـارات البواقي في النمـوذج الأساسي مـن معرفـة قيمـة التباين المشترك للمتغيرات الداخلة من المعادلة كالأتي:

$$
\begin{aligned}
& \text { مسار البواقي م ب = R2 } 1 \text { - R2 } \\
& \text { فيصبح قيمة مسار البواقي م مب = }
\end{aligned}
$$
وبذلك يصبح النموذج بعد التعديل كالأتي:

$$
\begin{aligned}
& 11, \cdot \mathrm{R} 2= \\
& \cdot, 91=40
\end{aligned}
$$




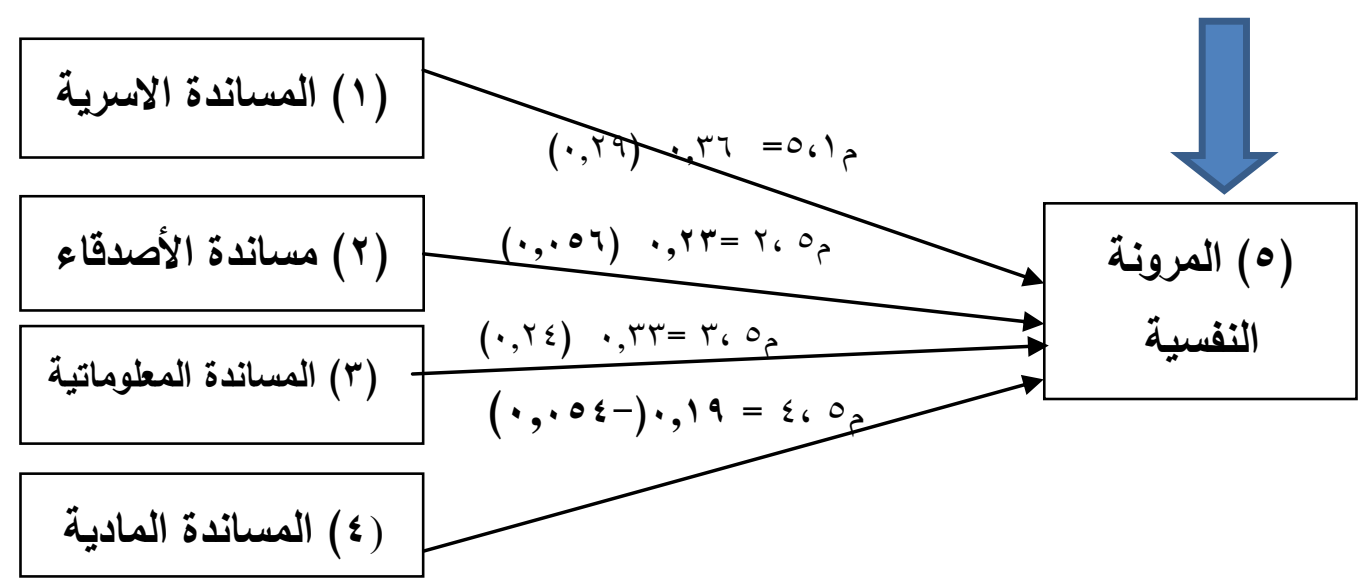

شكل (r) (r) (1) (1)

النموذج السببي المعدل للمرونة النفسية وأبعاد المساندة الاجتماعية (المساندة الأسرية مساندة الأصدقاء- - المساندة المعلوماتية- المساندة المادية أو الإجرائية. ويتضح من الثكل (ץ) بعد التوصل للنموذج السببي والمعدل ما يلي: • أن المساندة الأسرية رقم (1) تعد أكثر أبعاد المساندة الاجتماعيـة اسهاما في المرونـة النفسية لاي عينة البحث حيث بلغت قيمة المسار (9 ب, •). هليه المساندة المعلوماتية حيث بلغت قيمة المسار ( ع ب, •). • • • • •ليه مساندة الأصدقاء حيث بلغت قيمة المسار ( 07 •., •). واخير المساندة المادية حيث بلغت قيمة المسار (- ـه •. • •).

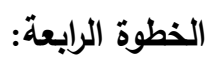

تم التأكد من صحة النموذج السببي من خلال الخطوات الأثية: - مقارنة قيمة النباين الشترك (R2) الموضحة بالنموذج السببي الأساسي والمعدل،

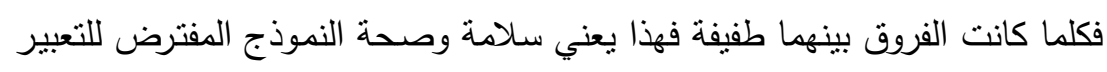
عن العلاقات السبيية بين المتغيرات، ويتضح ذللك من الجدول التي: لتئي 


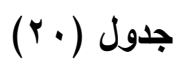

نتائج مقارنة التباين المشترك (R2) الموضحة بالنموذج السببي الأساسي والمعدل للمتغيرات

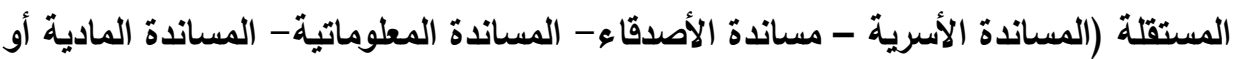

الإجرائية) والمتغير التابع (المرونة النفسية).

\begin{tabular}{|c|c|c|c|c|}
\hline \multicolumn{2}{|c|}{ النموذج المعدل } & \multicolumn{2}{|l|}{ النموذج الأساسي } & \multirow[b]{2}{*}{ المتغير التابع } \\
\hline عدد الهتغيرات التي يتنبأ & $\mathbf{R} 2$ & عدد المتغيرات التي يتتبأ بها & $\mathbf{R} 2$ & \\
\hline$\varepsilon$ & $\cdot, 11$ & $\varepsilon$ & $\cdot, 1$ & المرونة النفسية \\
\hline
\end{tabular}

$$
\text { يلاحظ من الجدول (·r) ما يلي: }
$$

لا يوجد فرق بين التباين المشترك في النموذج السببي الأساسي و التباين المشترك في

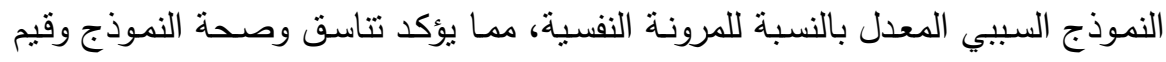

$$
\text { معاملات المسار المحسوبة. }
$$

r باب النباين الكلي للمتغير التابع من المتغيرات المستقلة والبواقي:

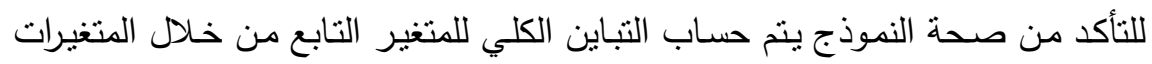
المستقلة والبواقي، حيث أن التباين الكلي لأي متغير تابع يسـاوي الواحد لكي يعبر عن التحديد الكلي للمتغير - الكن.

تحديد تباين المتغير التابع (المرونـة النفسية) من خـلال المتغيرات المستقلة (المساندة

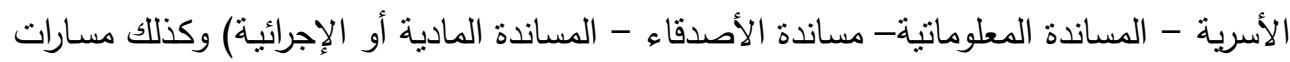
البواقي المتغيرات الأخري التي تؤثر علي المرونة النفسية ولم يتم نتاولها بالدراسة. التباين الكلي للمرونة النفسية = (مهب) + R2 نسبة التباين المشترك

$$
1=\cdot, 99=\cdot, 1 \wedge+r(\cdot, 91)=
$$

وبما أن التباين الكلي للمتغير (0) المرونة النفسية = 1 إذن فهذا يعني صحة النموذج

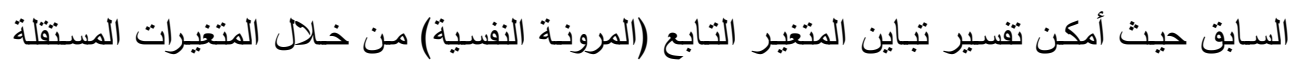
وهي(المساندة الأسرية - المساندة المعلوماتية- مساندة الأصدقاء- المساندة المادية أو الإجرائية) 


\section{المجلة العلمية لكلية رياض الاطفال - جامعة اسيوط}

والتي أسهوت بنسبة ه \\% من التباين الكلي للمرونة النفسية، بينما متغيرات البواقي التي لم تدرس

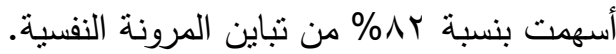

r- تحديد الأثر المباشر وغير المباشر لارتباط كل متغير في النموذج.

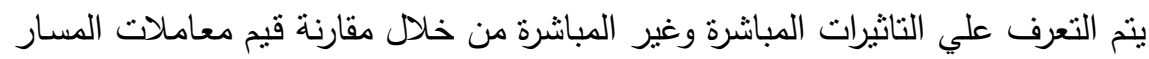

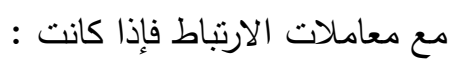

تذل علي ناثير مباشر فقط.

تدل علي تأثير مباشر وغير مباشر

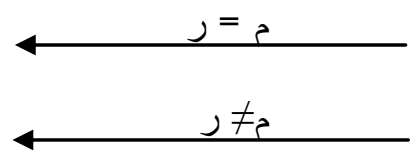

$$
\text { والتاثيرات غير المباشرة =ر - م }
$$

وبالنسبة للمتغير التابع (المرونـة النفسية) يوجد تأثثر مباشـر وغير مباشـر للمسـاندة

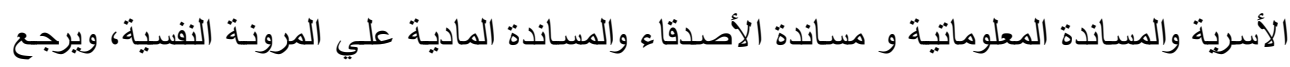
ذلك التاثير إلي الفرق بين معامل المسار ومعامل الارتباط حيث إن هناك ارتباط بين المساندة

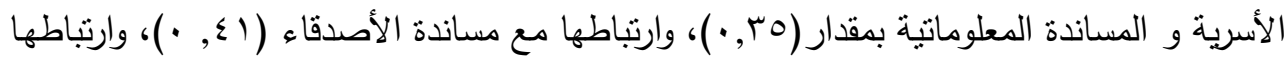

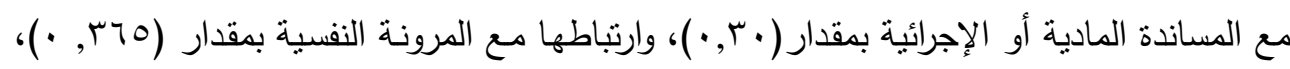

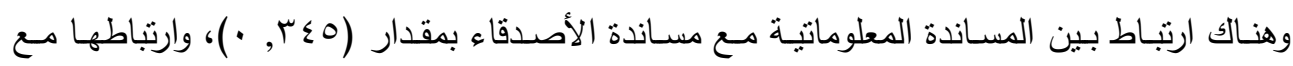

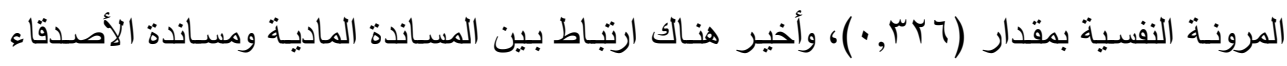

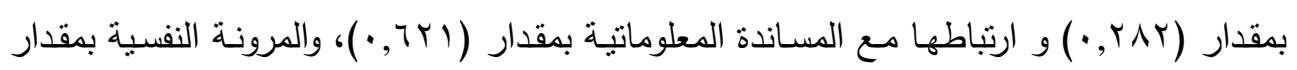
$\cdot(\cdot, 1 \wedge \wedge)$

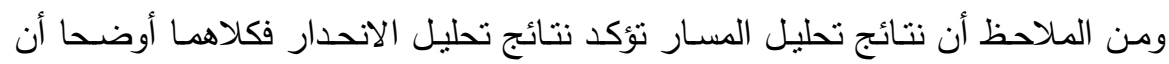

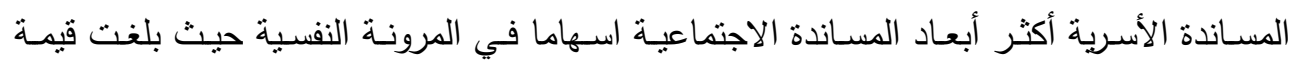

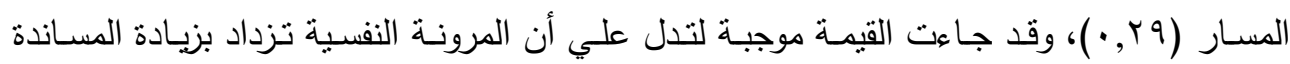

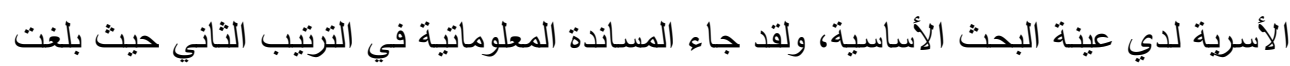

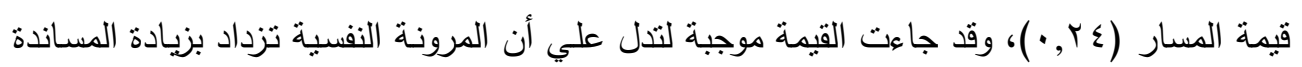
المعلوماتية لدي عينة البحث الأساسية

وعلي الرغم من أن تحليل الانحدار لم بسفر عن امكانية التتبؤ بالمرونة النفسية من خلال مساندة الأصدقاء والمساندة المادية أو الإجرائية إلا أن تحليل المسار أوضح أنس أن هناك تاثيراً مباشراً 
وغير مباشراً لمساندة الأصدقاء علي المرونة النفسية لاي عينة البحث الأساسية حيث بلغت قيمة

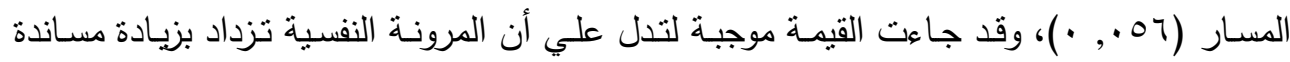

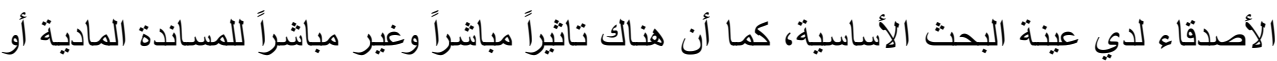
الإجرائية علي المرونة النفسية لاي عينة البحث الأساسية حيث بلغت قيمة المسار (-ـه . •.)، وقد جاءت القيمة سالبة لتنل علي أن المرونة النفسية تقل بزيادة مساندة المادية أو الإجرائية لدي عينة البحث الأساسية.

وتتفق هذه النتيجة مع ما أكده كل من (Freedman, R. \&. Boyer, A. 2000) أن الأسرة هي أكبر مقدمي الدعم للأشخاص ذوي الإعاقة النمائية، فإن أفراد الأسرة، وهم عادة الآباء والأمهات، هم العمود الفقري لنظام دعم المجتمع المحلي، وتشمل أنـواع الدعم الأسـري خدمات الراحة، والرعاية الصحية المنزلية، والتعليم العائلي والتدريب، وتقديم المشورة الأسرية، ودعم الأسرة،

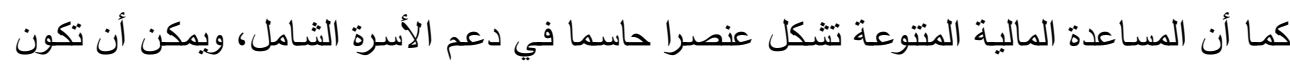
هذه المسـاعدات في شكل إعانـات نقديـة أو قسـائم أو تعوبضـات تسـتخدمها الأسـر للدفع تكـاليف العلاجات أو الأدويـة أو المعدات التكيفية أو الأنشطة الترفيهية التي لا يستطيعون تحملها. وتمكن هذه الأموال الأسر من اختيار وشراء الدعم والخدمات المصممة خصيصا لتلبية احتياجاتها الفربدة. فالمساندة الاجتماعيـة الذي نتلقاه الأسرة من الأقارب والأصدقاء والجيران ، يسهل عليها

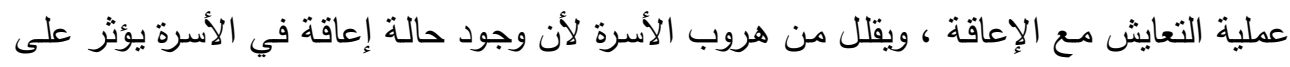
نشاطها إذا لم تجد الدعم والمساندة الاجتماعية المناسبة من الآخرين.

ويـري كمـال مرسـي ( . . ب) أن المسـاندة الاجتماعيـة التى يحصـل عليها الإنسـان مـن

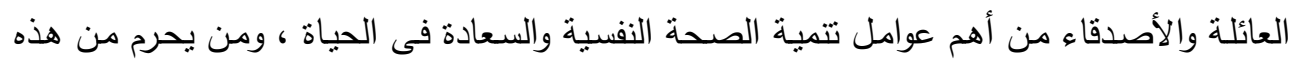
المساندة يعيش فى عزلة ووحدة نفسية ، تجعله عرضة للاضطرابات والأزمات . وتري خولة يحيي (T . . r) إن أفضل دعم تحتاجه الأسرة هو الذي يتمثل بمؤازرة أفرادها بعضهم بعضاً وخاصة الوالدين، ويتفق ذلك مع ما أثنار إليه بطرس (0 . . ب) من أن للدعم المقدم من جانب الأسرة والأصدقاء دوراً كبيراً في توافق الفرد، حيث إن الأفراد الذين يتمتعون بقدر كبير من الدعم الأسري هم أقل عرضة للاضطرابات والضغوط والمشكلات النفسية. واتفقت هذه النتيجة مع ما جاءت به دراسة أميرة بخش ( . . . . لتؤكد علي وجود علاقة دالة بين درجة الضغوط النفسية ودرجة الدعم الإجتماعي المتوافر، وبالنسبة لمصادر الدعم 


\section{المجلة العلمية لكلية رياض الاطفال - جامعة اسيوط}

الاجتهـاعي فقد جاء دعم الزوج، ودعم الأبناء غير المعاقين في المرتبـة الأولي، ثم دعم الأهل

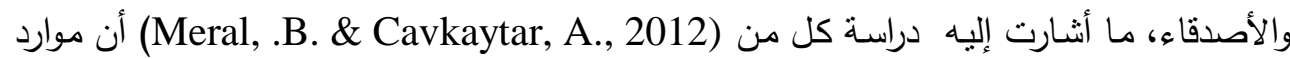

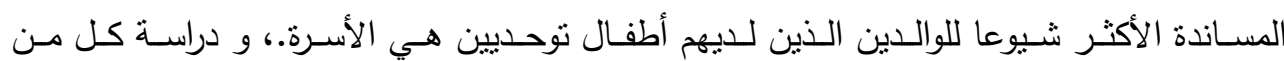
(Greeff, A. \&Walt, K., 2010 )

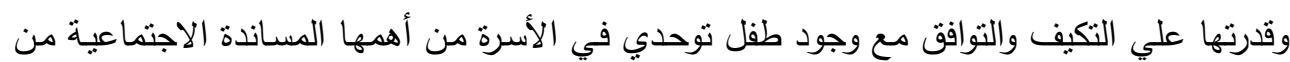
الأسرة والأصدقاء والمجتمع وأولياء أمور الأطفال المصابين بالتوحد.

بلغت قيمة معامل المسار للمساندة المعلومانية علي المرونة النفسية (ع ب, ·) وهي قيمة

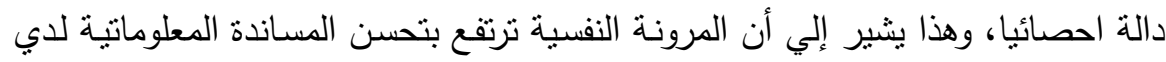

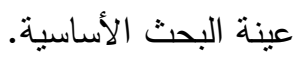

حيث يشمل الدعم المعلوماتي تقديم المعلومات ووجهات النظر أو الآراء والنصائح بحيث تجعل هذه المعلومات الفرد أكثر تبصرا بعوامل النجاح أو الفشل، فيزداد قدرة على مواصلة النجاح وعلى تحمل الفثل والإحباط، بل قد يجد في النصائح ما يساعده على تحويل الفنشل إلى نجاح. ويؤكد كل من (Freedman, R. \&. Boyer, A., 2000) أن الأسر تحتاج إلى (إنى

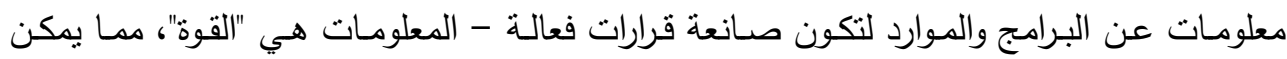

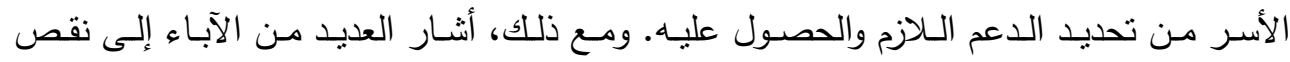

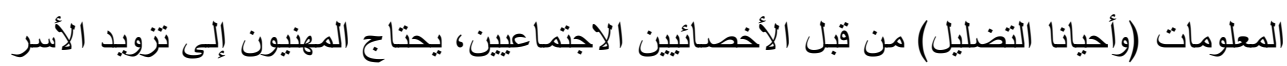

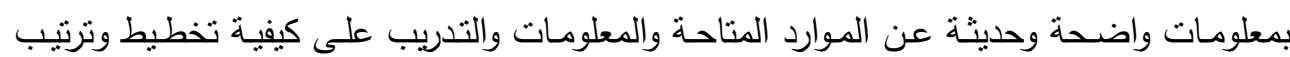

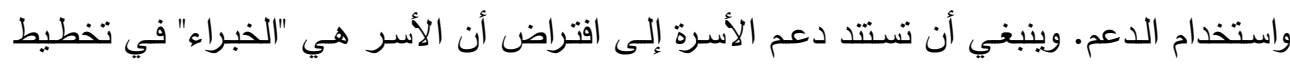

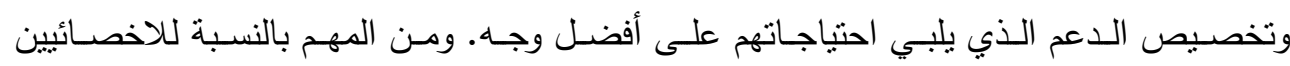
الاجتماعيين وغيرهم من العاملين في مجال الرعاية الصحية أن يساعدوا في تعزيز معارف الأسرة

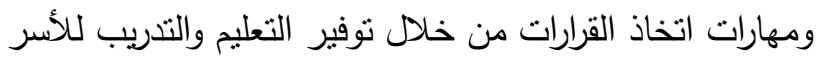

ويري عبد العزيز السرطاوى (9 . ب؟) أن توفير المعلومات يعد فى مقدمة الاحتياجات

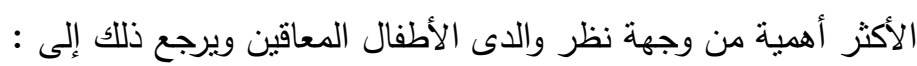

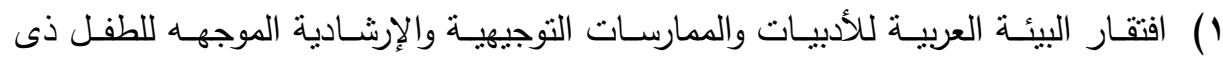

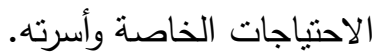


r) محدودية الخدمات التى تقدمها المؤسسات والمراكز ذات العلاقة فى تزويد أولياء الأمور

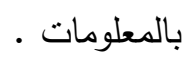

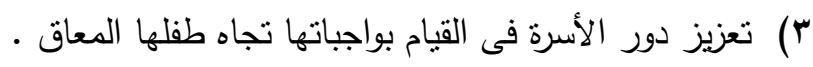

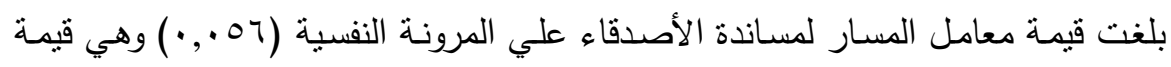

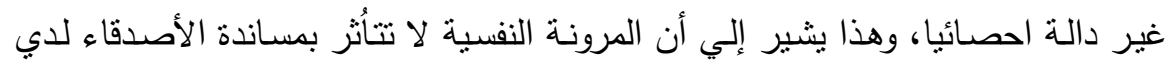

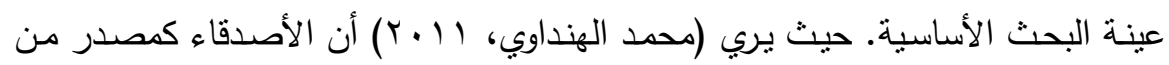

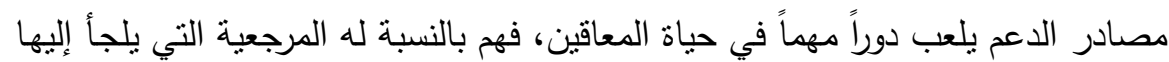

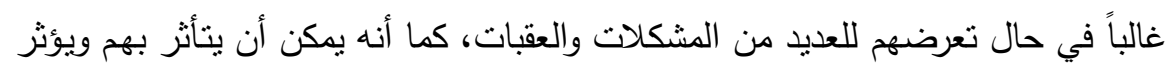

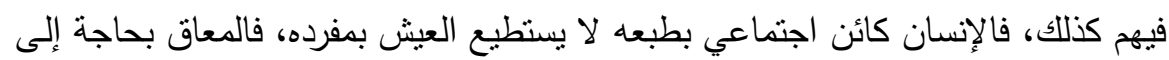

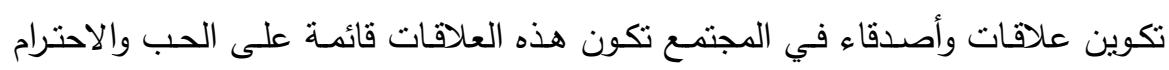
والتقدير وتقبل كل منهم للآخر .

بلغت قيمة معامل المسار للمساندة المادية علي المرونـة النفسية (-ـه •., ·) وهي قيمة

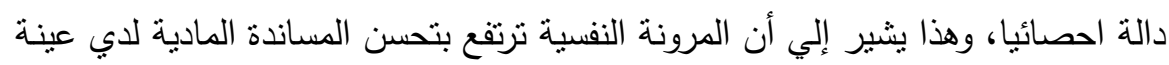

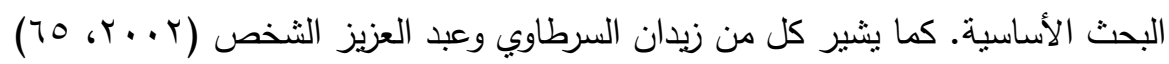
إلي حاجة أسرة الطفل المعاق إلى الدعم المجتمي المتمثل بتوفير الدير المراكز والجمعيات

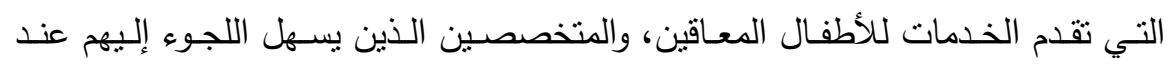

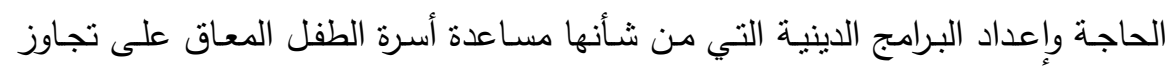

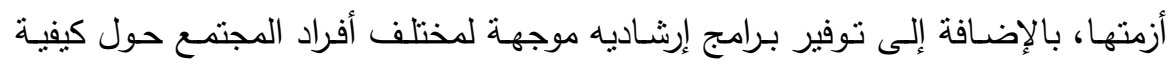

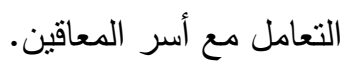

إن المساندة الإجتماعية التي ينلقاها الفرد من الآخرين سواء الأسرة أو خارجها تعد عاملا

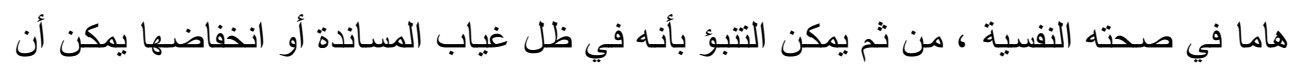

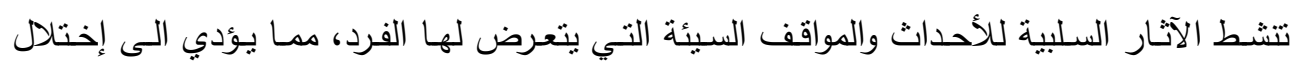

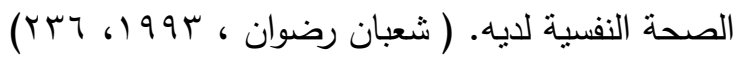


بناء على النتائج التي توصلت اليها ة نوصي بما يلي :

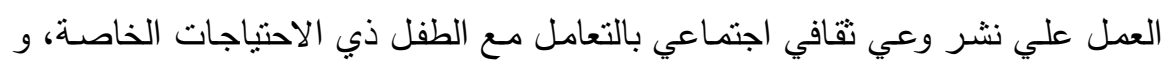

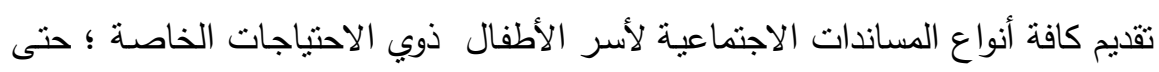

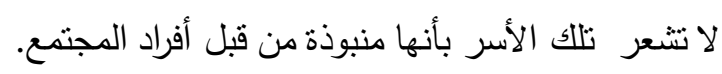

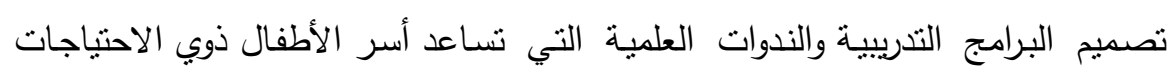
الخاصة على كيفية التعامل بمرونة إيجابية مع كافة الضغوط التي تواجهها. إجراء دراسات حول أسـاليب تتميـة المرونـة النفسية لدى أسر الأطفال ذوي الاحتية الاحتياجات الخاصة. تصميم برامج تعمل على تعزز العمليات الرئيسية للمرونة لاى الأسر وتقلل من الضغط النفسي زيادة الإهتمام بأسر الأطفال المعاقين سواء من قبل الباحثين في دراسة عوامل أخرى ، أو

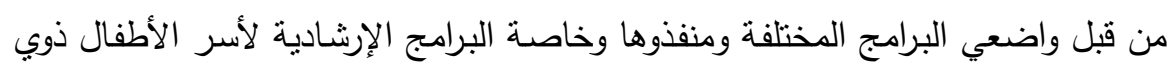

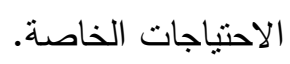

\section{البحوث المقترحة :}

فاعلية برنامج ارشاد معرفي عقلاني لتتمية المرونة النفسية لاى أولياء أمور الأطفال ذوي الاحنياجات الخاصة.

فاعليـة برنـامج ارشـاد سـوكي لتتميـة المرونـة النفسية لـدى الأطفـال ذوبي الاحتياجـات الخاصة.

المساندة الاجتماعية وعلاقتها ببعض المتغيرات الديموجرافية و النفسية لدى أولياء أمور الأطفال ذوي الاحنباجات الخاصة. 


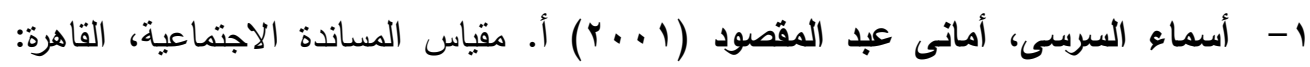
مكتبة الانجلو المصرية.

r - أسماء السرسى، أمانى عبد المقصود ( ( . ب) ب. المساندة الاجتماعية كما بدركها المراهقين وعلاقتها ببعض المتغيرات النفسية، مجلة كلية التربية ببنها، جامعة الزقازيق،

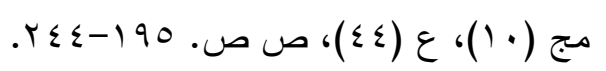

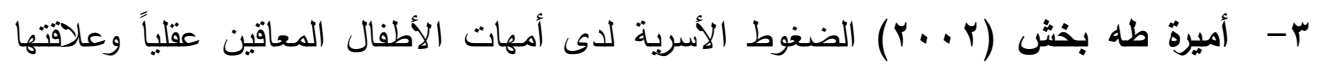

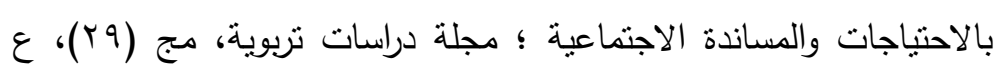

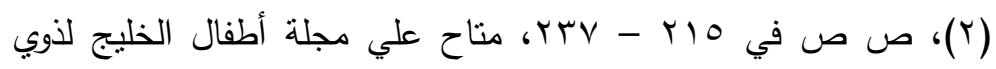

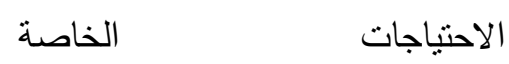

http://www.gulfkids.com/ar/index.php?action=show_res\& r_id=68\&topic_id=1356 ع - أيت حمودة حكيمة، فاضلي أحمد، مسيلي رشيد (11 + ب). أهمية المساندة الاجنماعية في تحقيق التوافق النفسي والاجتماعي لاى الثباب البطال، مجلة العلوم

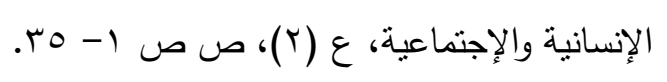

ه - إيمان فؤاد الكاشف ( . . . .). دراسة لبعض انواع الضغوط لدي أمهات الأطفال المعاقين وعلاقتها بالاحتياجات الأسرية ومصادر المساندة الاجتماعية ، مجلة كلية

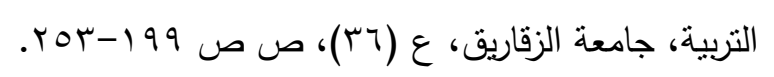

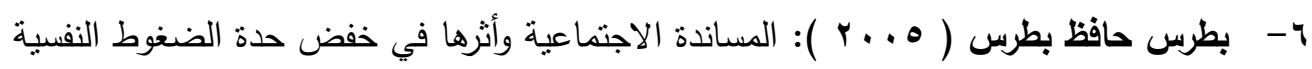
للأطفال المتفوقين عقلياً ذوي صعوبات القراءة . المؤتمر السنوي الثاني عشر للإرشاد النفسي، الإرشاد النفسي من أجل التتمية في عصر المعلومات

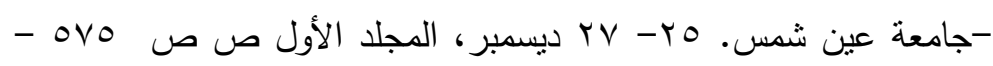
משת

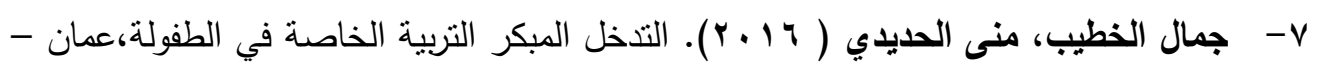

$$
\text { الأردن: دار الفكر }
$$

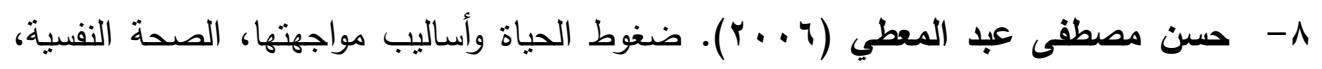

$$
\text { القاهرة : مكتبة زهراء الثرق للنشر والتوزيع. }
$$


9- خولة أحمد يحيي (^ + . ץ). إرشاد أسر ذوى الاحتباجات الخاصة. عمان، الأردن، دار الفكر

$$
\text { العربي. }
$$

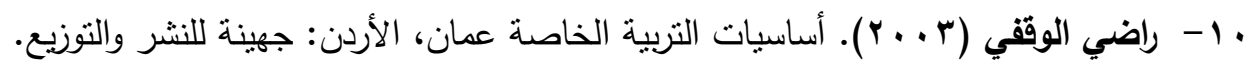

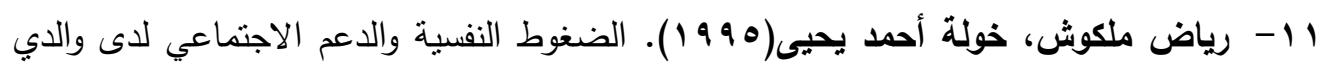

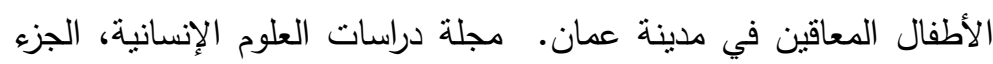

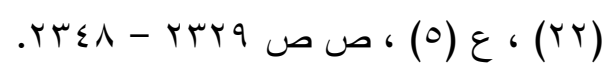

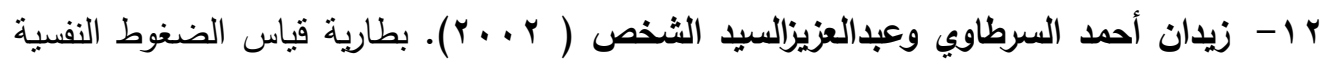

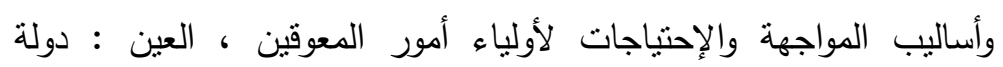

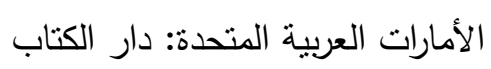

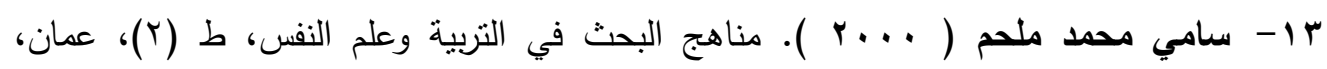

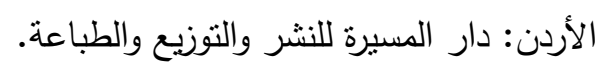

؛ ا- السيد إبراهيم السمادوني (99 ( I)). مقياس المساندة الاجتماعية، كراسة التعليمات، القاهرة:

$$
\text { مكتبة النهضة المصرية. }
$$

ه - شعبان جاب الله رضوان (ب9911). علم النفس الاجتماعي والصحة النفسية، القاهرة : دار

$$
\text { غريب للنشر. }
$$

41- صفوت فرح (1991). التحليل العاملي في العلوم السلوكية، ط (ץ)، القاهرة، مكتبة الإنجلو

$$
\text { المصرية. }
$$

IV

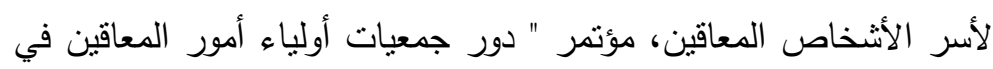

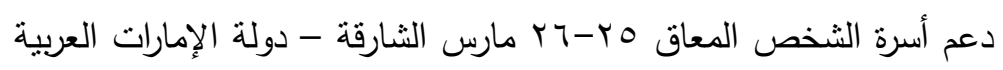

$$
\text { المتحدة. }
$$

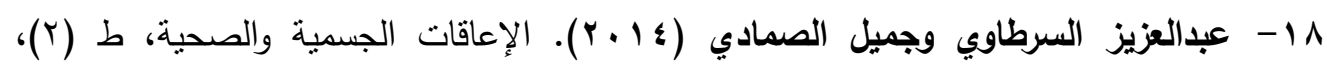
الكويت: مكتبة الفلاح للنشر والتوزيع.

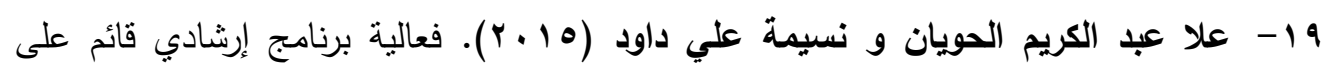

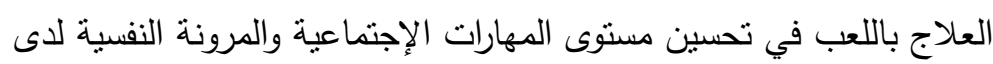

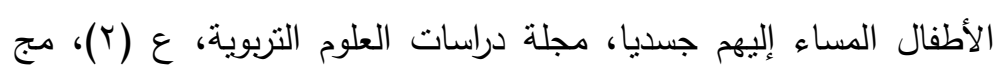

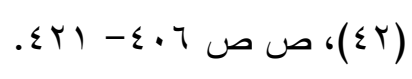


• ץ - علي عبد السلام علي ( . . . . ). المساندة الاجتماعية وأحداث الحياة الضاغطة وعلاقتهما بالتوافق مع الحياة الجامعية لدى طلاب الجامعة المقيمين مع أسرهم

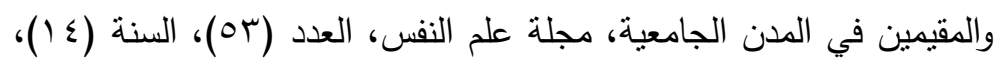
الهيئة العامة للكتاب، القاهرة. ا - - علي عبدالنبي محمد حنفي ( V . . . . . العمل مع أسر ذوي الإحتياجات الخاصة، القاهرة: العلم والإيمان للنشر والتوزيع.

r r - عماد علي عبد الرازق ( 1991 ): المساندة الاجتماعية كمتغير وسيط في العلاقة بين

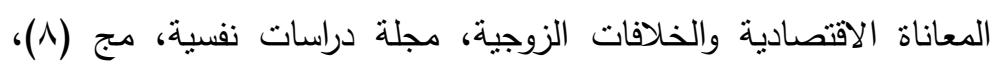

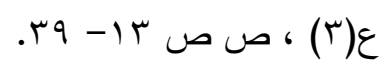

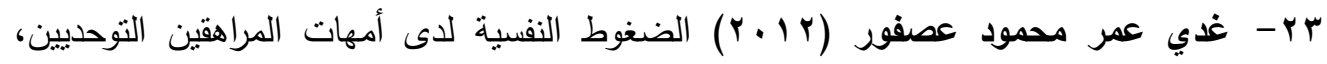
رسالة ماجستير ، كلية العلوم التربوية والنفسية، جامعة عمان العربية.

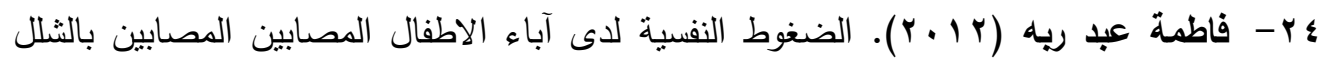
الدماغي في ضوء بعض المتغيرات. رسالة ماجستير غير منشورة، معهد

$$
\text { الدراسات التربوية، جامعة القاهرة. }
$$

ه r- كمال إبراهيم مرسي ( . . . r). السعادة وتتمية الصحة النفسية المبكرة ، القاهرة : دار النشر

$$
\text { لإمانعات. }
$$

צ - - محمد حامد إبراهيم الهنداوي (11 ( ب). الدعم الاجتماعي وعلاقته بمستوى الرضا عن جودة الحياة لدى المعاقين حركياً بمحافظات غزة، رسالة ماجستير، كلية التربية

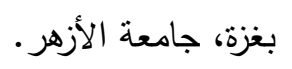

V - محمد محروس الشناوي ، محمد السيد وعبد الرحمن ( ع99 19 ). المساندة الاجتماعية والصحة النفسية، مراجعة نظرية ودراسات تطبيقية، القاهرة: مكتبة الانجلو

$$
\text { المصرية. }
$$

^ ץ - محمد محمد محمد عودة ( • • r). الخبرة الصادمة وعلاقتها بأساليب التكيف مع الضغوط والمساندة الإجتماعية والصلابة النفسية لدى أطفال المناطق الحدودية بقطاع

غزة، رسالة ماجستير، كلية التربية ، الجامعة الإسلامية بغزة.

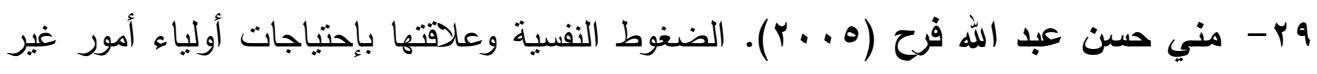

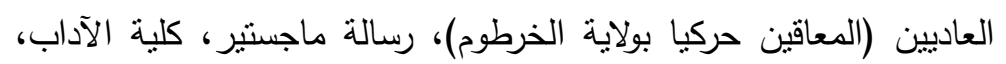

$$
\text { جامعة الخرطوم. }
$$


• ب- ناجي الخشاب (r . . ץ). دينامية العلاقة بين المساندة النفسية الاجتماعية وإرادة الحياة والاكتئاب لاي مرضي الإيدز (دراسة إكلينيكية)، رسالة دكتوراه، كلية الأداب ، جامعة عين شمس.

اس- نعمات شعبان علوان، عبدالرؤوف الطلاع (ع ا ب ؟). فاعلية برنامج إرشادي لتتمية الثقة بالنفس وأثره في زيادة المرونة الإيجابية "دراسة على عينة من أفراد الثرطة

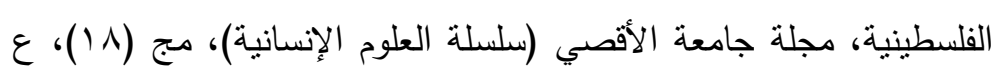
.r

ץ r- هارون توفيق الرشيدي ( 999 ( 199 ). الضغوطات النفسية، طبيعتها، نظرياتها، القاهرة: مكتبة الأنجلو المصرية.

ب - - هثام إبراهيم عبدالله ( 099 19 ). المساندة الاجتماعية وعلاقتها بالاكنئاب واليأس لدى عينة

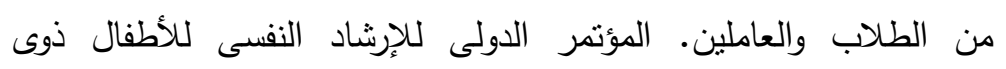
الحاجات الخاصة، مركز الإرشاد النفسى مركز الإرشاد النفسى بجامعة عين شمس،القاهرة، ص ص ص س

34- American Psychological Association (2002). The road to resilience, http://www.apa.org/helpcenter/road-resilience.aspx

35- Boyd, A. B. (2002). Examining the Relationship between Stress and Lack of Social Support in Mothers of Children with Autism, Focus on Autism and Other Developmental Disabilities, 17(4): 208-215 .

36- Cheng, S. \& Chan, A. (2004). The multidimensional scale of perceived social support: Dimensionality and age and gender differences in adolescents. Personality and Individual Differences, 37(7):1359-1369.

37- Connor, M.K. \& Davidson, R.T.J. (2003). Development of a new resilience scale: The Connor-Davidson Resilience Scale (CD-RISC), Depression and anxiety, 18:76-82.

38- Cuzzocrea, F, Murdaca, A. M. Costa, S. , Filippello, P. \& Larcan, R. (2015). Parental stress, coping strategies and social support in families of children with a disability, Journal Child Care in Practice, 22(1): 3-19.

39- Felizardoa, S., Ribeiroa, E. \& Amanteaa, M. J. (2016). Parental adjustment to disability, stress indicators and the influence of social support, Procedia - Social and Behavioral Sciences, 21(7): $830-837$. 

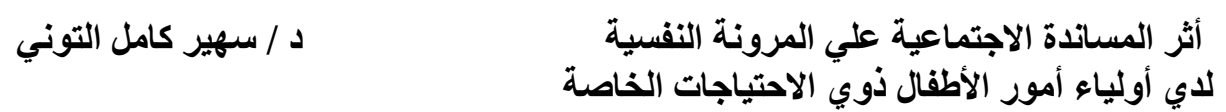

40- Fletcher, D. \& Sarkar, M. (2013). Psychological Resilience: A Review and Critique of Definitions, Concepts, and Theory, European Psychologist, https://www.researchgate.net/publication/263651506. 96, 213-221. doi: 10.1016/j.drugalcdep. 2008.03.007

41- Freedman, R., \& Boyer, N. C. (2000). The power to choose: Support for families caring for individuals with developmental disabilities. Health Social Work, 25: 59-68

42- Friborg, O. (2006). Validation of scale to measure resilience in adults, Doctoral thesis, Department of Psychology, Faculty of Social Sciences, University of Troms $\emptyset$. Validation of a scale to

43- Gerstein, E., Crnic, K., Blacher, J. \& Baker, B. (2009). Resilience and the course of daily parenting stress in families of young children with intellectual disabilities, Journal of intellectual disability research, 53(12):981-97.

44- Graungaard, A.H. \& Skov, L. (2006). Why do we need a diagnosis? A qualitative study of parent's experiences, coping and needs, when the newborn child is severely disabled. Child: Care, Health and Development, 33 (3): 296-307.

45- Greeff, A. \& Walt, K. (2010). Resilience in Families with an Autistic Child, Education and Training in Autism and Developmental Disabilities, 45(3), 347-355.

46- Grotberg, E.H. (1995). A guide to promoting resilience in children: strengthening the human spirit - Early Childhood Development: Practice \& Reflections Number 8, Holland, Bernard van Leer Foundation.

47- Ha, J. , Greenberg, J. S. \& Seltzer, M. M. (2012). Parenting a child with a disability: The role of social support for African American parents, Family Process, 92(4): 405- 411.

48- Hastings R. P., Beck A. \& Hill C. (2005). Positive contributions made by children with an intellectual disability in the family: Mothers' and fathers' perceptions. Journal of Intellectual Disability 9, 155-65.

49- Hawley, D. R., \& DeHaan, L. (1996). Toward a definition of family resilience: Integrating life span and family perspectives. FamilyProcess, 35(3):283-98.

50- Hedov, G., Wikblad, K. \& Annerén, G. (2002). First information and support provided to parents of children with Down 
syndrome in Sweden: clinical goals and parental experiences, Acta Paediatrica, 91(12):1344-1349.

51- Heiman, T. (2002). Parents of Children with Disabilities: Resilience,

Coping, and Future Expectations, Journal of

Developmental and Physical Disabilities, 14(2):159-171.

52- Hill, F., Newmark. R. \& Le Grange, L. (2003). Subjective perceptions of stress and coping by mothers of children with an intellectual disability: A needs assessment, International Journal of special education, 18 (1): 36- 43.

53- Kerr, S. \& McIntosh, J. (2000). Coping when a child has a disability: Exploring the impact of parent to parent support, Child health care and development, 26 (4): 309-322.

54- Lee, H. H., \& Cranford, J. A. (2008). Does resilience moderate the associations between parental problem drinking and adolescents' internalizing and externalizing behaviours? A study of Korean Adolescents. Drug and Alcohol Dependence,

55- Lee, I., Lee, E., Kim, H., Park, Y., Song, M. \& Park, Y. (2004). Concept development of family resilience: a study of Korean families with a chronically ill child, Journal of clinical nursing, 3(5):636-645.

56- M. Bayat, (2007). Evidence of resilience in families of children with autism, Journal of intellectual disability research, 51(9):702-714.

57- Masten, A. S. (2001). Ordinary Magic. Resilience Processes In Development, The American Psychologist, 56(3): 227238.

58- McCubbin, H. I., Thompson, A. I., \& McCubbin, M. A. (1996). Family assessment: resiliency, coping and adaptation-Inventories for research and practice. Madison, WI: University of Wisconsin System.

59- Meral, .B.F. \& Cavkaytar, A. (2012). A study om social support perception of parents who have children with autism, International Journal on New Trends in Education and Their Implications, 13 (3): 124-135.

60- Newman, R. (2002).The road to resilience, American psychological association, 33(9):62.

61- Plumb, J. C., (2011). The impact of social support and family resilience on parental stress in families with a child diagnosed with 
an autism spectrum disorder, Doctoral Dissertation, University of Pennsylvania, USA.

62- Rajan, A. M. \& John, R., (2017). Resilience and impact of children's intellectual disability on Indian parents, Journal of Intellectual Disabilities, http://journals.sagepub.com/doi/abs/10.1177/1744629516 654588

63- Rampe, M. (2010). Der R-Faktor. Hamburg \& Norderstedt: Books on Demand $\mathrm{GmbH}$.

64- Rivers, J. W., \& Stoneman, Z. (2003). Sibling relationships when a child has autism: marital stress and support coping. Journal of Autism and Developmental Disorders, 33: 383-394.

65- Roach, M. A., Ormond, G. I., and Barratt, M. S. (1999). Mothers and fathers of children with DownSyndrome: Parental stress and involvement in children. American Journal of Mental Retardation, 104: 422-436.

66- Scorgie K. \& Sobsey D. (2000). Transformational outcomes associated with parenting children who have disabilities. Mental Retardation, 38, 195-206.

67- Sen, E. \& Yurtsever, S. (2007). Difficulties experienced by families with disabled children, Journal for specialists in pediatric nursing, 12 (4): 238-252.

68- Skinner D., Rodriguez P. \& Bailey D. (1999). Qualitative analysis of Latino parents' religious interpretations of their child's disability. Journal of Early Intervention, 22, 271-85.

69- Soponaru, C., Iorga, M. (2015). Families with a Disabled Child, between Stress and Acceptance. A Theoretical Approach. Romanian Journal for Multidimensional Education, 7(1): 57-73.

70- Taunt H. M. \& Hastings R. P. (2002) Positive impact of children with developmental disabilities on their families: a preliminary study. Education and Training in Mental Retardation and Developmental Disabilities, 37: 410-20.

71- Thoits, P.A. (1982).Conceptual, methodological and theoretical problems in studying social support as buffer against life stress. Journal of Health and Social Behavior, 23(2):145159.

72- Van Galen, M., De puijter, M. \& Smeets, C. (2006). Citizens and Resilience, Amsterdam: Dutch Knowledge \& Advise Centre. 


\section{المجلة العلمية لكلية رياض الاطفال - جامعة اسيوط}

73- Walsh F. (1998). Strengthening Family Resilience. Guilford Press, New York.

74- Walsh, F. (2003). Changing families in a changing world: reconstructing family normality. In: Normal Family Processes: Growing Diversity and Complexity, 3rd ed, Guilford Press, New York.

75- Wang, M., \& Brown, R. (2009). Family quality of life: A framework for policy and social service provisions to support families of children with disabilities, Journal of Family Social Work, 12(2):144-167.

76- Yusoff, Y. M. (2012). Self-Efficacy, Perceived Social Support and Psychological Adjustment in International Undergraduate Students in a Public Higher Education Institution in Malaysia, Journal of Studies in International Education, 16(4): 353-371. 